Supporting information

\title{
Supramolecular Engineering of Efficient Artificial Light-Harvesting Systems From Cyanovinylene Chromophores and Pillar[5]arene-Based Polymer Hosts
}

Xing-Huo Wang,,${ }^{\dagger}$ Xin-Yue Lou,${ }^{\dagger}$ Tong Lu, ${ }^{\dagger}$ Chunyu Wang,,${ }^{\dagger}$ Jun Tang,,${ }^{\dagger}{ }^{\dagger}$ Fengqi Liu, ${ }^{\dagger}$ Yan Wang, ${ }^{\dagger}$ and Ying-Wei Yang*,†,\&

${ }^{\dagger}$ College of Chemistry, Jilin University, 2699 Qianjin Street, Changchun 130012, P. R. China

ॠState Key Laboratory of Supramolecular Structure and Materials, Institute of Theoretical Chemistry, Jilin University, 2699 Qianjin Street, Changchun 130012, P. R. China

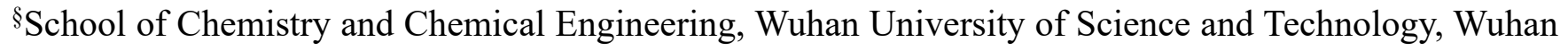
430081, P. R. China

*Corresponding authors. E-mail: chemjtang@jlu.edu.cn (J.T.); ywyang@jlu.edu.cn (Y.-W.Y.). 


\section{Table of Contents}

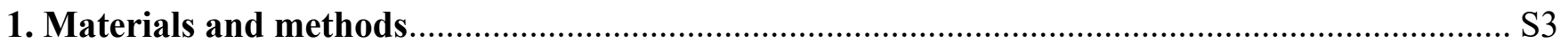

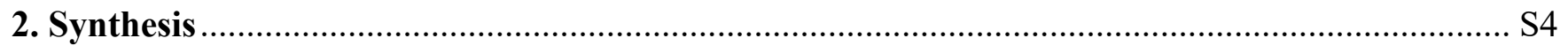

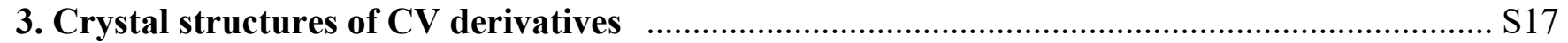

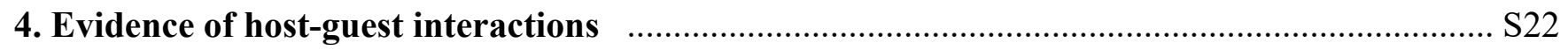

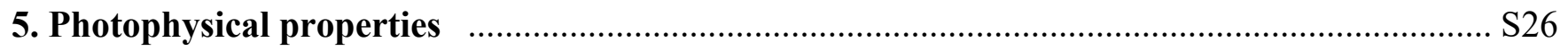

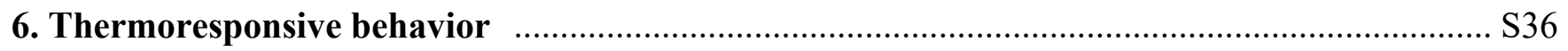

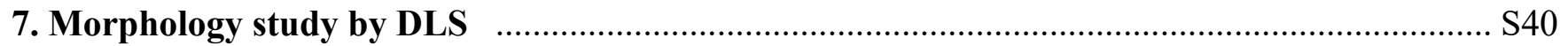

8. Tunable emission wavelength manipulated by polymer hosts …...................................... S42

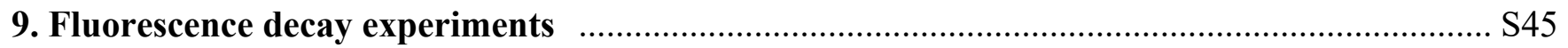

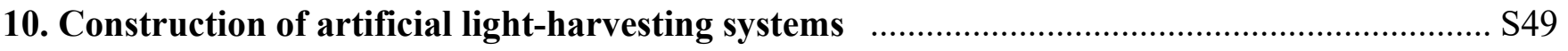




\section{Materials and methods}

All reagents and starting materials were purchased from commercial sources and without further purification unless otherwise noted. MMAP[5]A and 5-azidopentanenitrile were synthesized according to our reported method. ${ }^{\mathrm{S} 1}{ }^{1} \mathrm{H}$ NMR and ${ }^{13} \mathrm{C}$ NMR spectra were collected on a Bruker AVANCE III $400 \mathrm{MHz}$ NMR spectrometer. 2D DOSY NMR spectra were recorded on a Bruker AVANCE III $600 \mathrm{MHz}$ NMR spectrometer. Mass spectra were recorded on Bruker Daltonics Autofex Speed Series: High-Performance MALDI-TOF Systems. Gel permeation chromatography (GPC) was performed on a Malvern instrument, equipped with a PLgel MIXED guard column followed by a PLgel MIXED guard column (molecular weight range $2.0 \times 10^{2}-4.0 \times 10^{5} \mathrm{~g} / \mathrm{mol}$ ), column thermostated to $60{ }^{\circ} \mathrm{C}$ and calibrated by linear polystyrene standards. $N, N$-Dimethylformamide (DMF) was used as the eluent at a flow of $0.8 \mathrm{~mL} / \mathrm{min}$ at $60{ }^{\circ} \mathrm{C}$. Scanning electron microscope (SEM) images were obtained on a HITACHI-SU8082 instrument. The fluorescent experiments were conducted on a RF-5301 spectrometer (Shimadzu Corporation, Japan). The time-resolved fluorescence decay curves and absolute fluorescence quantum yields were obtained on a FLS920 instrument (Edinburgh Instrument). Quantum yields were calculated by means of an integrating sphere. Single-crystal X-ray diffraction data were measured by a Bruker D8 Venture diffractometer using the $\omega$-scan mode with graphite-monochromator Mo K $\alpha$ radiation $(\lambda=0.71073 \AA)$. The crystal structure were solved with SHELXD, ${ }^{\mathrm{S} 2}$ SHELXT,${ }^{\mathrm{S} 3}$ or by the direct methods with SHELXS-2014,${ }^{\mathrm{S} 4}$ refined by fullmatrix least squares on $|\mathrm{F}|^{2}$ by SHELXL, ${ }^{\mathrm{S} 5}$ and interfaced through the program OLEX2. ${ }^{\mathrm{S} 6}$ All density functional theory (DFT) calculations were carried out using Gaussian 09 (version D.01) package. The ground-state geometry was fully optimized using B3LYP-D3/6-311+g(d, p). Dynamic light scattering (DLS) was conducted on a Zetasizer Nano ZS instrument. 


\section{Synthesis}

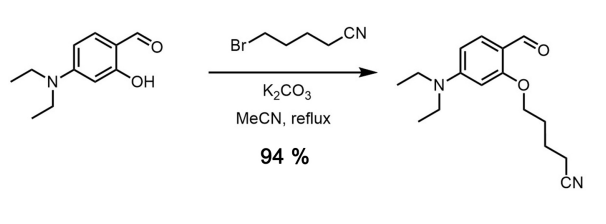

SA-1-CN

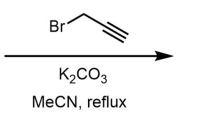

$93 \%$

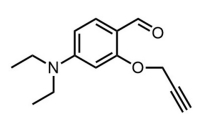

SA-1-AL

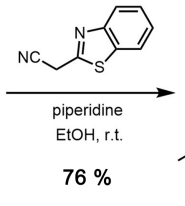

$76 \%$

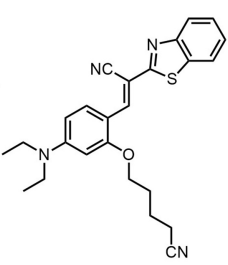

CV-1-CN
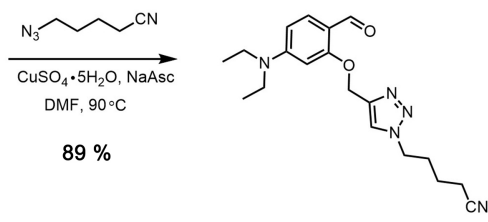

SA-1-TA-CN

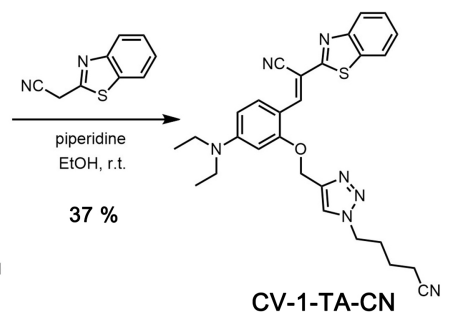

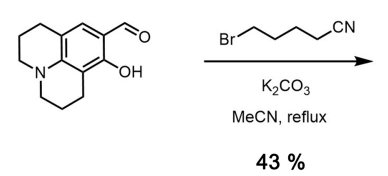

$43 \%$

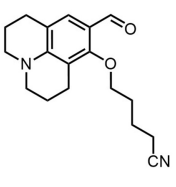

SA-2-CN

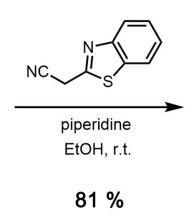

$81 \%$

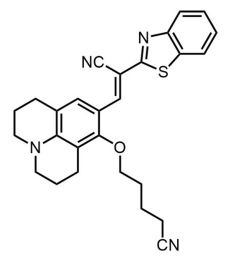

$\mathrm{CV}-2-\mathrm{CN}$

Figure S1. Synthetic routes to CV-1-CN, CV-1-TA-CN, and CV-2-CN.

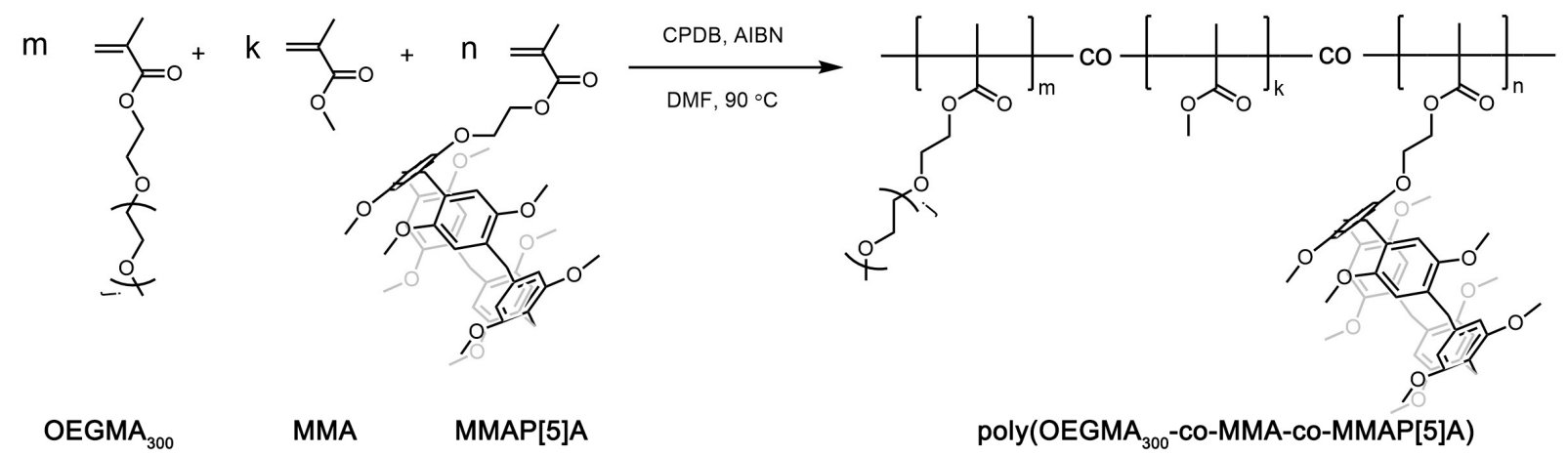

Figure S2. Synthetic route to poly(OEGMA300-co-MMA-co-MMAP[5]A). 


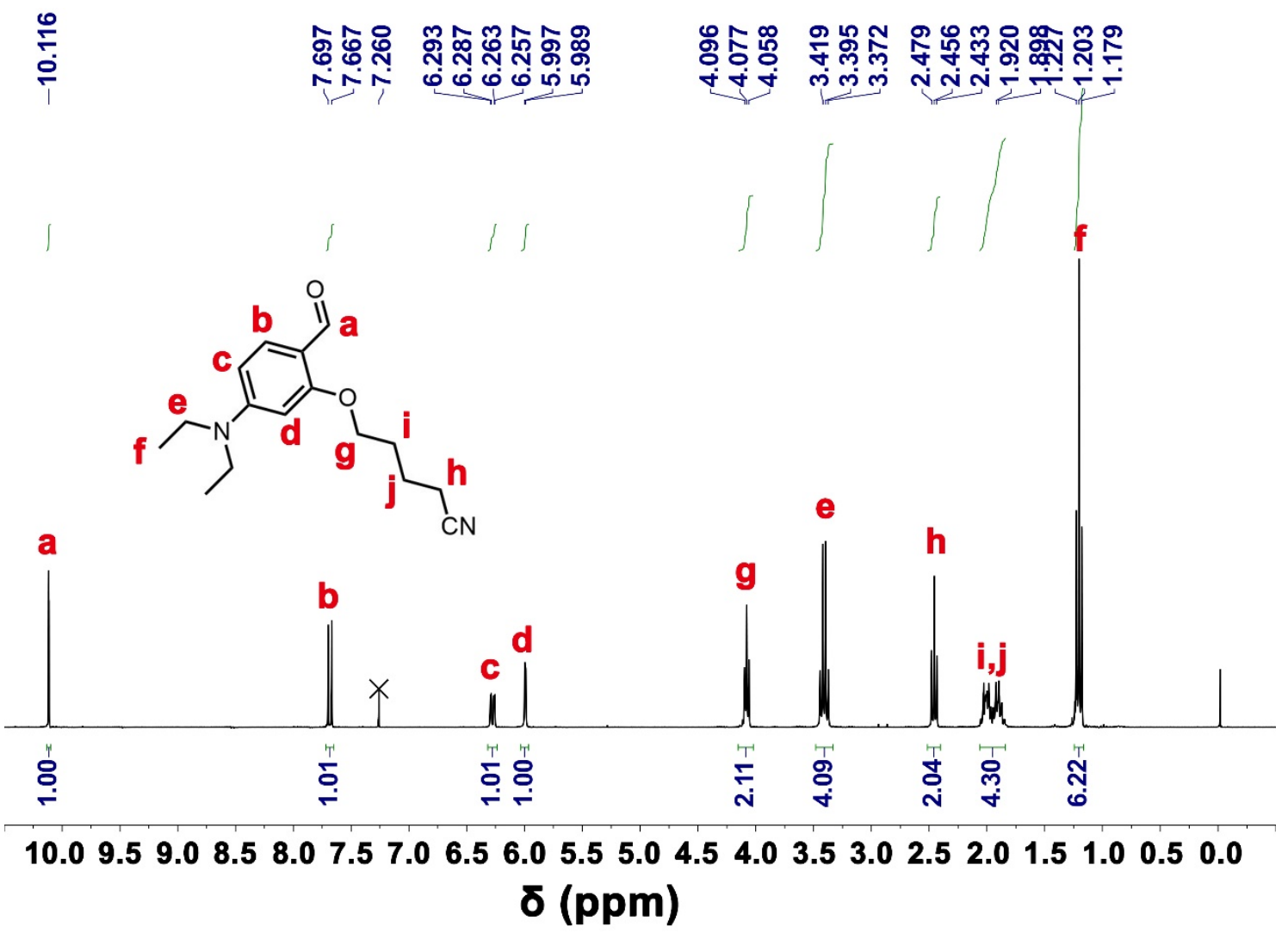

Figure S3. ${ }^{1} \mathrm{H}$ NMR spectrum $\left(400 \mathrm{MHz}, \mathrm{CDCl}_{3}, 298 \mathrm{~K}\right)$ of $\mathrm{SA}-1-\mathrm{CN}$.

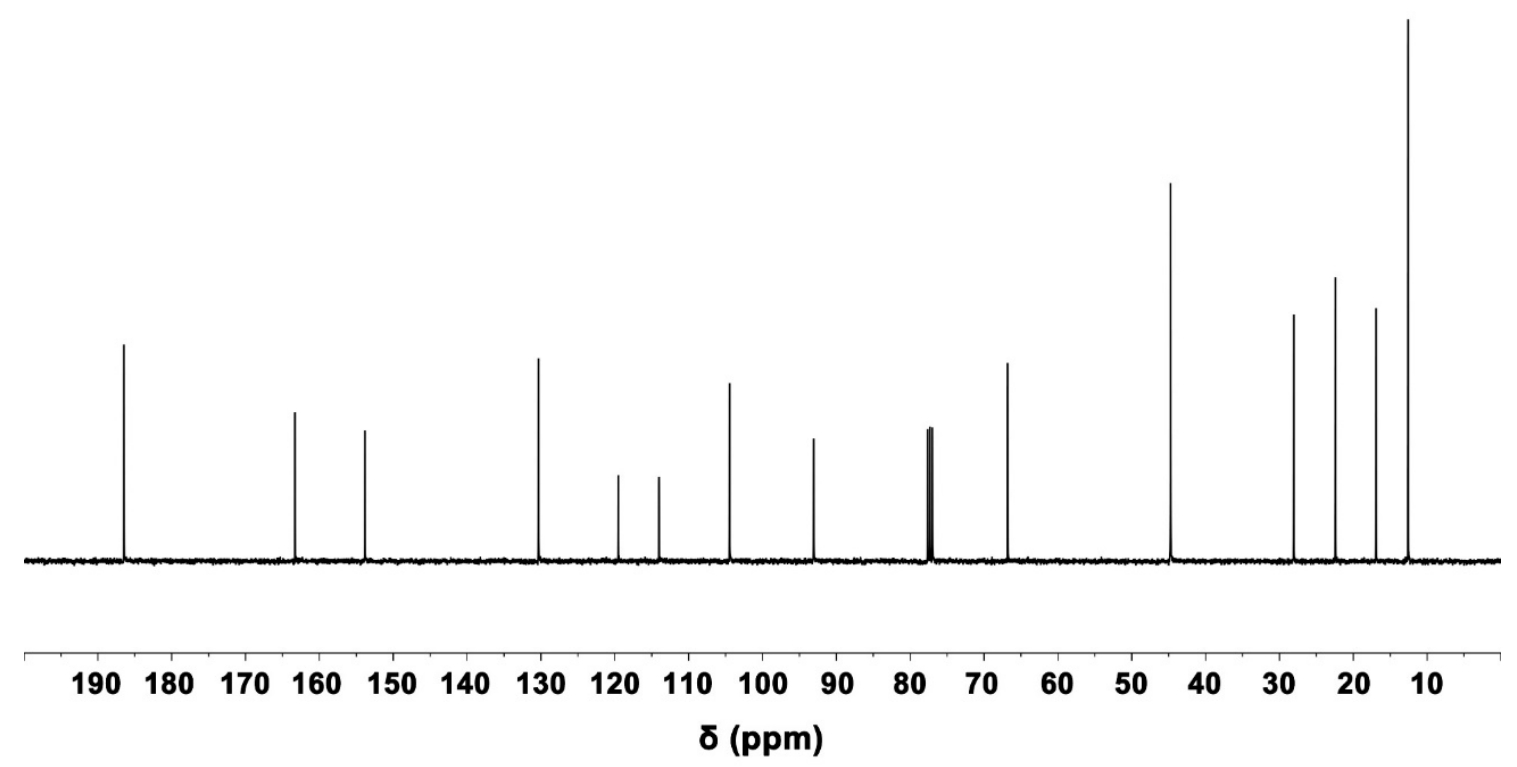

Figure S4. ${ }^{13} \mathrm{C}$ NMR spectrum $\left(100 \mathrm{MHz}, \mathrm{CDCl}_{3}, 298 \mathrm{~K}\right)$ of SA-1-CN. 


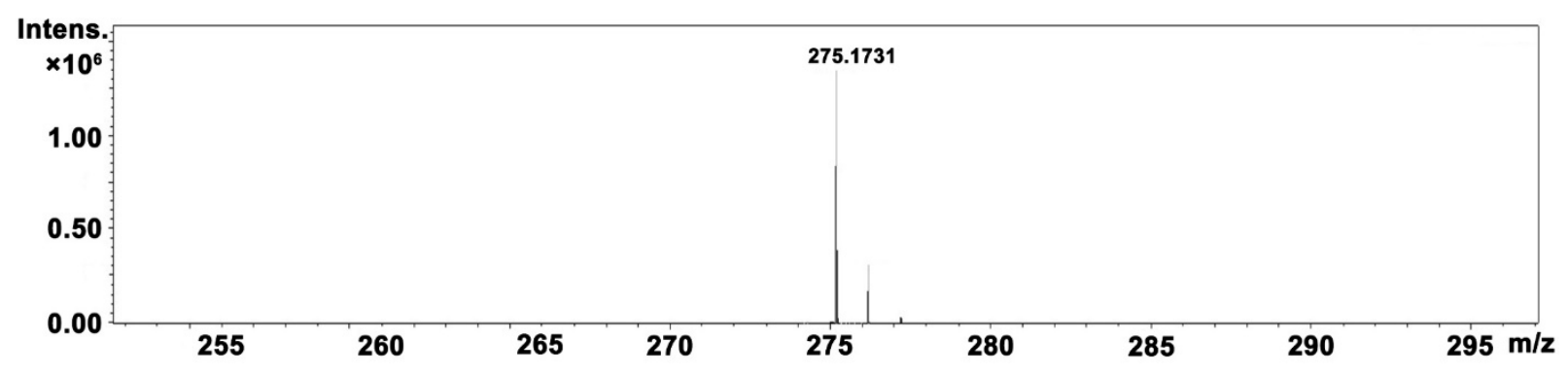

Figure S5. HR-ESI-MS spectrum of SA-1-CN.

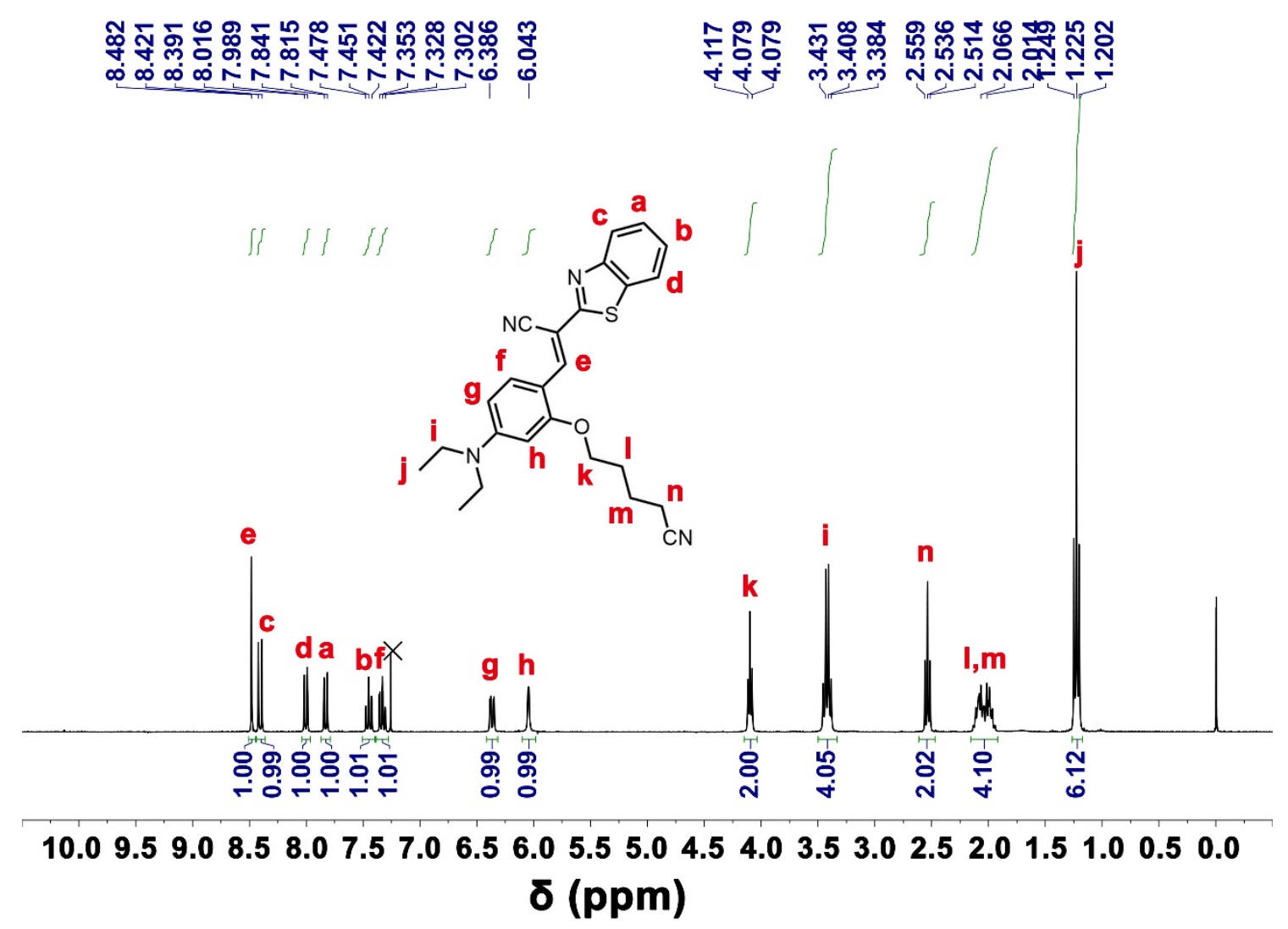

Figure S6. ${ }^{1} \mathrm{H}$ NMR spectrum $\left(400 \mathrm{MHz}, \mathrm{CDCl}_{3}, 298 \mathrm{~K}\right)$ of CV-1-CN. 


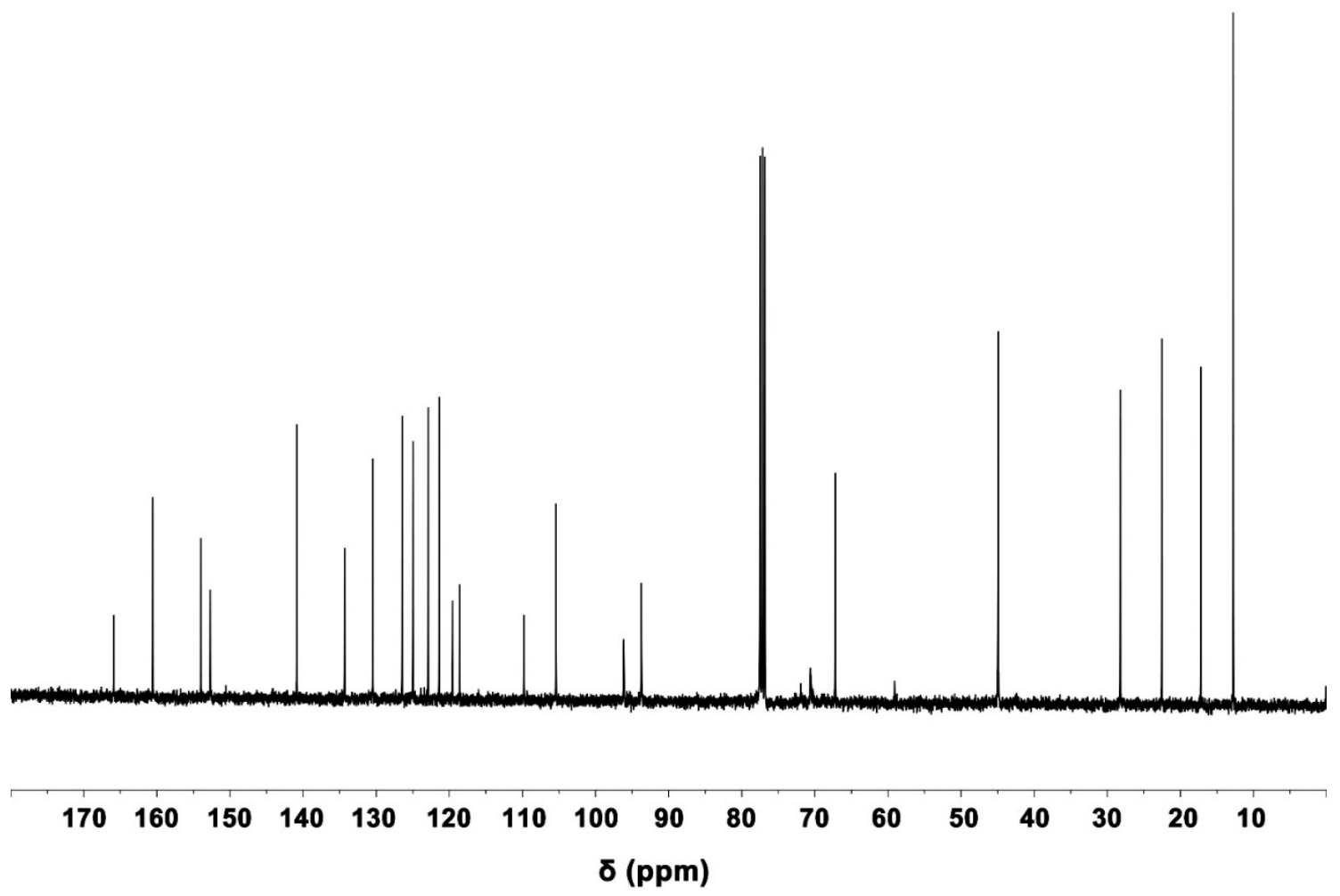

Figure S7. ${ }^{13} \mathrm{C}$ NMR spectrum $\left(100 \mathrm{MHz}, \mathrm{CDCl}_{3}, 298 \mathrm{~K}\right)$ of $\mathrm{CV}-1-\mathrm{CN}$.

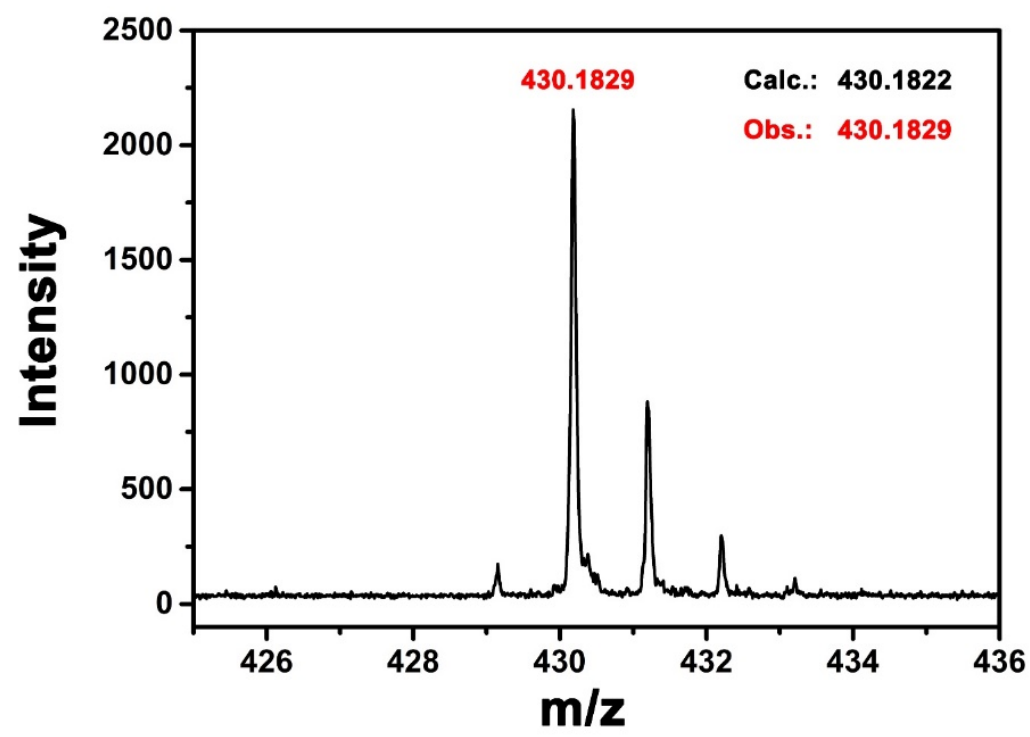

Figure S8. MALDI-TOF-MS spectrum of CV-1-CN. 


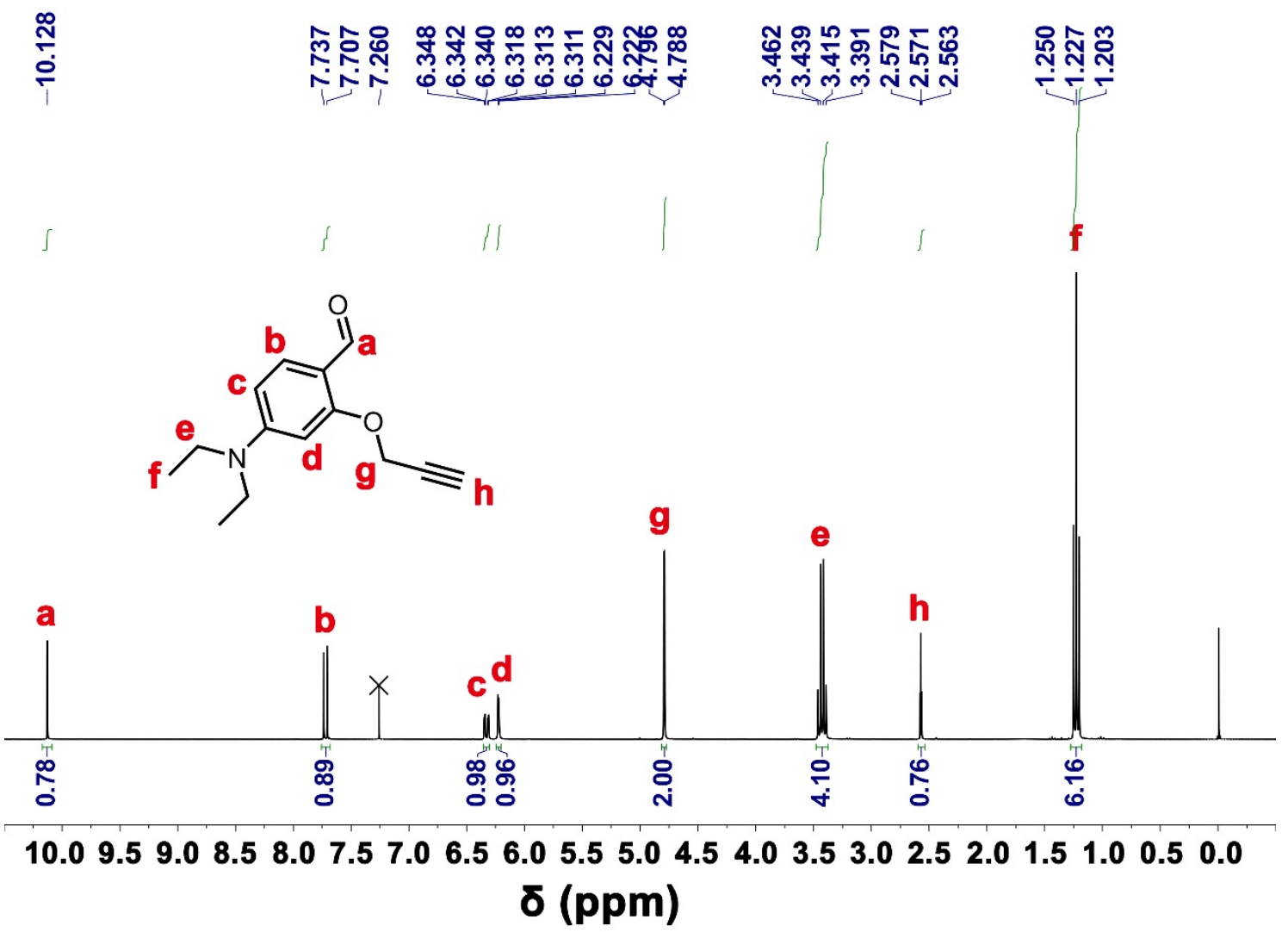

Figure S9. ${ }^{1} \mathrm{H}$ NMR spectrum $\left(400 \mathrm{MHz}, \mathrm{CDCl}_{3}, 298 \mathrm{~K}\right)$ of SA-1-alkyne.

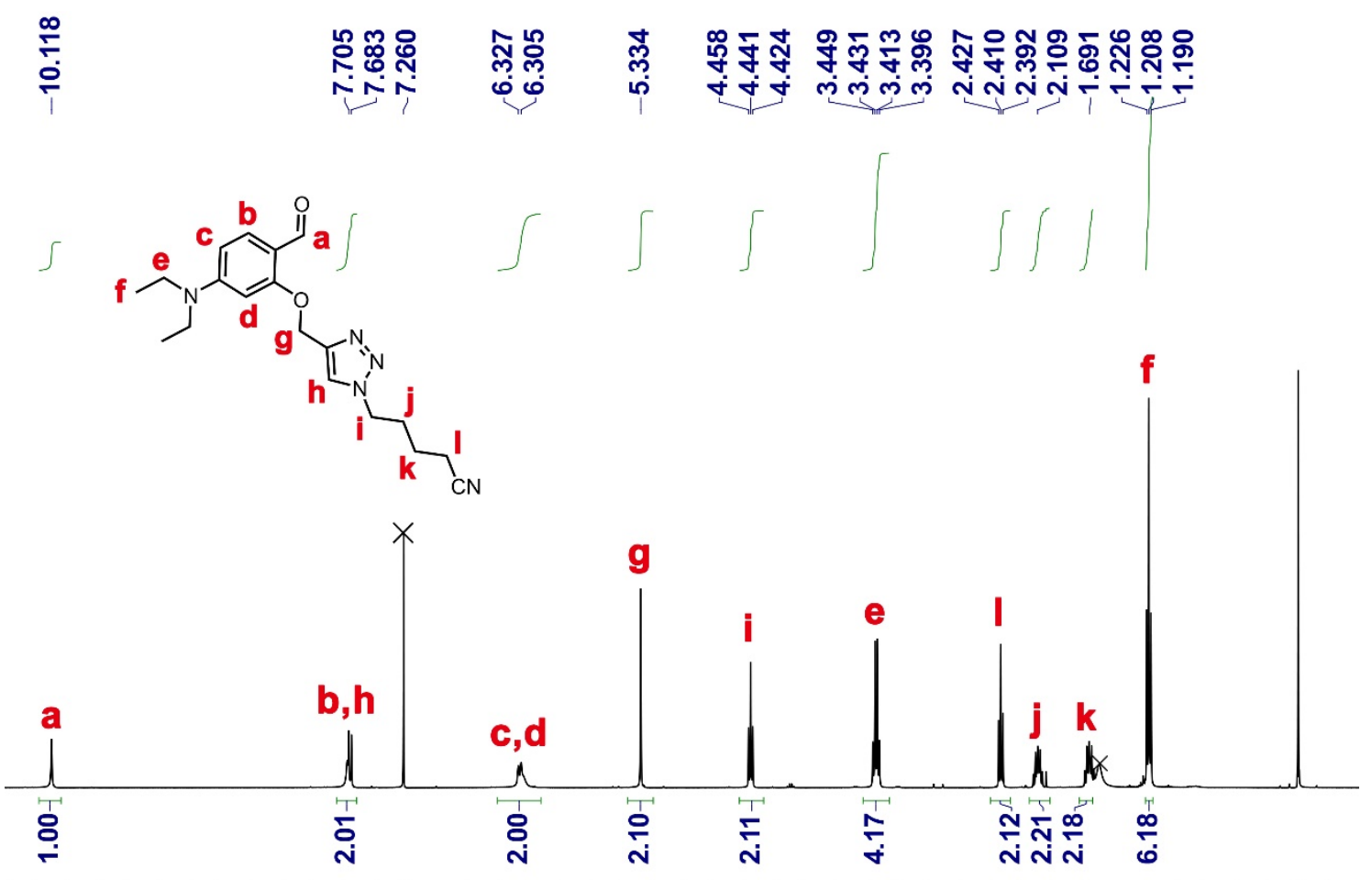

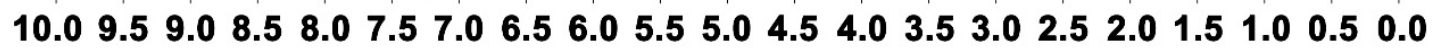
$\delta$ (ppm)

Figure S10. ${ }^{1} \mathrm{H}$ NMR spectrum $\left(400 \mathrm{MHz}, \mathrm{CDCl}_{3}, 298 \mathrm{~K}\right)$ of SA-1-TA-CN. 


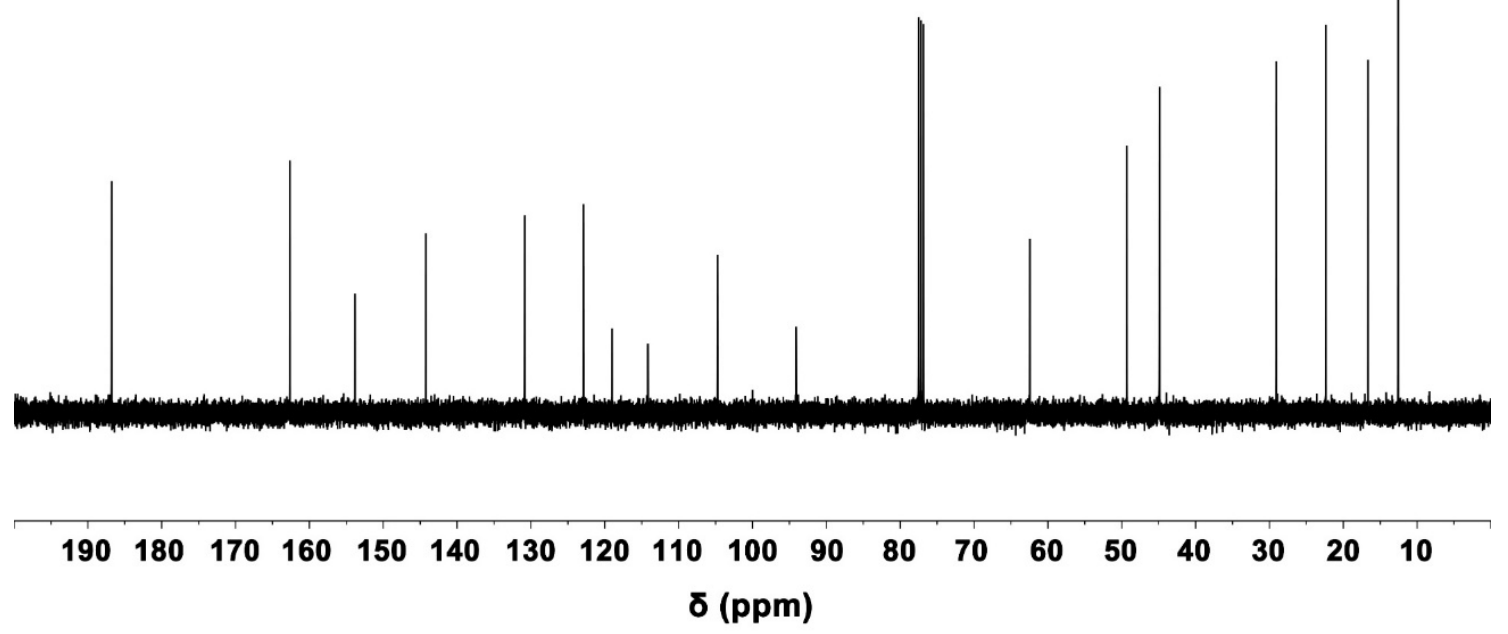

Figure S11. ${ }^{13} \mathrm{C}$ NMR spectrum $\left(100 \mathrm{MHz}, \mathrm{CDCl}_{3}, 298 \mathrm{~K}\right)$ of SA-1-TA-CN.

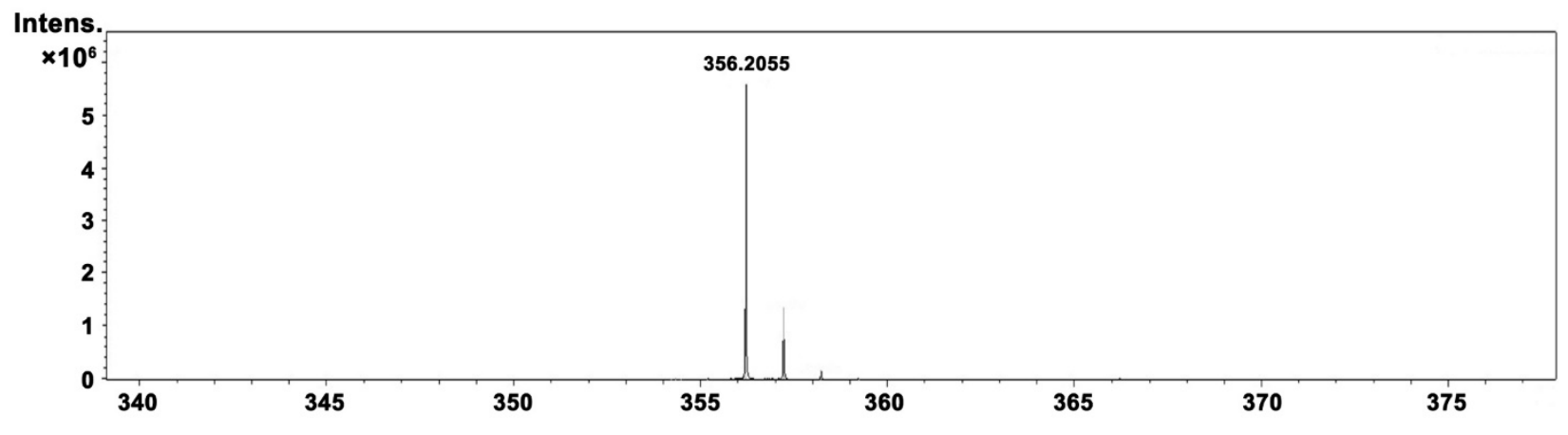

Figure S12. MALDI-TOF-MS spectrum of SA-1-TA-CN. 


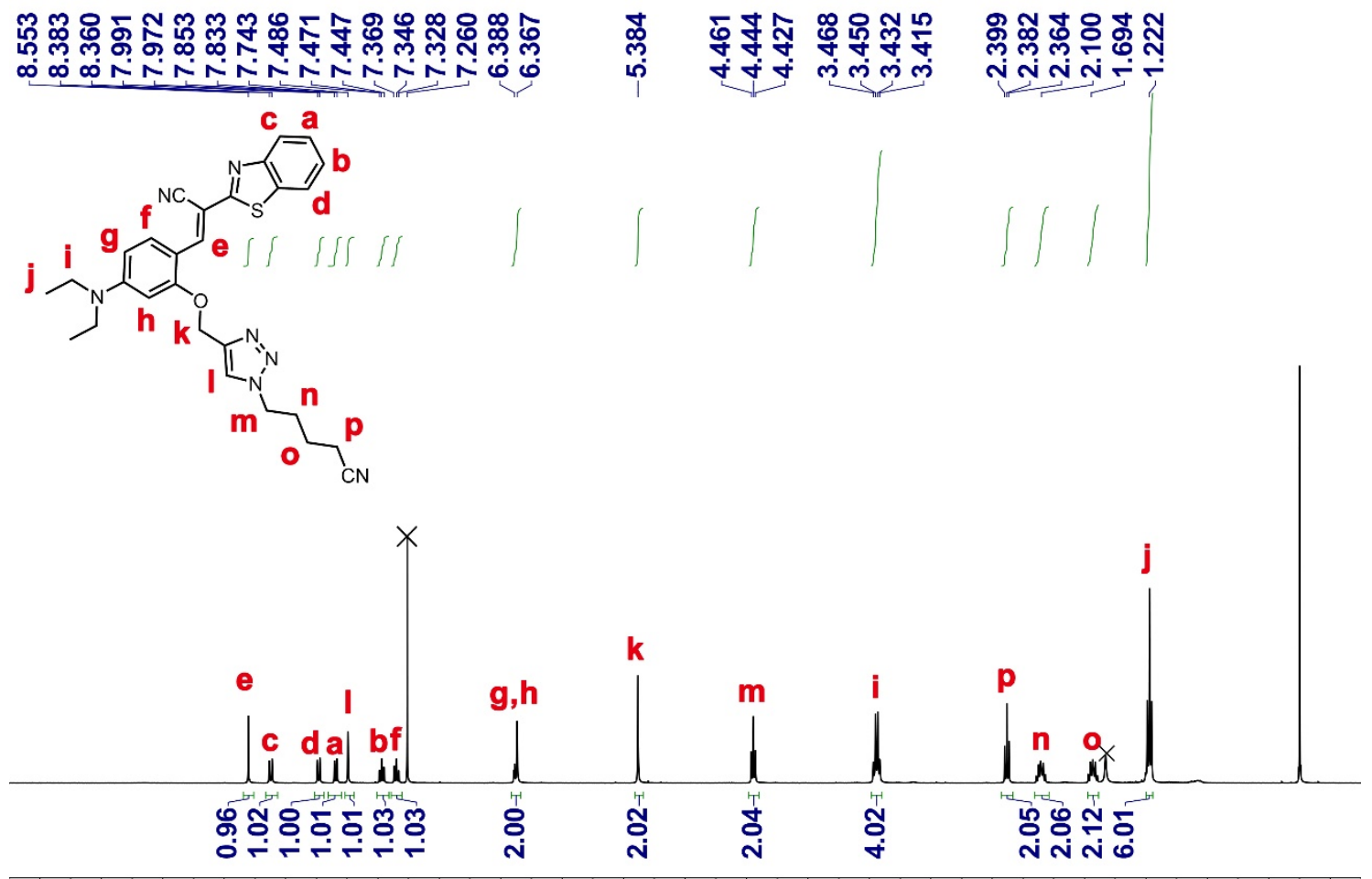

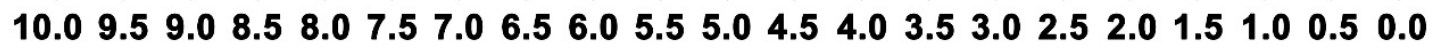
$\delta$ (ppm)

Figure S13. ${ }^{1} \mathrm{H}$ NMR spectrum $\left(400 \mathrm{MHz}, \mathrm{CDCl}_{3}, 298 \mathrm{~K}\right)$ of CV-1-TA-CN.

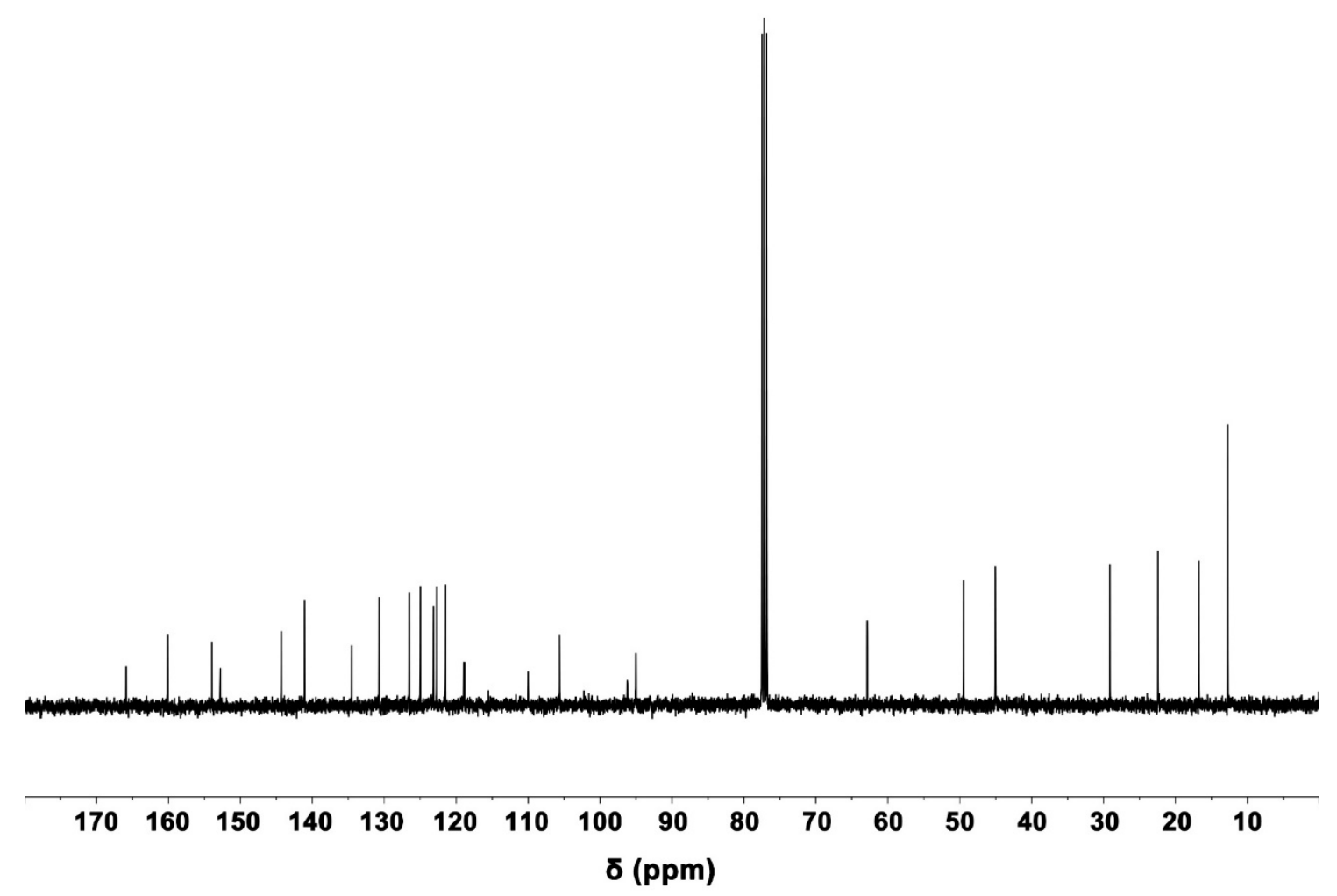

Figure S14. ${ }^{13} \mathrm{C}$ NMR spectrum $\left(100 \mathrm{MHz}, \mathrm{CDCl}_{3}, 298 \mathrm{~K}\right)$ of CV-1-TA-CN. 


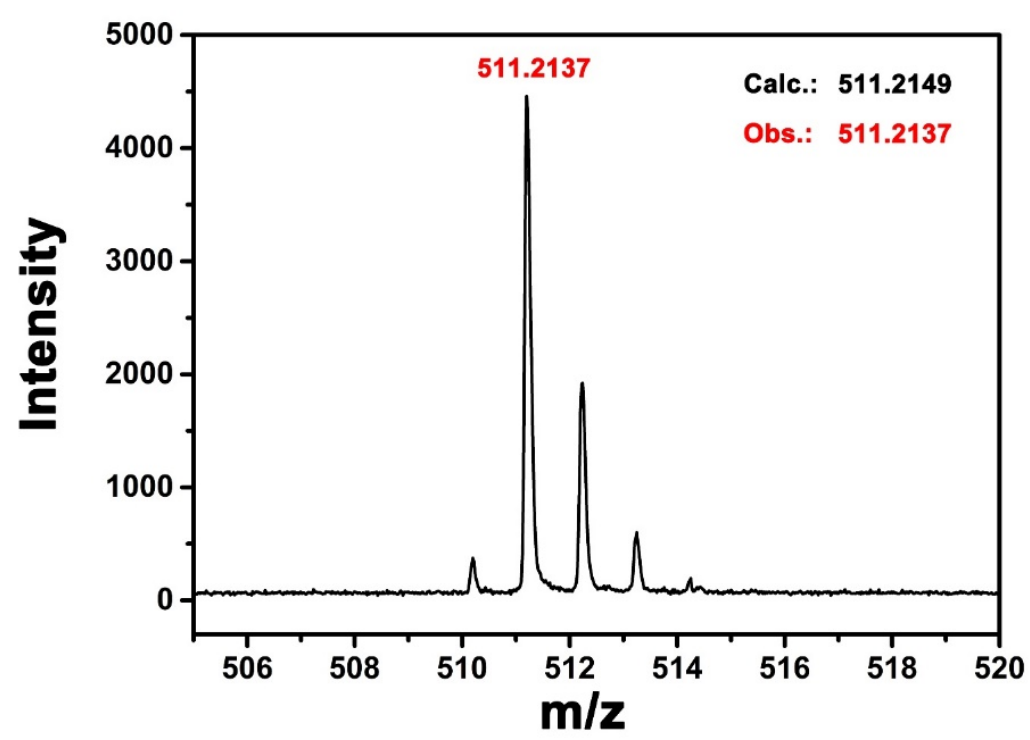

Figure S15. MALDI-TOF-MS spectrum of CV-1-TA-CN.

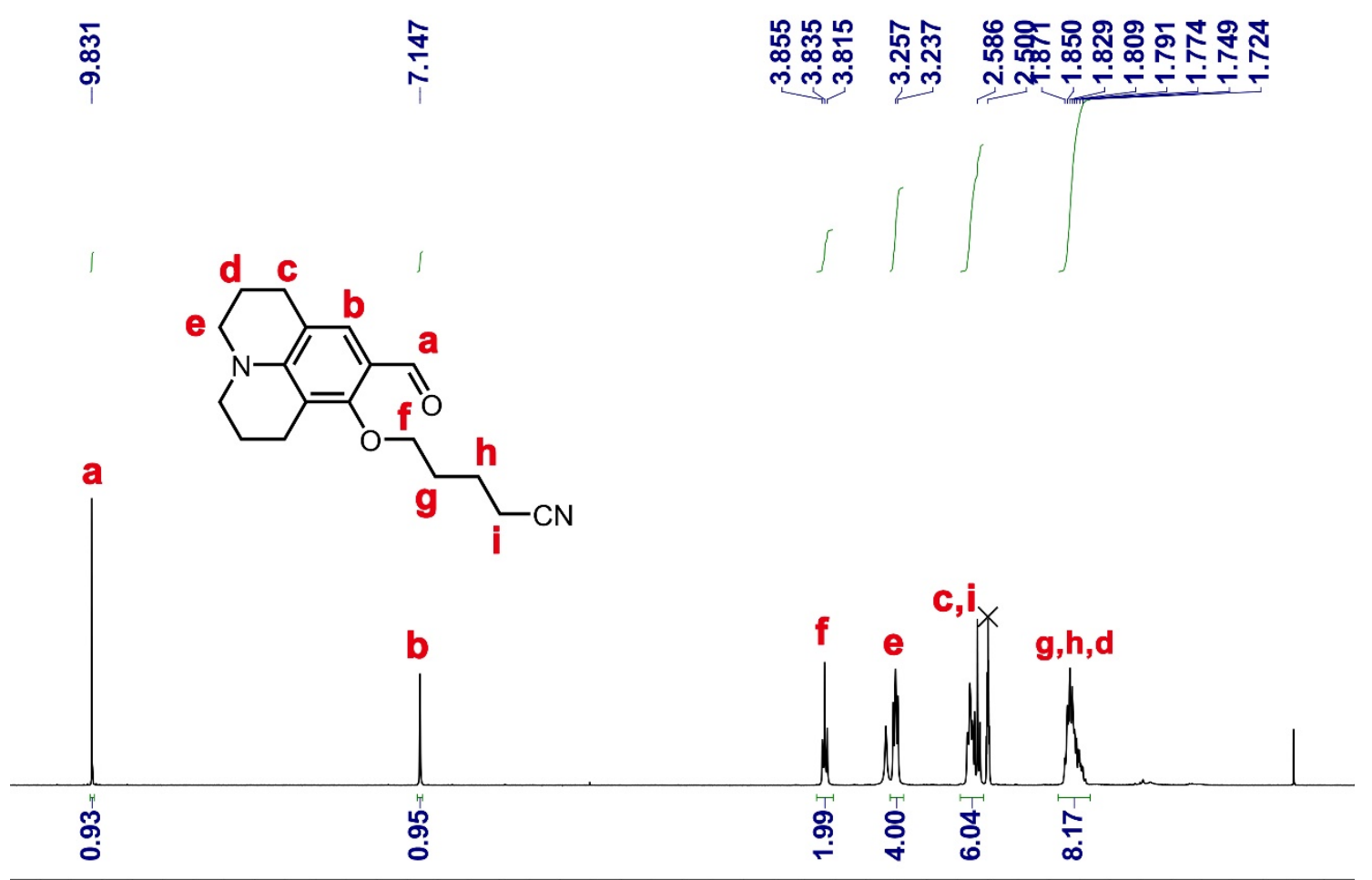

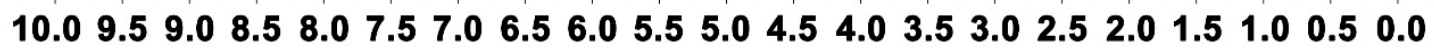
$\delta$ (ppm)

Figure S16. ${ }^{1} \mathrm{H}$ NMR spectrum $\left(400 \mathrm{MHz}, \mathrm{CDCl}_{3}, 298 \mathrm{~K}\right)$ of SA-2-CN. 


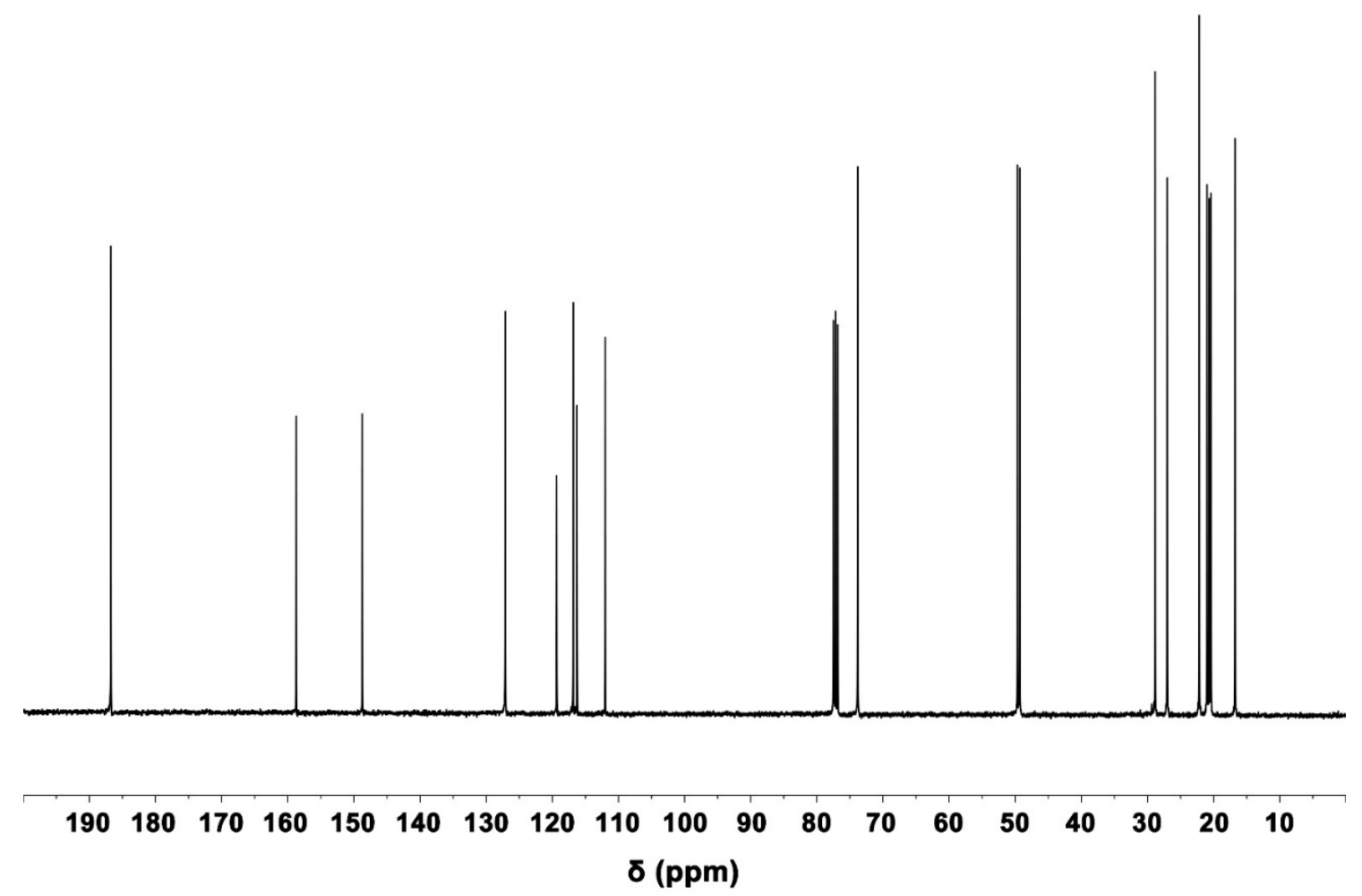

Figure S17. ${ }^{13} \mathrm{C}$ NMR spectrum $\left(100 \mathrm{MHz}, \mathrm{CDCl}_{3}, 298 \mathrm{~K}\right)$ of SA-2-CN.

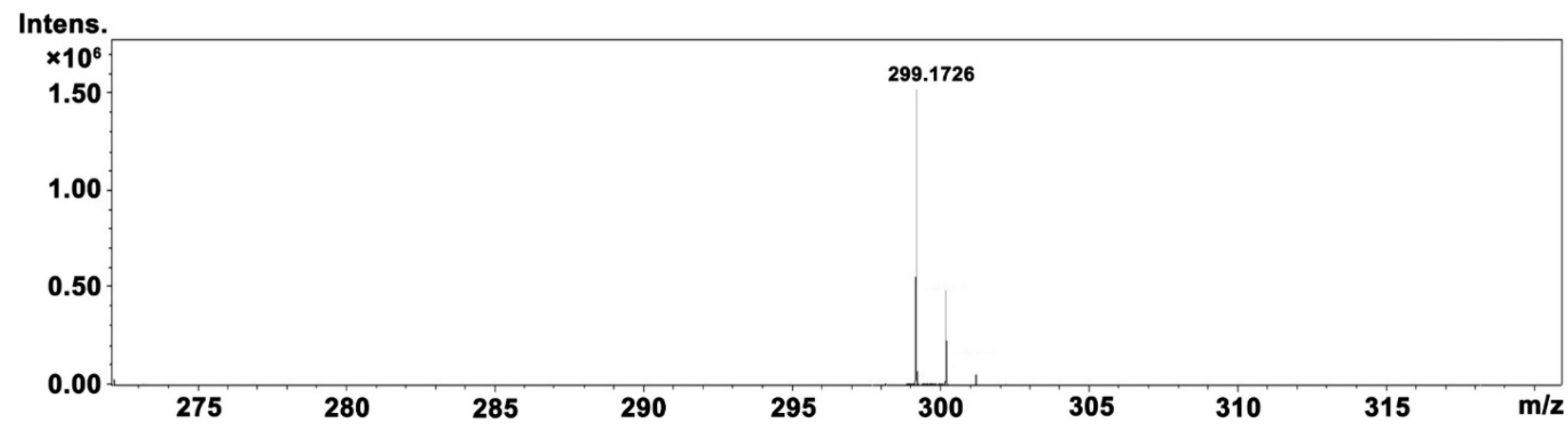

Figure S18. HR-ESI-MS spectrum of SA-2-CN. 


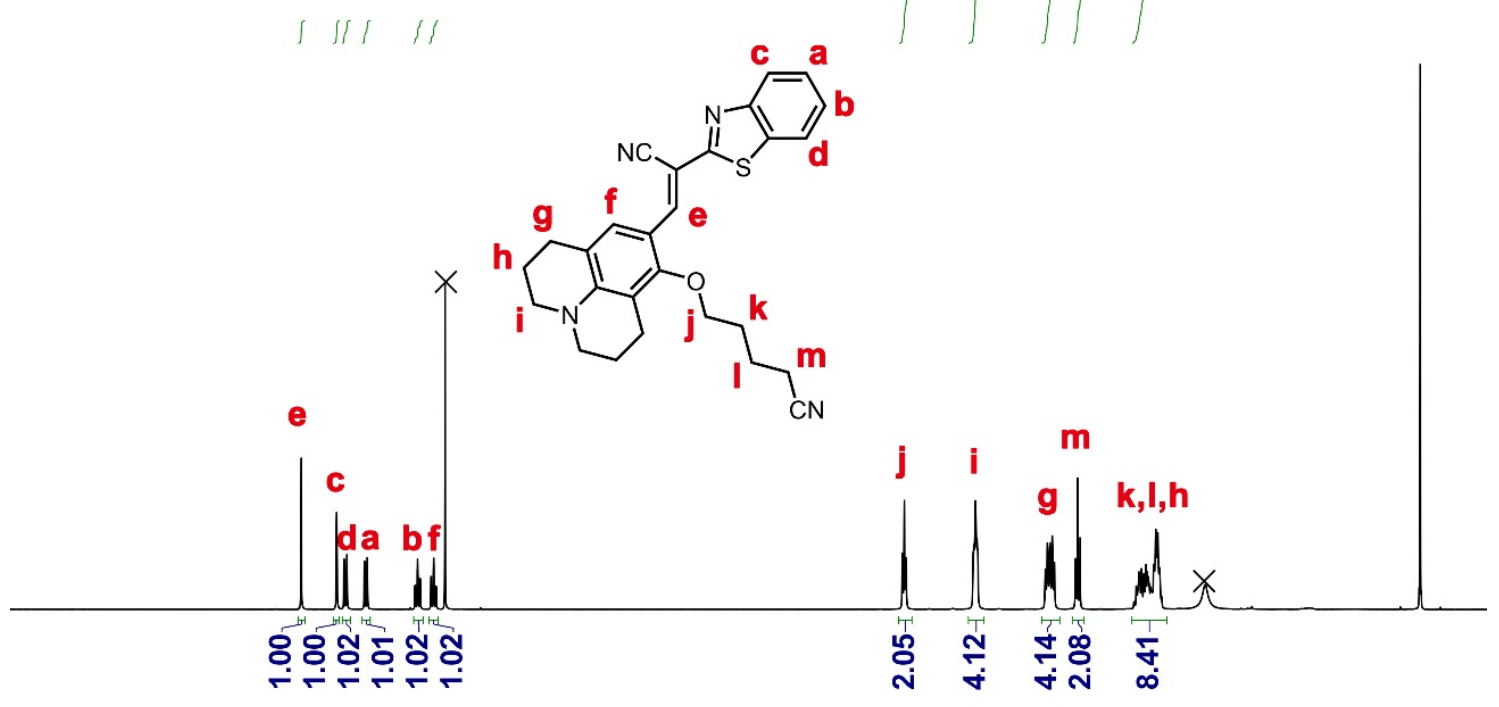

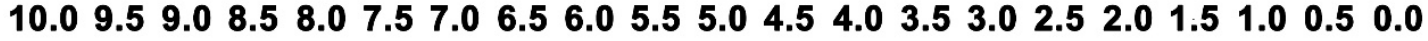
$\delta$ (ppm)

Figure S19. ${ }^{1} \mathrm{H}$ NMR spectrum $\left(400 \mathrm{MHz}, \mathrm{CDCl}_{3}, 298 \mathrm{~K}\right)$ of CV-2-CN.

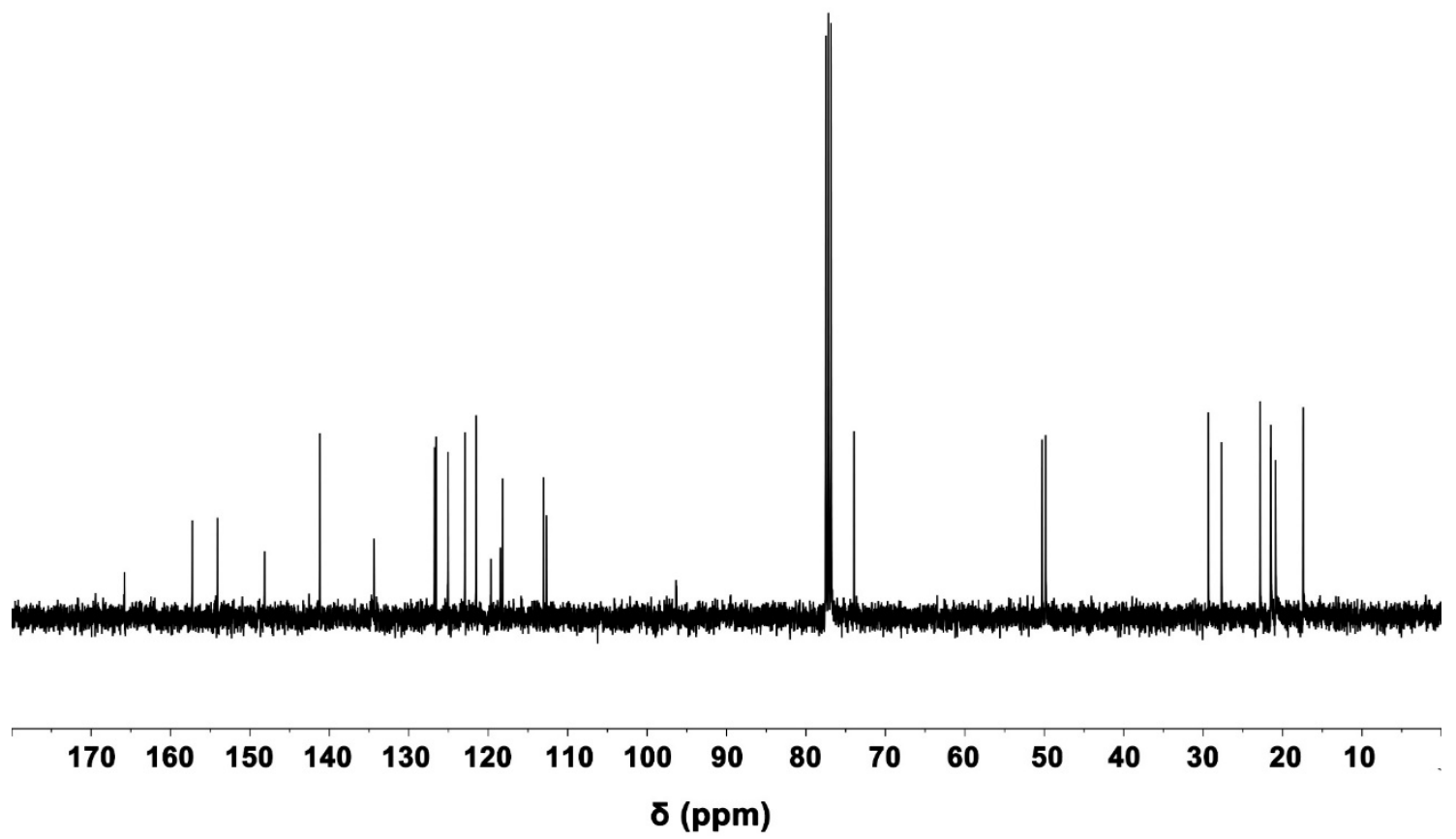

Figure S20. ${ }^{13} \mathrm{C}$ NMR spectrum $\left(100 \mathrm{MHz}, \mathrm{CDCl}_{3}, 298 \mathrm{~K}\right)$ of CV-2-CN. 


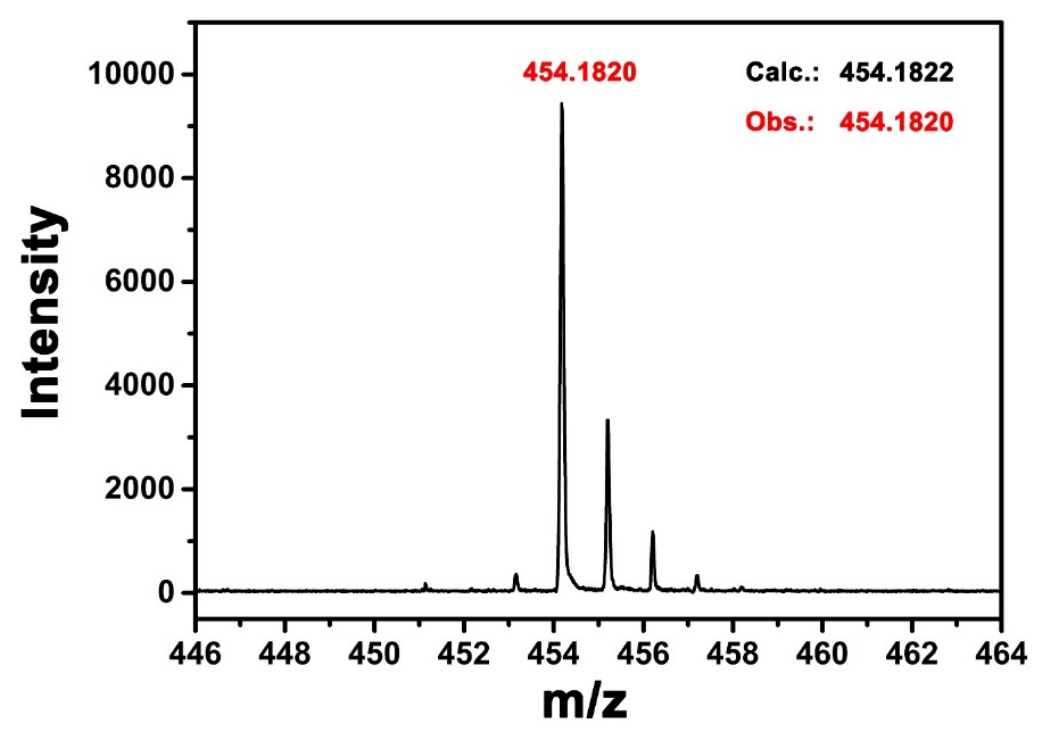

Figure S21. MALDI-TOF-MS spectrum of CV-2-CN.

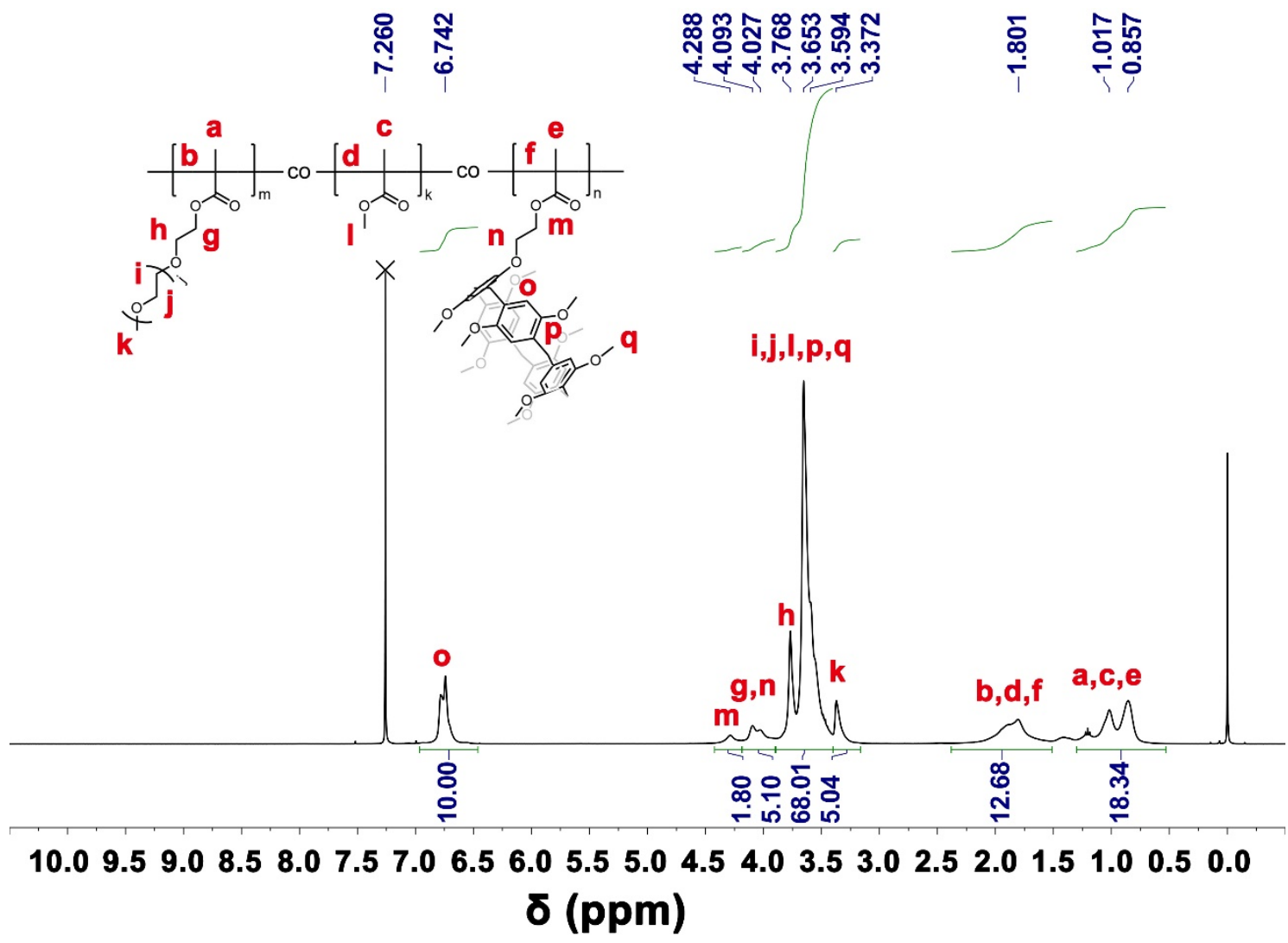

Figure S22. ${ }^{1} \mathrm{H}$ NMR spectrum $\left(400 \mathrm{MHz}, \mathrm{CDCl}_{3}, 298 \mathrm{~K}\right)$ of poly(OEGMA 300 -co-MMA-coMMAP[5]A)-1, namely PH-1. 


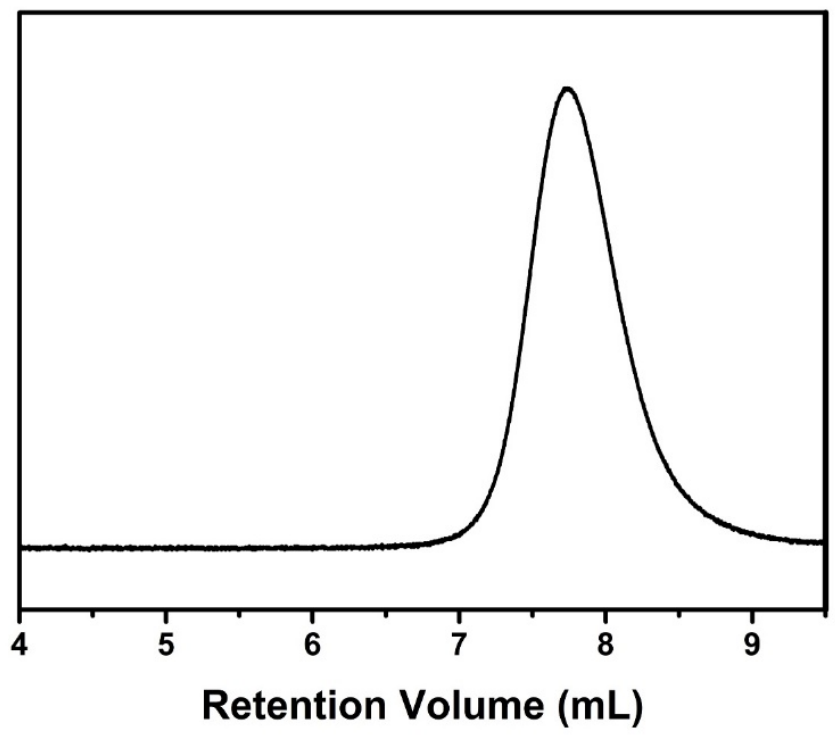

Figure S23. GPC trace of PH-1.

The molar ratio of MMA : OEGMA $300:$ MMAP[5]A of PH-1 was calculated to be 37:17:10 according to the ${ }^{1} \mathrm{H}$ NMR spectrum, and after the equivalent calculation, $1706 \mathrm{~g} / \mathrm{mol}$ polymer corresponds to one pillar[5] arene unit. The molecular weight of PH-1 was determined to be $20.74 \mathrm{~kg} \mathrm{~mol}^{-1}$ with $\mathrm{M}_{\mathrm{w}} / \mathrm{M}_{\mathrm{n}}$ of 1.26 . 


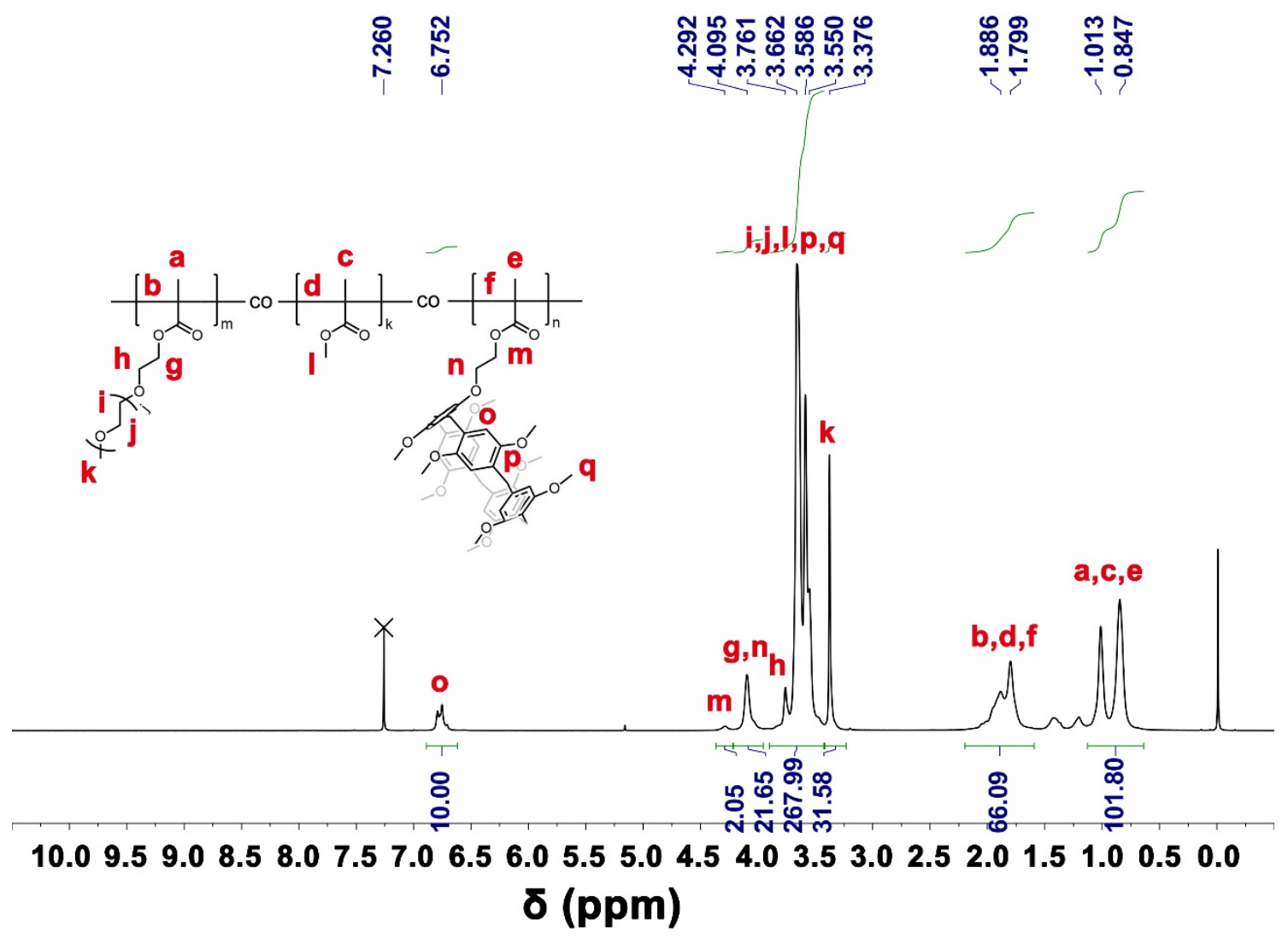

Figure S24. ${ }^{1} \mathrm{H}$ NMR spectrum $\left(400 \mathrm{MHz}, \mathrm{CDCl}_{3}, 298 \mathrm{~K}\right)$ of poly(OEGMA $300-c o-M M A-c o-$ MMAP[5]A)-2, namely PH-2.

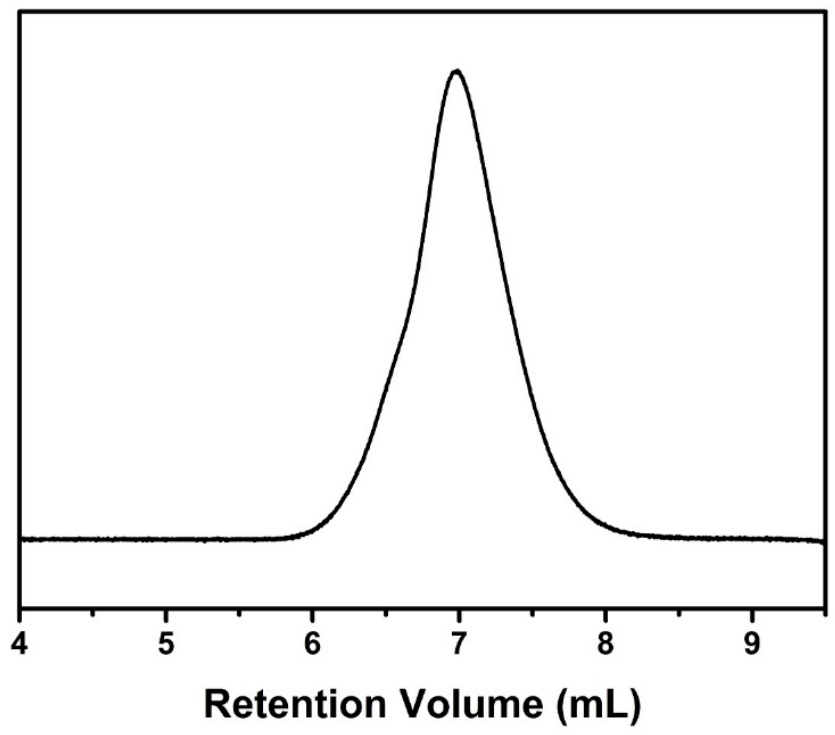

Figure S25. GPC trace of PH-2. 
The molar ratio of MMA : OEGMA 300 : MMAP[5]A of PH-2 was calculated to be 22:11:1 according to the ${ }^{1} \mathrm{H}$ NMR spectrum, and after the equivalent calculation, $6093 \mathrm{~g} / \mathrm{mol}$ polymer corresponds to one pillar[5] arene unit. The molecular weight of PH-2 was determined to be $66.50 \mathrm{~kg} \mathrm{~mol}^{-1}$ with $\mathrm{M}_{\mathrm{w}} / \mathrm{M}_{\mathrm{n}}$ of 1.36

\section{Crystal structures of CV derivatives}

The intramolecular hydrogen bonding $\mathrm{C}-\mathrm{H} \cdots \mathrm{N}\left(\mathrm{H} \cdots \mathrm{N}: 2.62 \AA, \mathrm{C}-\mathrm{H} \cdots \mathrm{N}: 151.47^{\circ}\right)$ formed between $\mathrm{CH}$ and $\mathrm{C} \equiv \mathrm{N}$ contributed nearly planar conformation in crystal, which benefitted the formation of intermolecular $\pi-\pi$ stacking structures (Figure S27). As indicated by the packing structures of CV-1-CN in Figures S28 and S29, each dimer interacts with adjacent dimers by two identical intermolecular hydrogen bonding formed between phenyl group and cyano group, $\mathrm{C}-\mathrm{H} \cdots \mathrm{N}(\mathrm{H} \cdots \mathrm{N}: 2.601 \AA, \mathrm{C}-\mathrm{H} \cdots \mathrm{N}$ : $\left.150.72^{\circ}\right)$

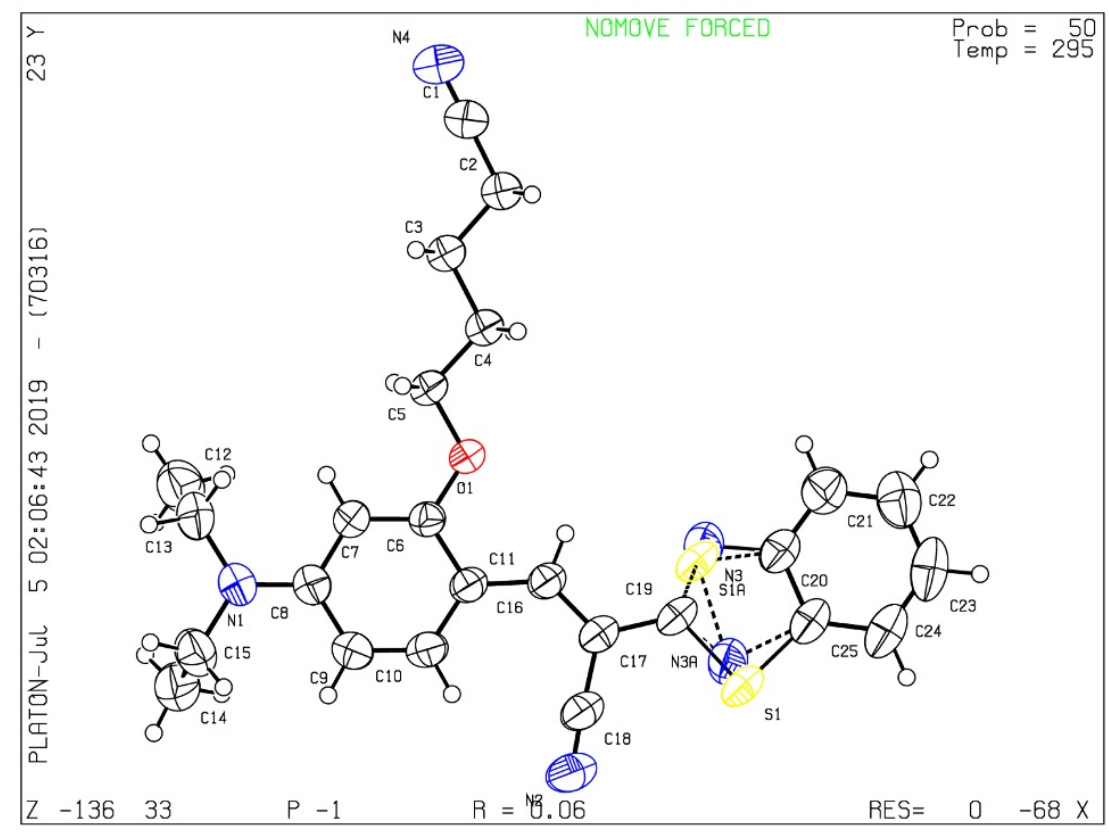

Figure S26. The ORTEP-style illustration of CV-1-CN structure, with probability ellipsoids (CCDC reference number 2022734). 


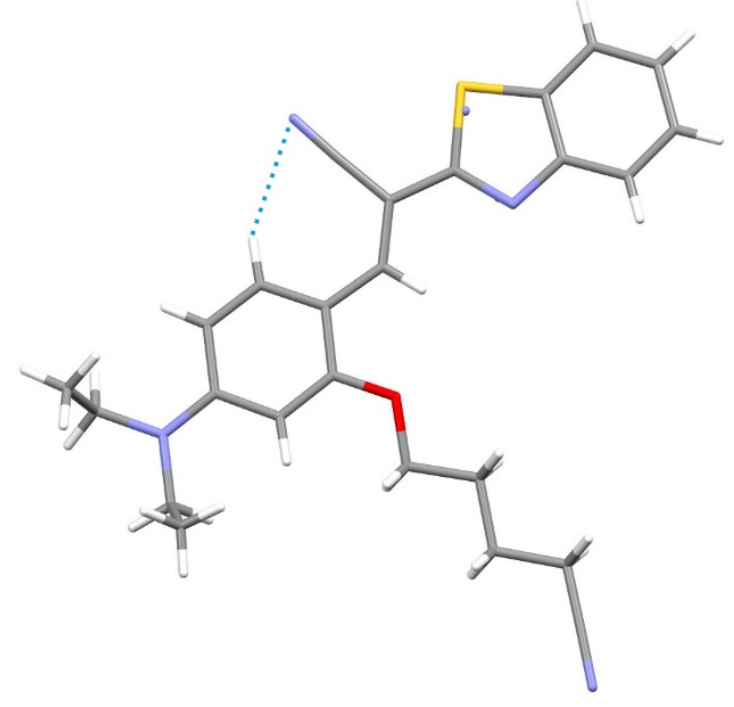

Figure S27. Intramolecular hydrogen bonding of CV-1-CN, C-H $\cdots \mathrm{N}\left(\mathrm{H} \cdots \mathrm{N}: 2.620 \AA ⿻, \mathrm{C}-\mathrm{H} \cdots \mathrm{N}: 151.47^{\circ}\right)$ (blue dashed line).

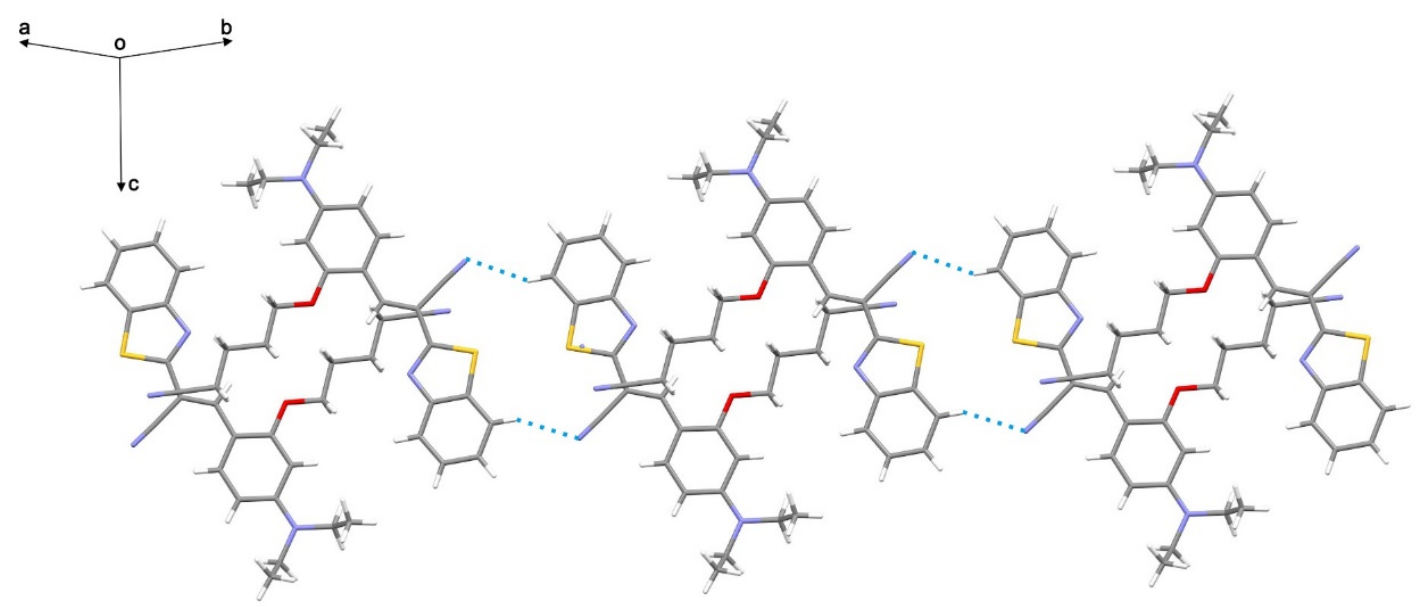

Figure S28. Packing structures of CV-1-CN in crystal from top view, $\mathrm{C}-\mathrm{H} \cdots \mathrm{N}(\mathrm{H} \cdots \mathrm{N}: 2.601 \AA, \mathrm{C}-\mathrm{H} \cdots \mathrm{N}$ : $\left.150.72^{\circ}\right)$

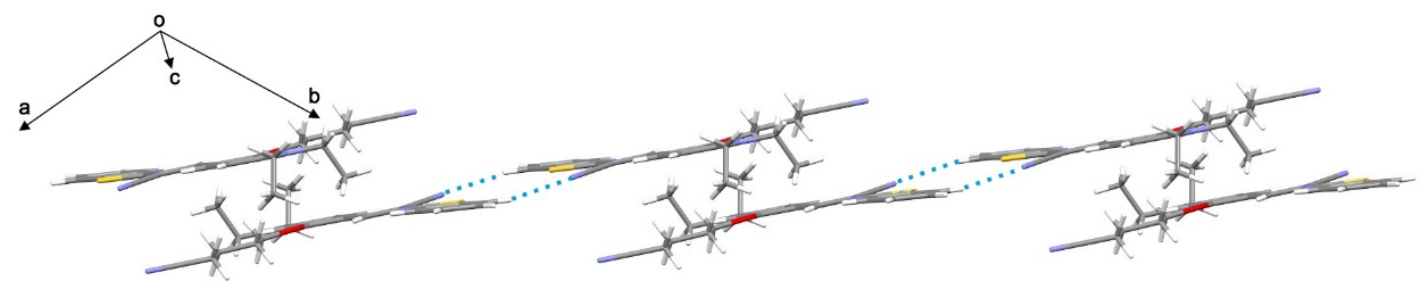

Figure S29. Packing structures of CV-1-CN crystal from side view, $\mathrm{C}-\mathrm{H} \cdots \mathrm{N}(\mathrm{H} \cdots \mathrm{N}: 2.601 \AA, \mathrm{C}-\mathrm{H} \cdots \mathrm{N}$ : $\left.150.72^{\circ}\right)$ 


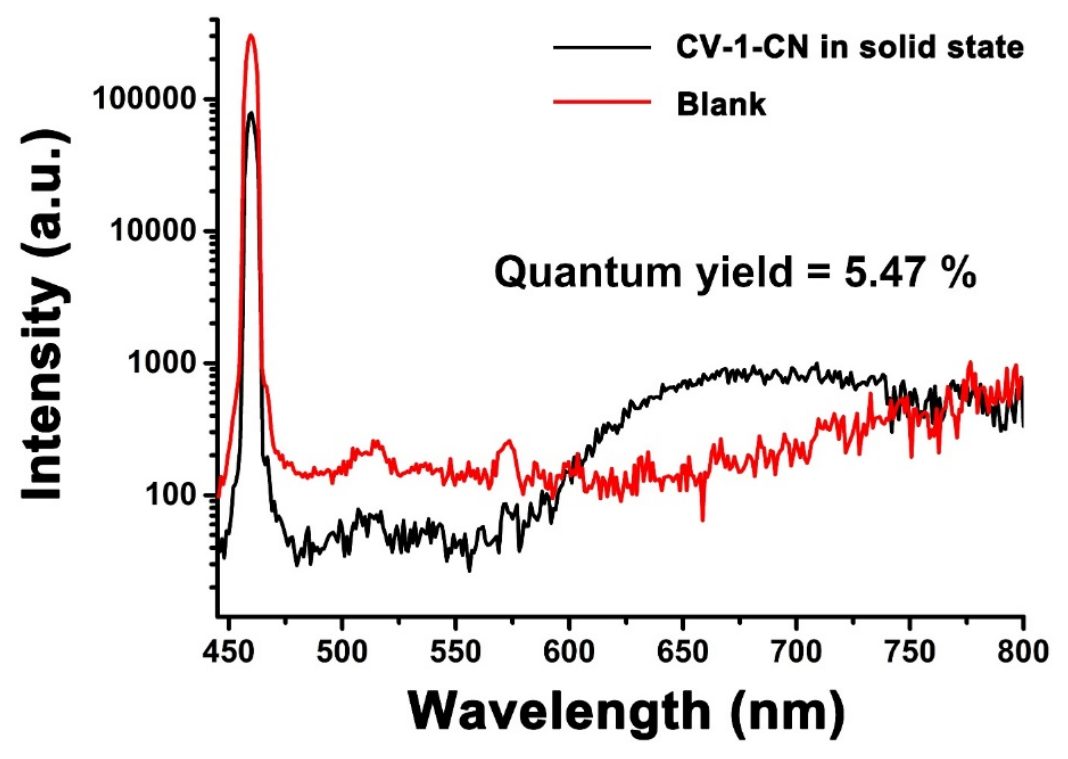

Figure S30. Absolute quantum yield of CV-1-CN in solid state. Experiment condition: $\lambda_{\mathrm{ex}}=460 \mathrm{~nm}$.

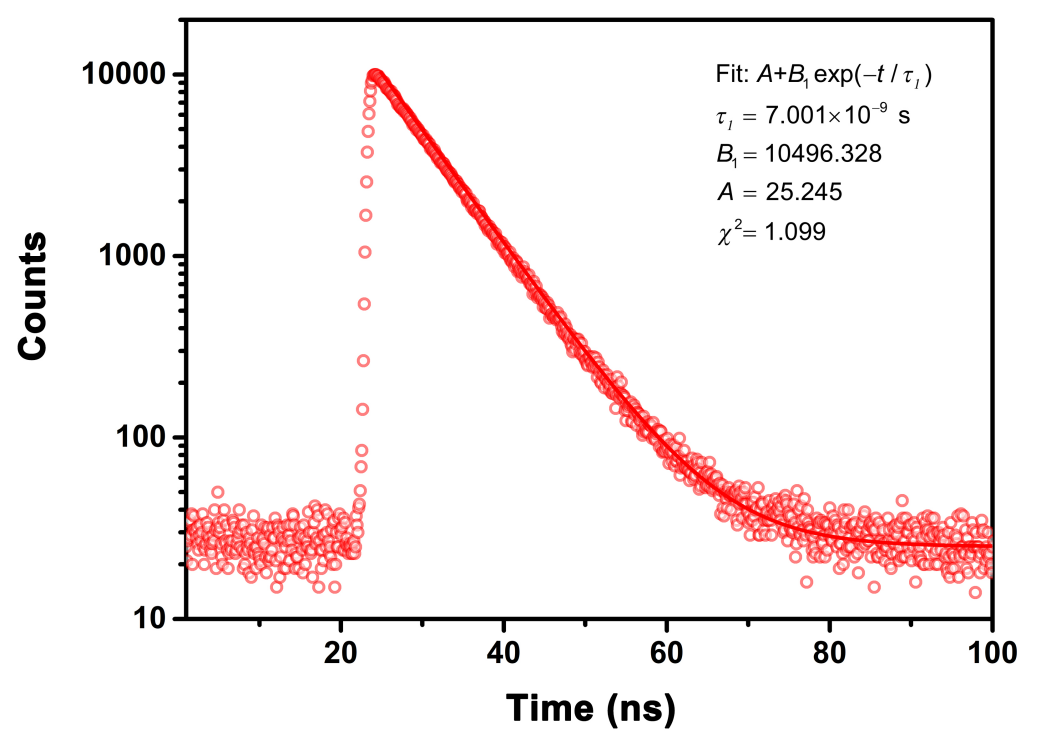

Figure S31. Fluorescence decay profile of CV-1-CN in solid state monitored at $540 \mathrm{~nm}$.

As shown in Figure S33, the intramolecular hydrogen bonding formed between $\mathrm{C}-\mathrm{H}$ and $\mathrm{C} \equiv \mathrm{N}$ of two CV-

2-CN with different conformation in one asymmetric unit was measured to be: a) $\mathrm{CV}-2-\mathrm{CN}-\mathrm{A}: \mathrm{C}-\mathrm{H} \cdots \mathrm{N}$ $\left(\mathrm{H}^{\cdots} \mathrm{N}: 2.596 \AA, \mathrm{C}-\mathrm{H}^{\cdots} \mathrm{N}: 150.82^{\circ}\right)$ and b) CV-2-CN-B: C-H $\cdots \mathrm{N}\left(\mathrm{H} \cdots \mathrm{N}: 2.616 \AA, \mathrm{C}-\mathrm{H} \cdots \mathrm{N}: 151.09^{\circ}\right)$ Due to the two molecules packing in one asymmetric unit in a body-to-shoulder fashion, intermolecular 
hydrogen bonding formed as depicted in Figure S34. Furthermore, as indicated by the packing structures of CV-1-CN in Figure S35, each dimer interacts with adjacent dimers by two identical intermolecular hydrogen bonding formed between phenyl group and cyano group $\mathrm{C}-\mathrm{H} \cdots \mathrm{N}\left(\mathrm{H}^{\cdots} \cdots \mathrm{N}: 2.731 \AA, \mathrm{C}-\mathrm{H} \cdots \mathrm{N}\right.$ : $152.91^{\circ}$ ) with interplanar stacking distance and displacement angle were measured to be $3.45 \AA$ and $67.6^{\circ}$.

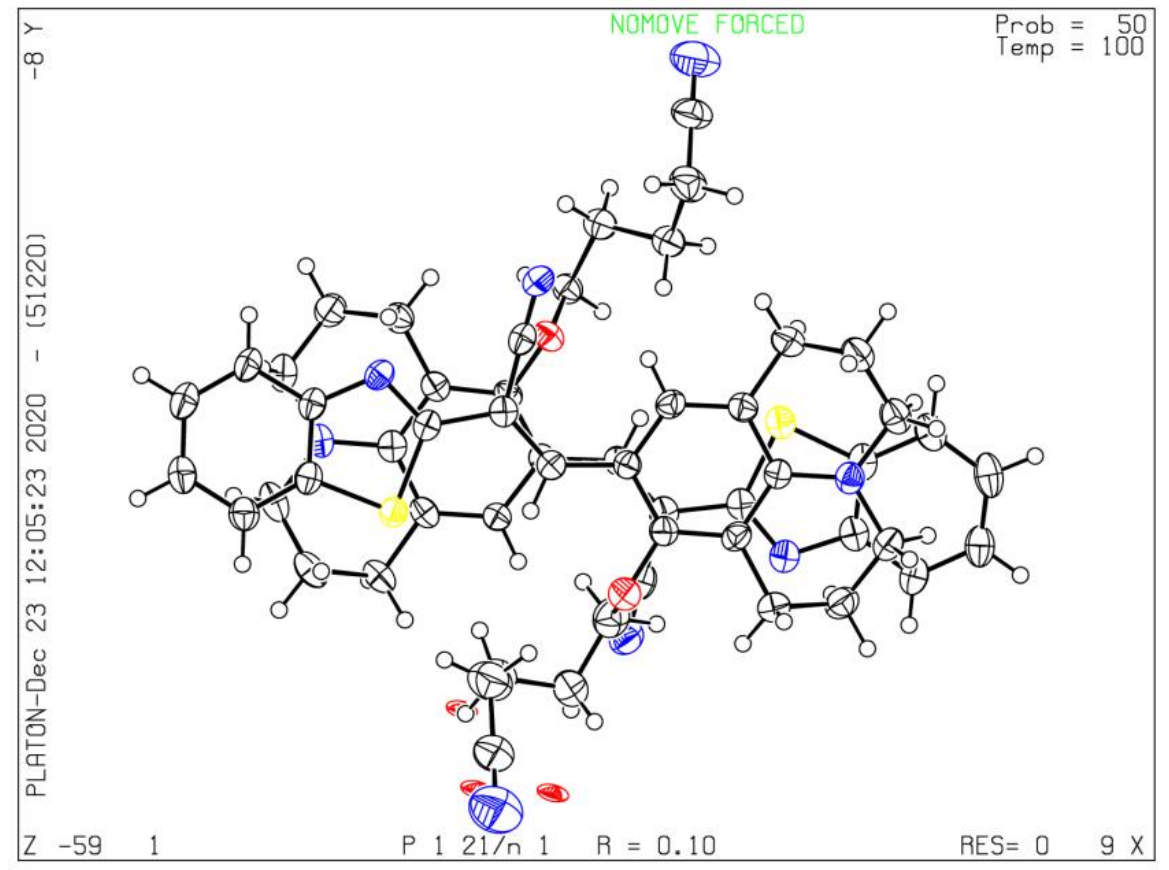

Figure S32. The ORTEP-style illustration of CV-2-CN structure, with probability ellipsoids (CCDC reference number 2033130).

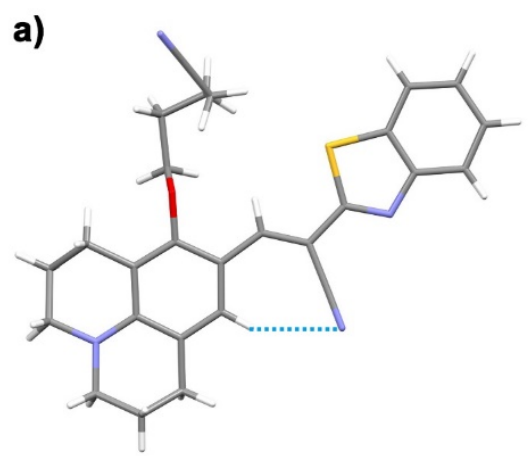

CV-2-CN-A

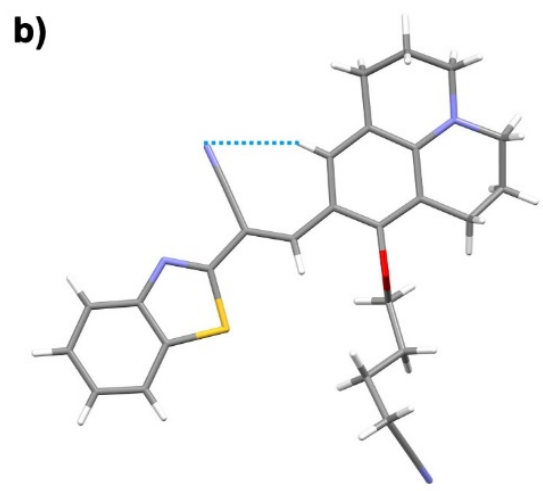

CV-2-CN-B

Figure S33. Intramolecular hydrogen bonding of CV-2-CN in one asymmetric unit. a) CV-2-CN-A: C$\mathrm{H}^{\cdots} \mathrm{N}\left(\mathrm{H} \cdots \mathrm{N}: 2.596 \AA, \mathrm{C}-\mathrm{H} \cdots \mathrm{N}: 150.82^{\circ}\right)$; b) CV-2-CN-B: C-H $\cdots \mathrm{N}\left(\mathrm{H}^{\cdots} \cdots \mathrm{N}: 2.616 \AA, \mathrm{C}-\mathrm{H} \cdots \mathrm{N}: 151.09^{\circ}\right)$. 


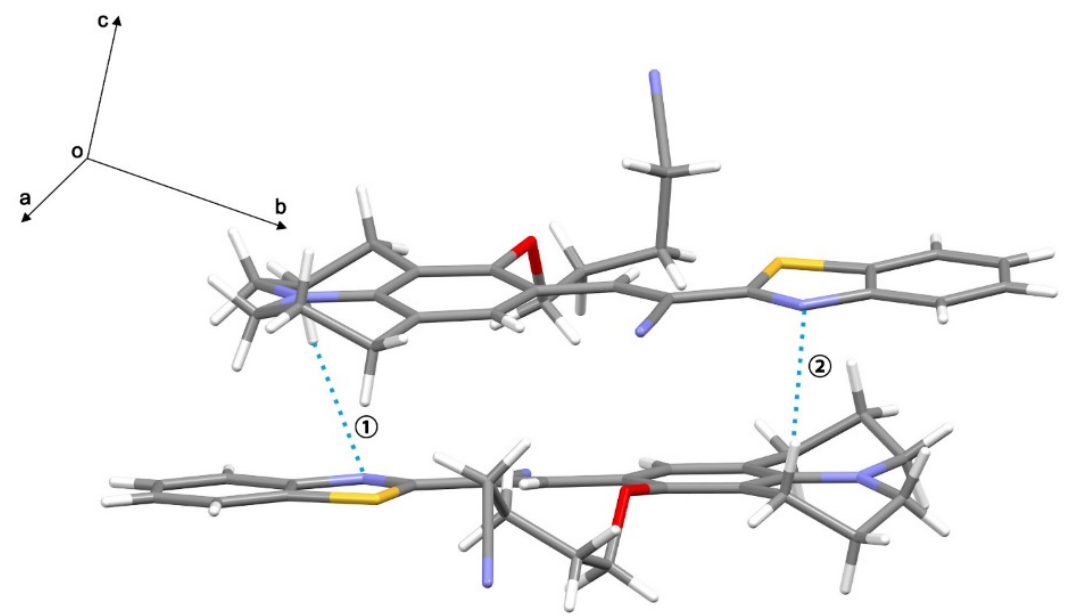

Figure S34. Packing structures of CV-2-CN in one asymmetric unit, (1) $\mathrm{C}-\mathrm{H} \cdots \mathrm{N}(\mathrm{H} \cdots \mathrm{N}: 2.658 \AA$, C$\left.\mathrm{H}^{\cdots} \cdots \mathrm{N}: 169.72^{\circ}\right),(2) \mathrm{C}-\mathrm{H}^{\cdots} \cdots \mathrm{N}\left(\mathrm{H}^{\cdots} \cdots \mathrm{N}: 2.501 \AA, \mathrm{C}-\mathrm{H}^{\cdots} \cdots \mathrm{N}: 152.34^{\circ}\right)$.

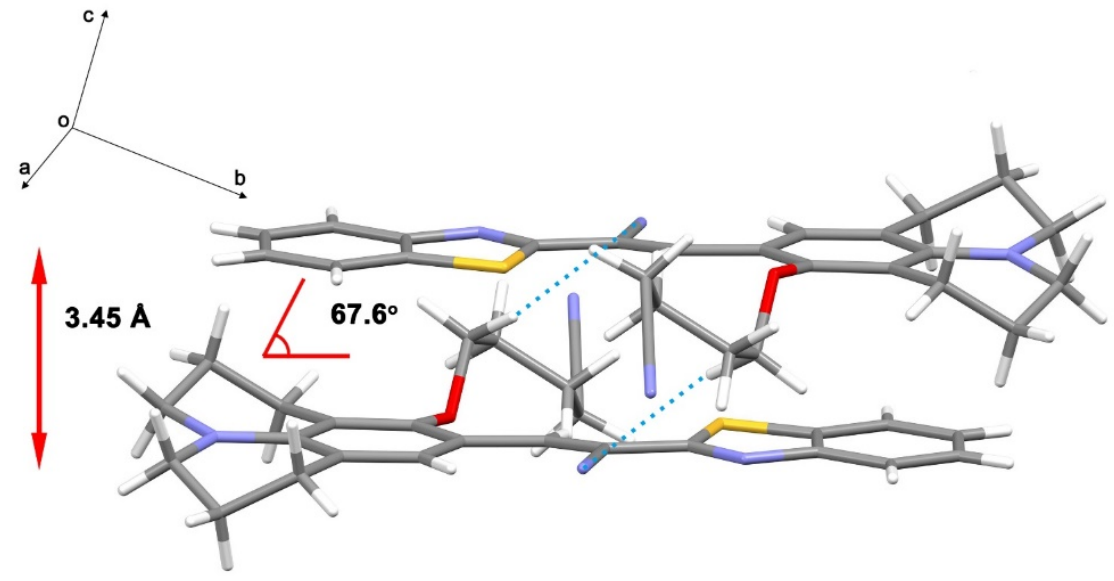

Figure S35. Packing structures of CV-2-CN crystal, C-H $\cdots \mathrm{N}\left(\mathrm{H}^{\cdots} \cdots \mathrm{N}: 2.731 \AA, \mathrm{C}-\mathrm{H} \cdots \mathrm{N}: 152.91^{\circ}\right)($ blue dash line). 


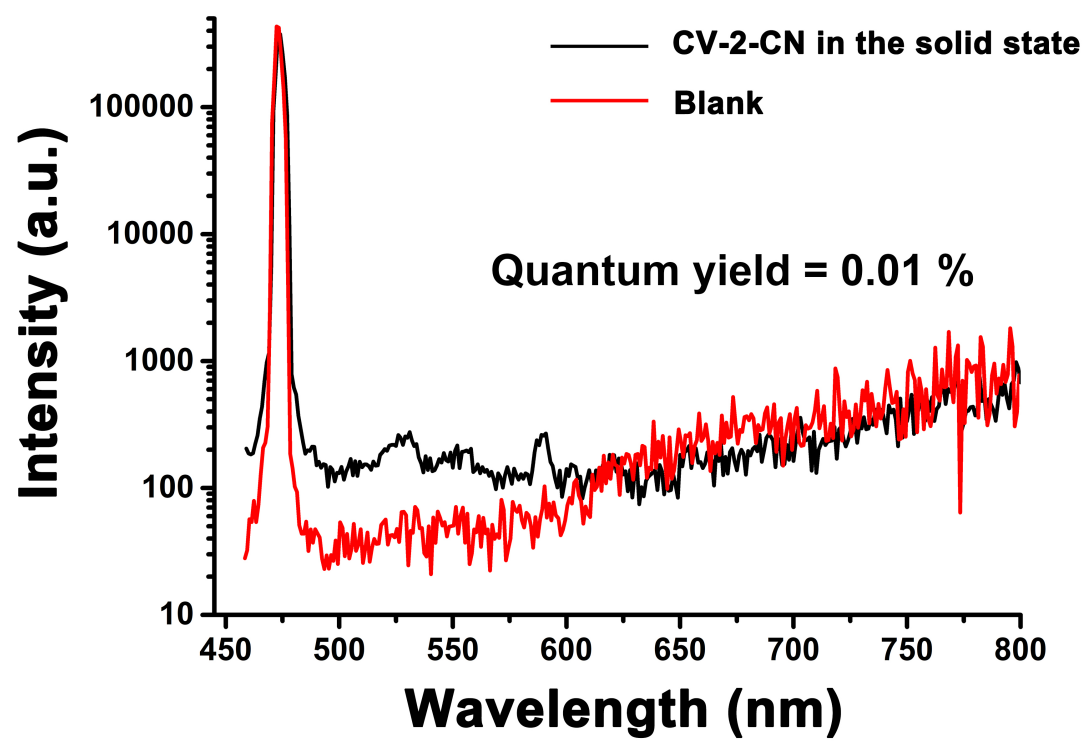

Figure S36. Absolute quantum yield of CV-2-CN in the solid state. Experiment condition: $\lambda_{\mathrm{ex}}=474 \mathrm{~nm}$.

\section{Evidence of host-guest interactions}

For another type of guest moiety, i.e., trizaole-alkyl-cyano-group, the binding affnity towards DMP[5]A was characterized by implementing ${ }^{1} \mathrm{H}$ NMR and 2D DOSY experiments in $\mathrm{CDCl}_{3}$. The resonance peaks of $\mathrm{H}_{1}, \mathrm{H}_{2}, \mathrm{H}_{3}$ and $\mathrm{H}_{4}$ corresponding to $\mathrm{CV}-1-\mathrm{TA}-\mathrm{CN}$ underwent upfield shift upon the addition of DMP[5]A ranged from 0.8 to 1.5 equimolar (Figure S37) due to the inclusion interactions between DMP[5]A and CV-1-TA-CN. Meanwhile, the signals of inclusion complexes exhibited a welldefined line in 2D DOSY spectra, indicating that the formation of stable host-guest complexes whose $D$ value was measured to be $6.37 \times 10^{-10} \mathrm{~m}^{2} \mathrm{~s}^{-1}$ compared to that of free DMP[5]A measured to be $1.19 \times 10^{-9}$ $\mathrm{m}^{2} \mathrm{~s}^{-1}$ in $\mathrm{CDCl}_{3}$ (Figure S38). In addition, 2D ROESY NMR spectroscopy of DMP[5]A and CV-1-TA$\mathrm{CN}$ mixture showed the correlations between $\mathrm{H}_{\mathrm{a}}$ corresponding to phenyl of DMP[5]A and $\mathrm{H}_{1}, \mathrm{H}_{2}, \mathrm{H}_{3}$ and $\mathrm{H}_{4}$ corresponding to trizaole-alkyl-cyano-group of CV-1-TA-CN, strongly suggesting that inclusion complexes formed because of host-guest interactions (Figure S39). The binding ability of guest molecules, $\mathrm{CV}-2-\mathrm{CN}$ containing julolidine as donor, toward DMP[5]A was characterized by ${ }^{1} \mathrm{H}$ NMR and 2D DOSY 
experiments to validate that host-guest interactions caused the formation of inclusion complexes. As shown in Figure S40, the signals corresponding to $\mathrm{H}_{1}$ and $\mathrm{H}_{4}$ of guest moieties disappeared after adding DMP[5]A into CV-2-CN solution because of the strong broadening effect. Meanwhile, a well-defined line in 2D DOSY spectra indicated the formation of host-guest complexes (Figure S41).

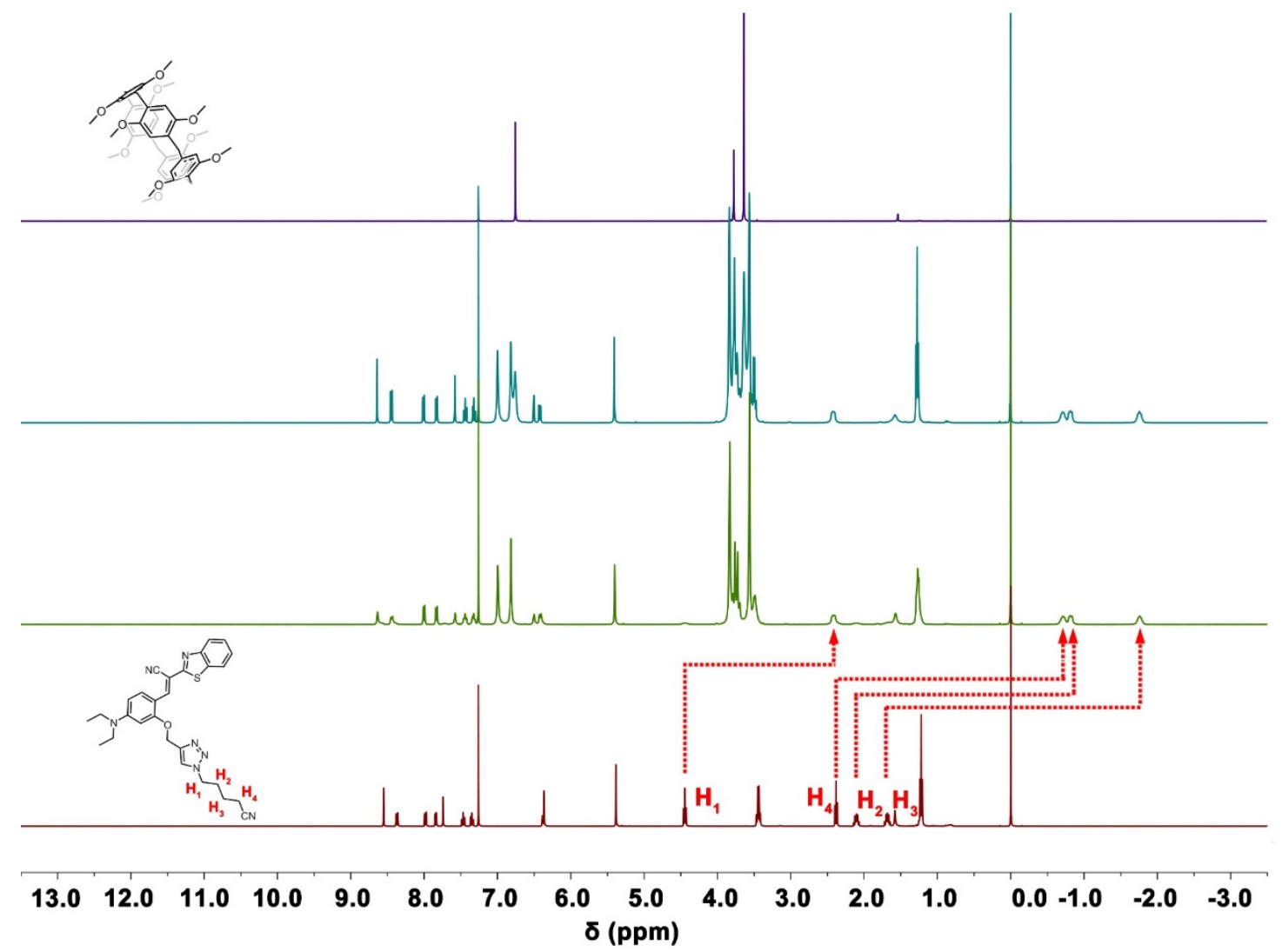

Figure S37. ${ }^{1} \mathrm{H}$ NMR spectra $\left(400 \mathrm{MHz}, \mathrm{CDCl}_{3}, 298 \mathrm{~K}\right)$ of $\mathrm{CV}-1-\mathrm{TA}-\mathrm{CN}$ in the presence of increasing amount of DMP[5]A; from bottom to top: 0.0, 0.8, 1.5 equivalents and uncomplexed DMP[5]A. 


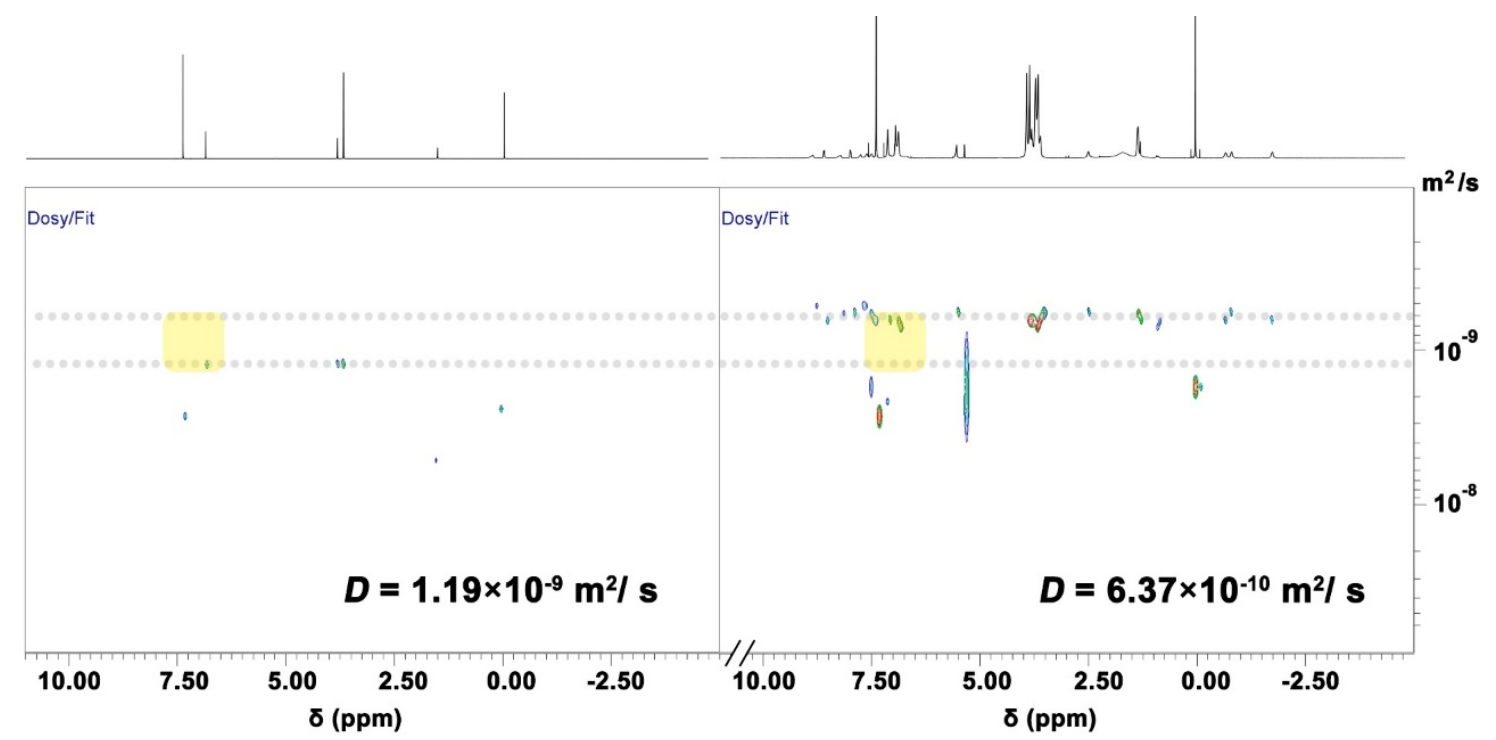

Figure S38. 2D DOSY spectra (600 $\left.\mathrm{MHz}, \mathrm{CDCl}_{3}, 298 \mathrm{~K}\right)$ of i) DMP[5]A and ii) CV-1-TA$\mathrm{CN} \subset \mathrm{DMP}[5] \mathrm{A},[\mathrm{CV}-1-\mathrm{TA}-\mathrm{CN}]=5 \mathrm{mM},[\mathrm{DMP}[5] \mathrm{A}]=5 \mathrm{mM}$.

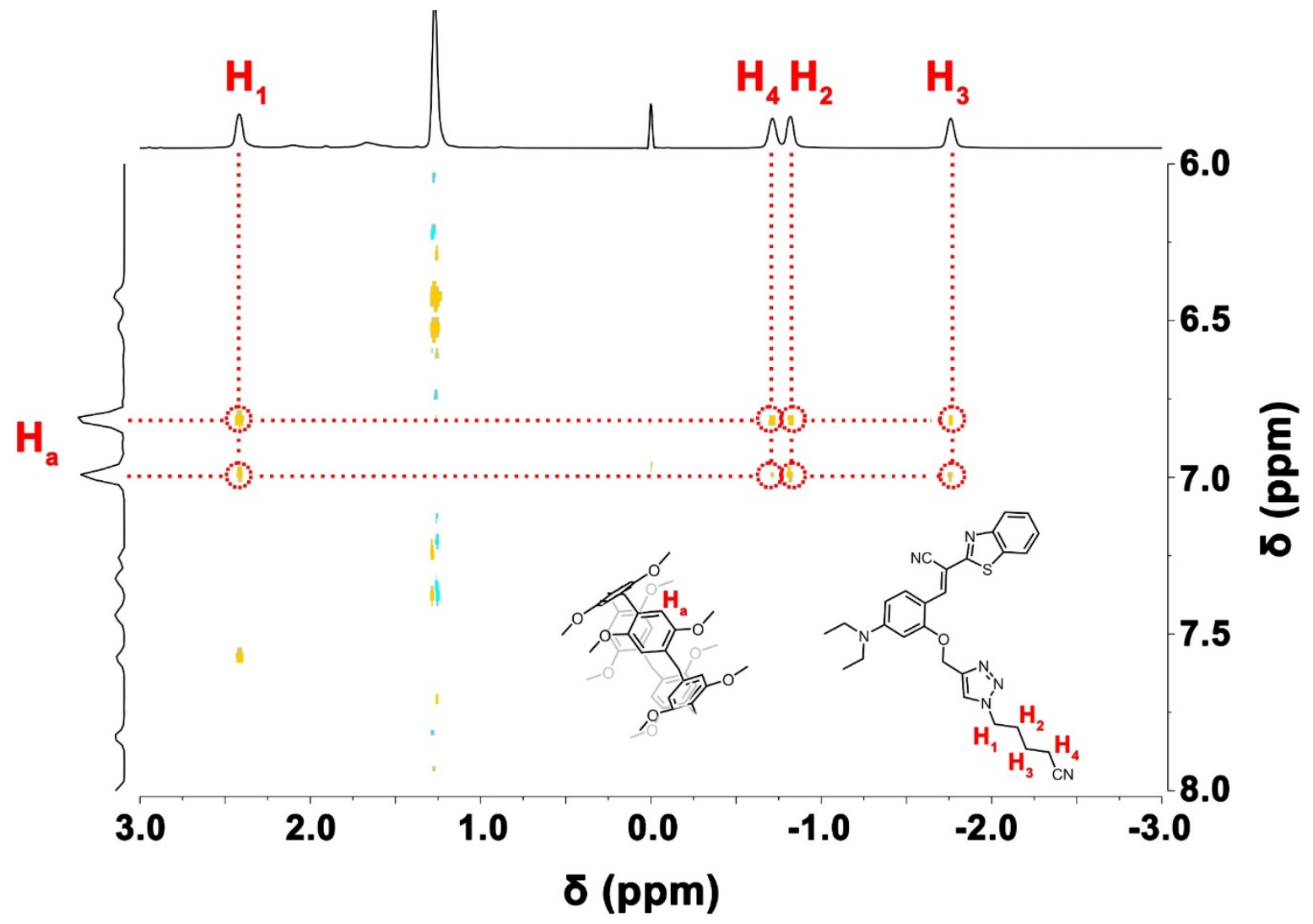

Figure S39. Partial 2D ROESY spectrum (600 MHz, $\mathrm{CDCl}_{3}$, $298 \mathrm{~K}$ ) of CV-1-TA-CNCDMP[5]A, [CV$1-\mathrm{TA}-\mathrm{CN}]=20 \mathrm{mM},[\mathrm{DMP}[5] \mathrm{A}]=20 \mathrm{mM}$. 


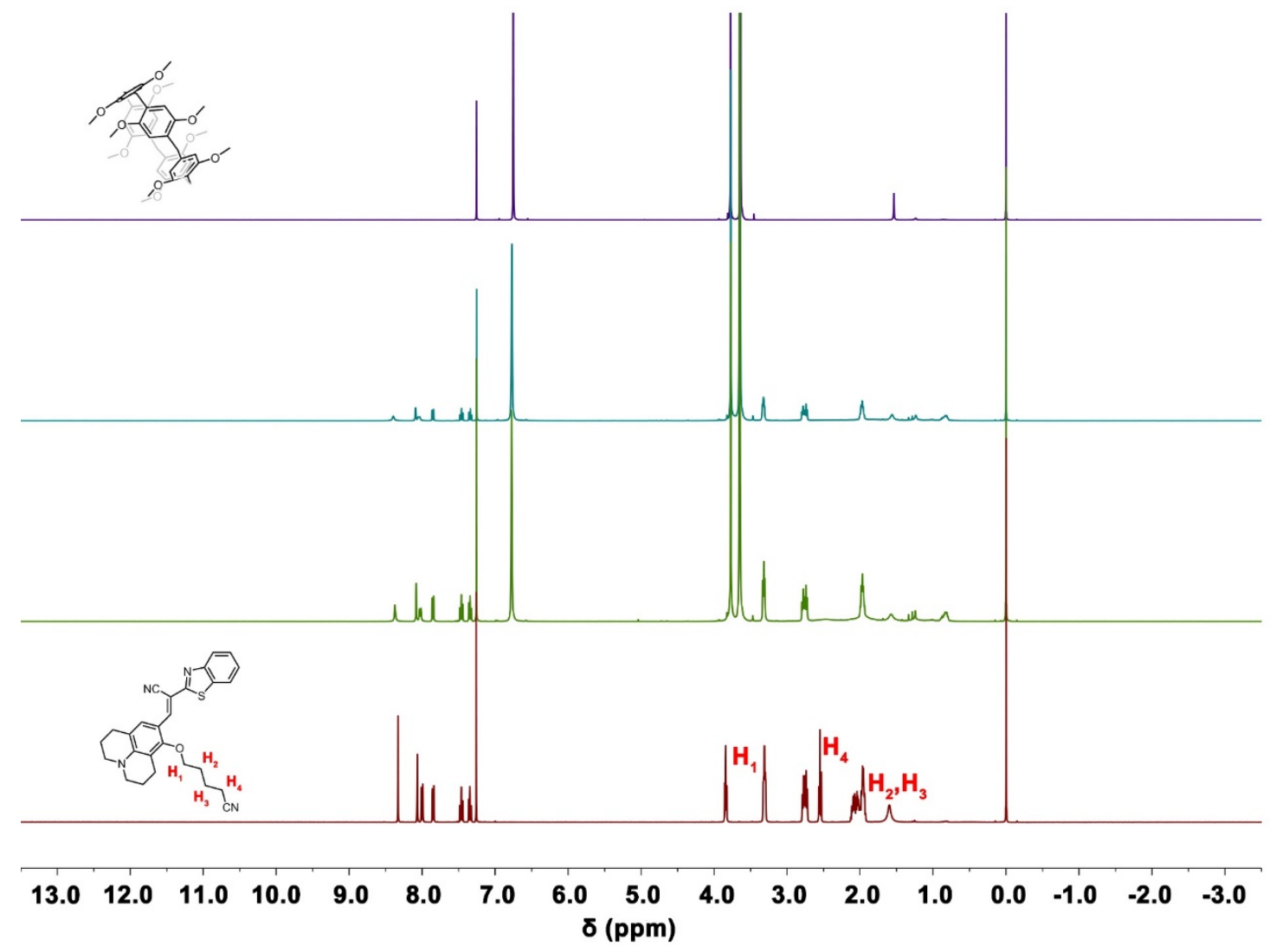

Figure S40. ${ }^{1} \mathrm{H} \mathrm{NMR}$ spectra $\left(400 \mathrm{MHz}, \mathrm{CDCl}_{3}, 298 \mathrm{~K}\right)$ of CV-2-CN in the presence of increasing amount of DMP[5]A; from bottom to top: 0.0, 0.8, 1.5 equivalents and uncomplexed DMP[5]A.

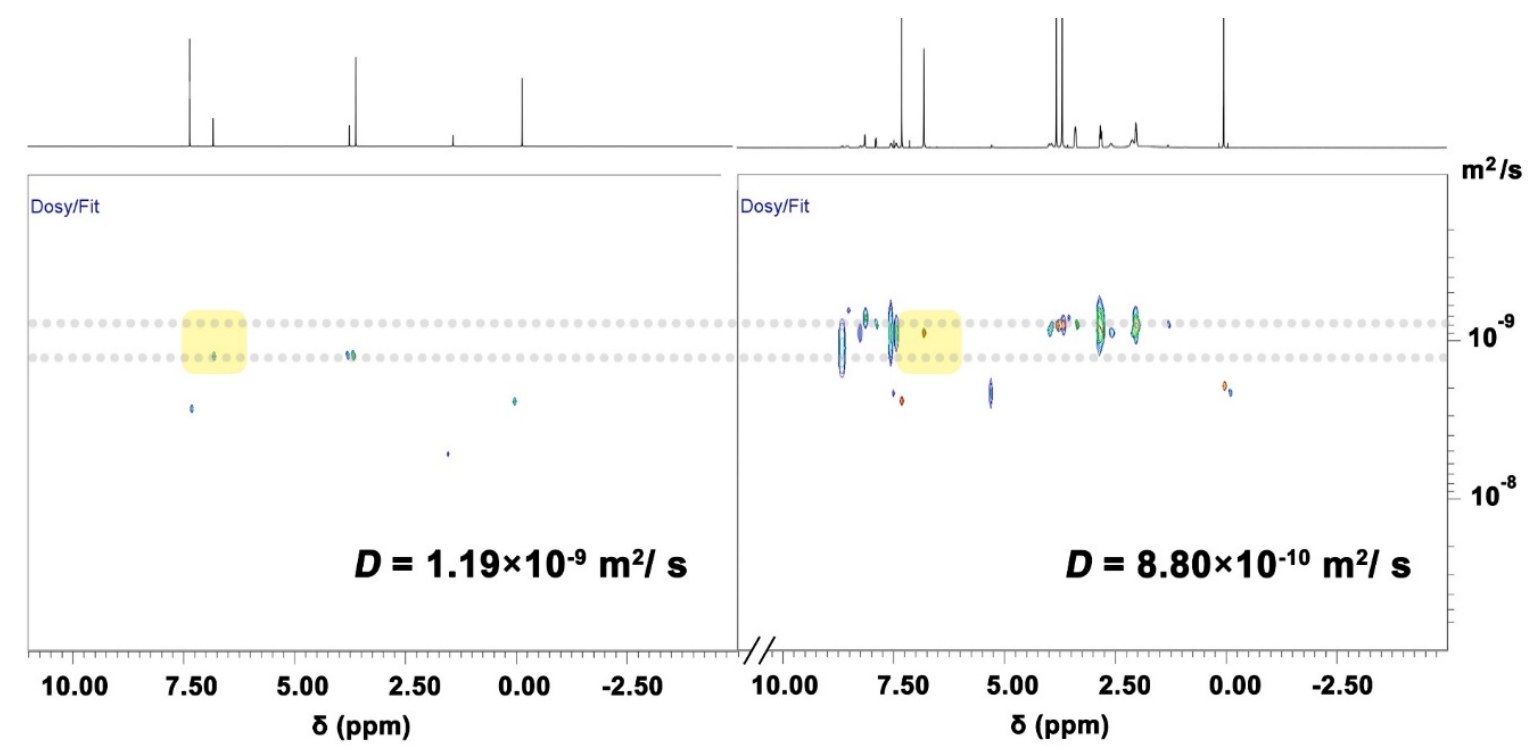

Figure S41. 2D DOSY spectra (600 MHz, $\left.\mathrm{CDCl}_{3}, 298 \mathrm{~K}\right)$ of i) DMP[5]A and ii) CV-2-CNcDMP[5]A, $[\mathrm{CV}-2-\mathrm{CN}]=5 \mathrm{mM},[\mathrm{DMP}[5] \mathrm{A}]=5 \mathrm{mM}$. 


\section{Photophysical properties}

The absorption maxima of $\mathrm{CV}$ derivatives containing $N, N$-diethylaniline or julolidine as donor were measured to be $460 \mathrm{~nm}$ and $476 \mathrm{~nm}$ in THF, respectively (Figure S42). The absorption of CV-1-CN at $460 \mathrm{~nm}$ was increased upon increasing the water fraction and reached a maximum at $\mathrm{f}_{\mathrm{w}}$ of $80 \%$, however, the absorption underwent a moderate decrease at $f_{w}$ of $90 \%$, suggesting that the formation of aggregates (Figure S43). The absorption peak of CV-1-CNсDMP[5]A at $460 \mathrm{~nm}$ increased and show red-shift upon addition of water, yet the baseline of CV-1-CNCDMP[5]A was drifted when $\mathrm{f}_{\mathrm{w}}$ reached to $90 \%$ on account of heterogeneity caused by a large quantity of hydrophobic molecules (Figure S44).

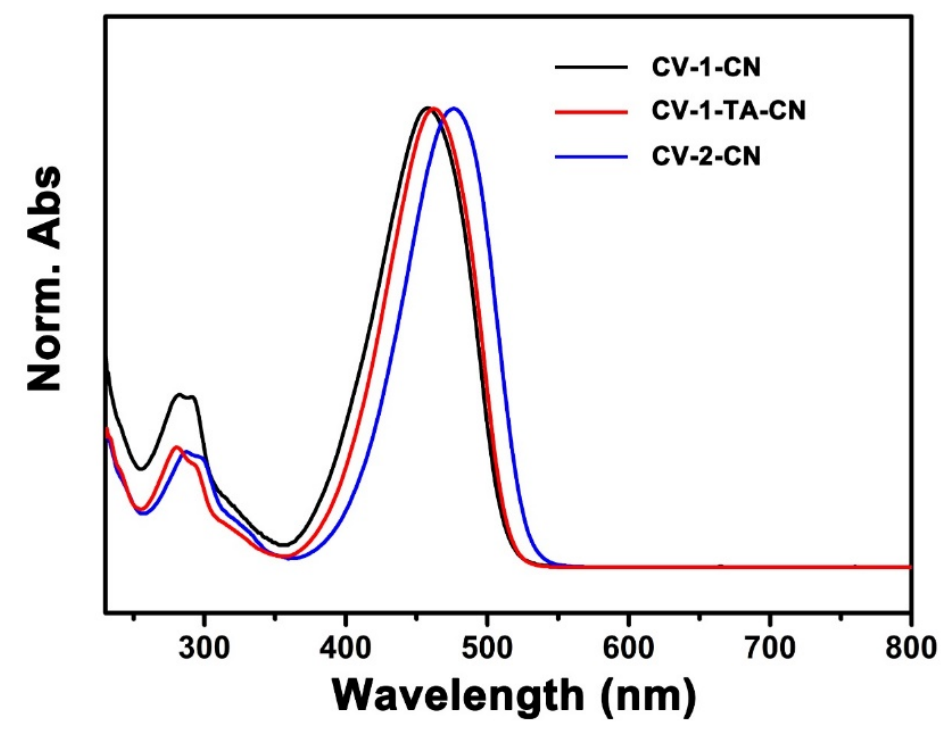

Figure S42. UV-Vis spectra of CV-1-CN (black line), CV-1-TA-CN (red line) and CV-2-CN (blue line) in THF. Experimental condition: $[\mathrm{CV}-1-\mathrm{CN}]=4 \mu \mathrm{M} ;[\mathrm{CV}-1-\mathrm{TA}-\mathrm{CN}]=4 \mu \mathrm{M} ;[\mathrm{CV}-2-\mathrm{CN}]=4 \mu \mathrm{M} ; 25^{\circ} \mathrm{C}$. 


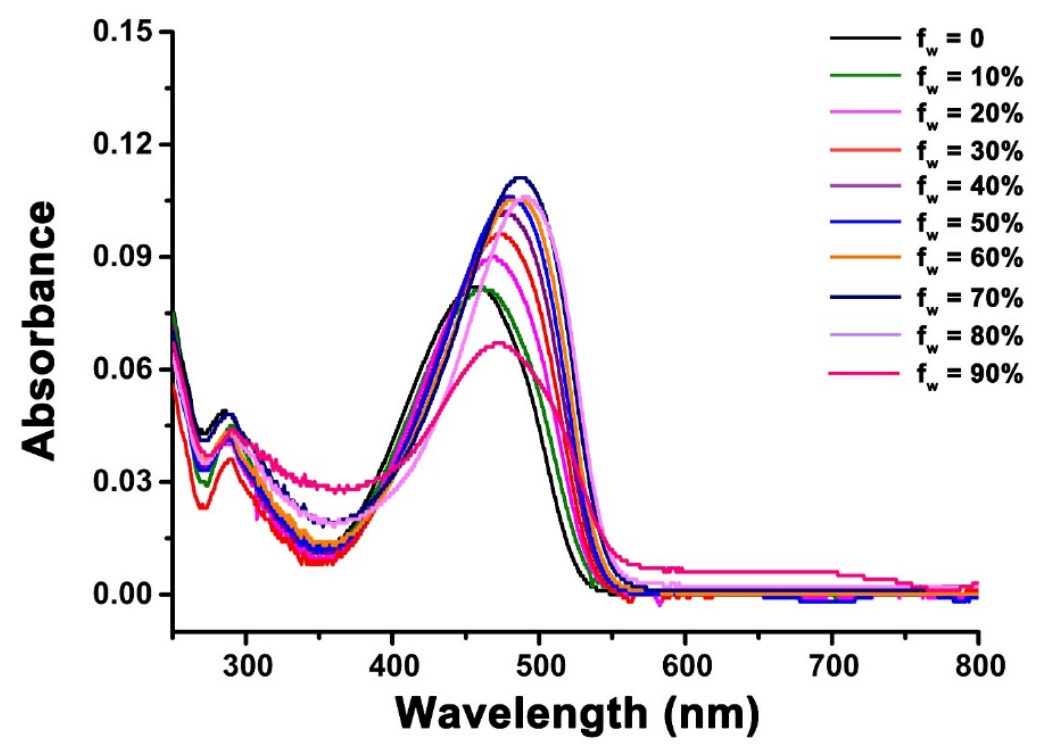

Figure S43. UV-Vis spectra of CV-1-CN in THF upon addition of water of different $\mathrm{f}_{\mathrm{w}}$. Experimental condition: $[\mathrm{CV}-1-\mathrm{CN}]=4 \mu \mathrm{M} ; 25^{\circ} \mathrm{C}$.

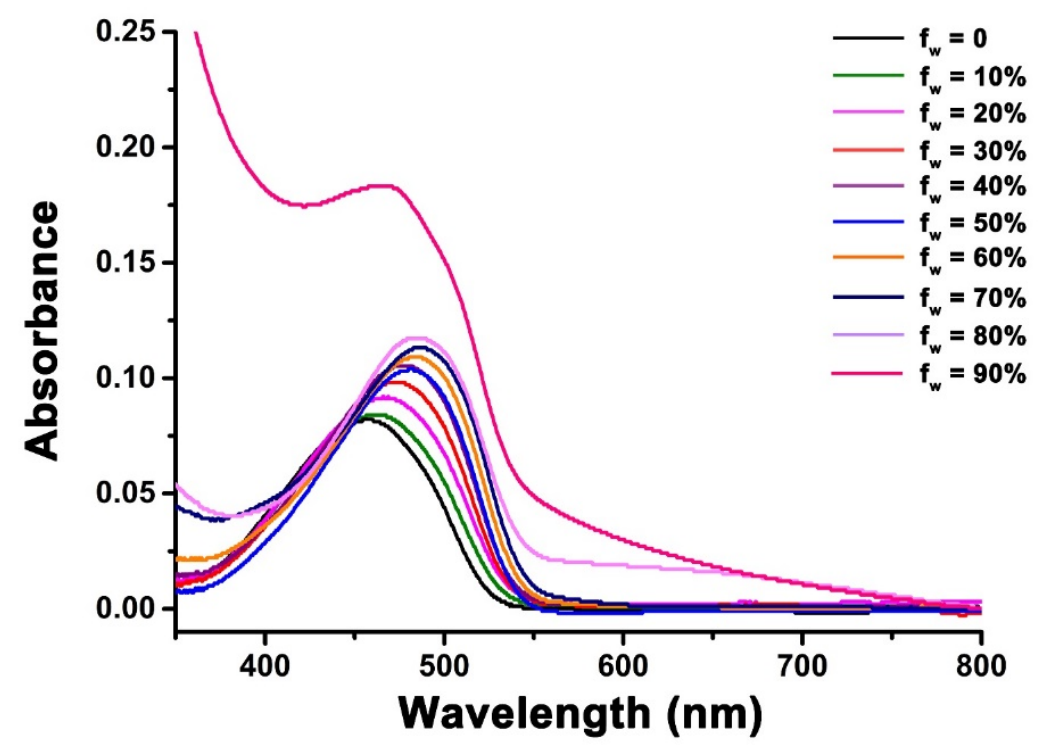

Figure S44. UV-Vis spectra of CV-1-CNCDMP[5]A in THF upon addition of water of different $f_{w}$. Experimental condition: $[\mathrm{DMP}[5] \mathrm{A}]=36 \mu \mathrm{M} ;[\mathrm{CV}-1-\mathrm{CN}]=4 \mu \mathrm{M} ; 25^{\circ} \mathrm{C}$. 
a)

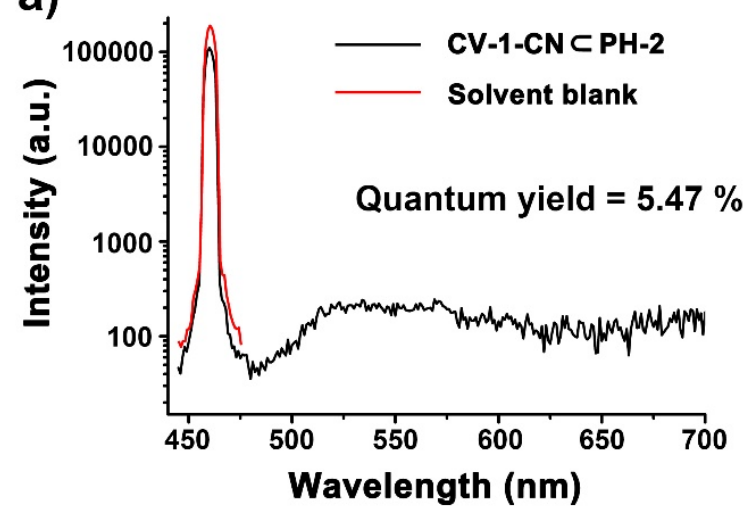

C)

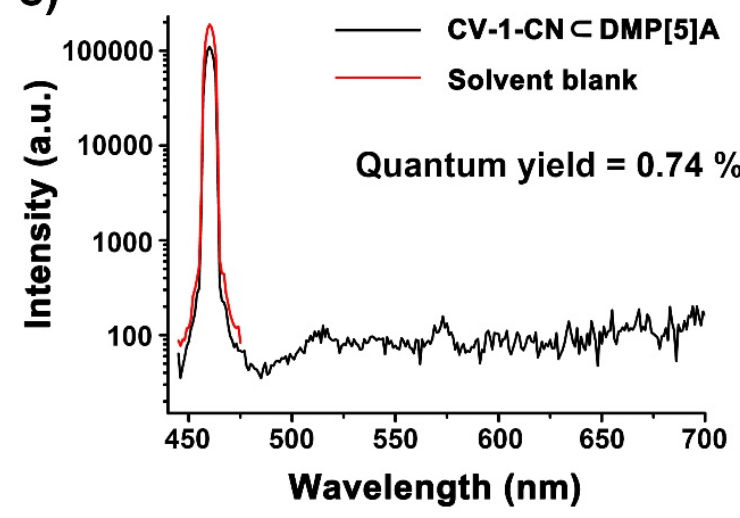

b)

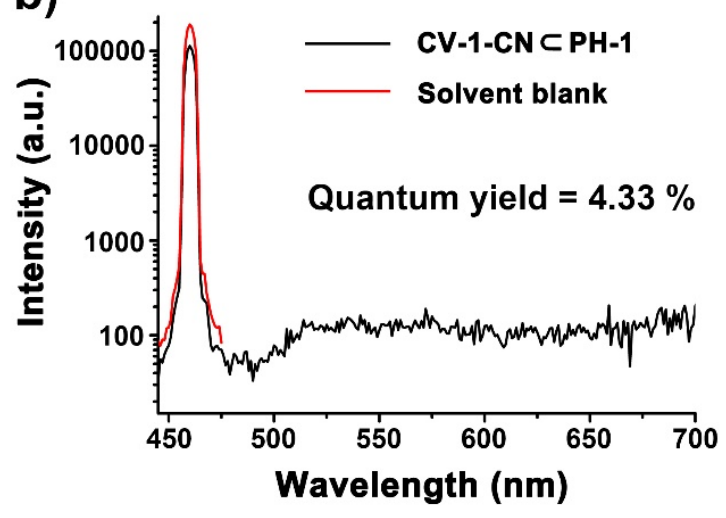

d)

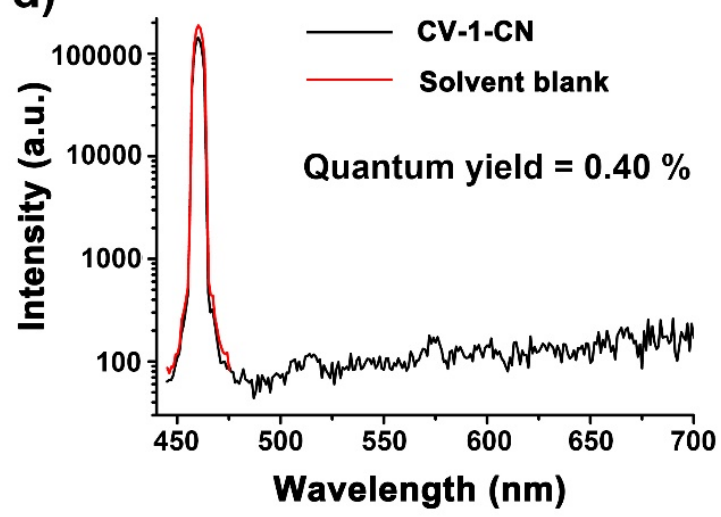

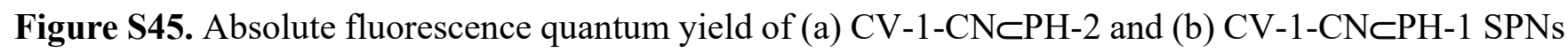
in $\mathrm{THF} / \mathrm{H}_{2} \mathrm{O}$ mixed solvent, $\mathrm{f}_{\mathrm{w}}=90 \%$. Experiment condition: $\lambda_{\mathrm{ex}}=460 \mathrm{~nm}$, [pillar[5]arene unit $]=36 \mu \mathrm{M}$,

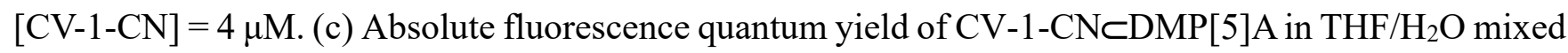
solvent, $\mathrm{f}_{\mathrm{w}}=90 \%$. Experiment condition: $\lambda_{\mathrm{ex}}=460 \mathrm{~nm},[\mathrm{DMP}[5] \mathrm{A}]=36 \mu \mathrm{M},[\mathrm{CV}-1-\mathrm{CN}]=4 \mu \mathrm{M}$. (d) Absolute fluorescence quantum yield of $\mathrm{CV}-1-\mathrm{CN}$ in $\mathrm{THF} / \mathrm{H}_{2} \mathrm{O}$ mixed solvent, $\mathrm{f}_{\mathrm{w}}=90 \%$. Experiment condition: $\lambda_{\mathrm{ex}}=460 \mathrm{~nm},[\mathrm{CV}-1-\mathrm{CN}]=4 \mu \mathrm{M}$.

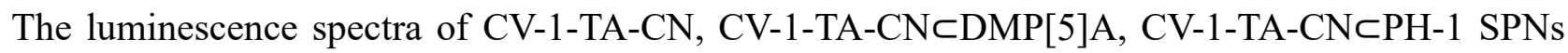
and CV-1-TA-CNCPH-2 SPNs were measured upon addition of water in $\mathrm{THF} / \mathrm{H}_{2} \mathrm{O}$ mixed solvent, and the maximum fluorescence intensity was obtained by manipulating CV-1-TA-CN with PH-2 (Figures S46-S51). The fluorescence intensity of CV-1-TA-CN was enhanced slightly with the increasing water fraction in $\mathrm{THF} / \mathrm{H}_{2} \mathrm{O}$ mixed solvent due to the restriction of $\mathrm{D}-\pi-\mathrm{A}$ rotors and/or limitation of vibration. 
The broadening emission peak of CV-1-TA-CN indicating the formation of aggregates when $\mathrm{f}_{\mathrm{w}}$ reached to $90 \%$. Moreover, the fluorescence emission of CV-1-TA-CN further intensified with the increasing $\mathrm{f}_{\mathrm{w}}$ when introducing DMAP[A] into mixture, especially, the most efficient supramolecular ensembles were fabricated by using PH-2 as polymer host materials. The absolute quantum yields of CV-1-TA-CN, CV-

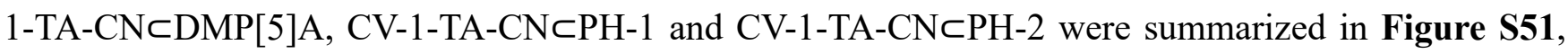
indicating the improved photophysical properties manipulated by supramolecular interactions. All these results showcased that the efficient strategy to compress and separate $\mathrm{CV}$ derivatives, that is, the fluorophores were anchored on polymer hosts through inclusion interactions to construct SPNs with the aid of amphiphilicity of polymer hosts. Significantly, when we changed the donor of fluorophores from $\mathrm{N}, \mathrm{N}$-diethylaniline to julolidine, luminescent $\mathrm{SPNs}$ with longer emission wavelength and brighter fluorescence could be fabricated compared with CV-1-CN and/or CV-1-TA-CN (Figures S52-S57).

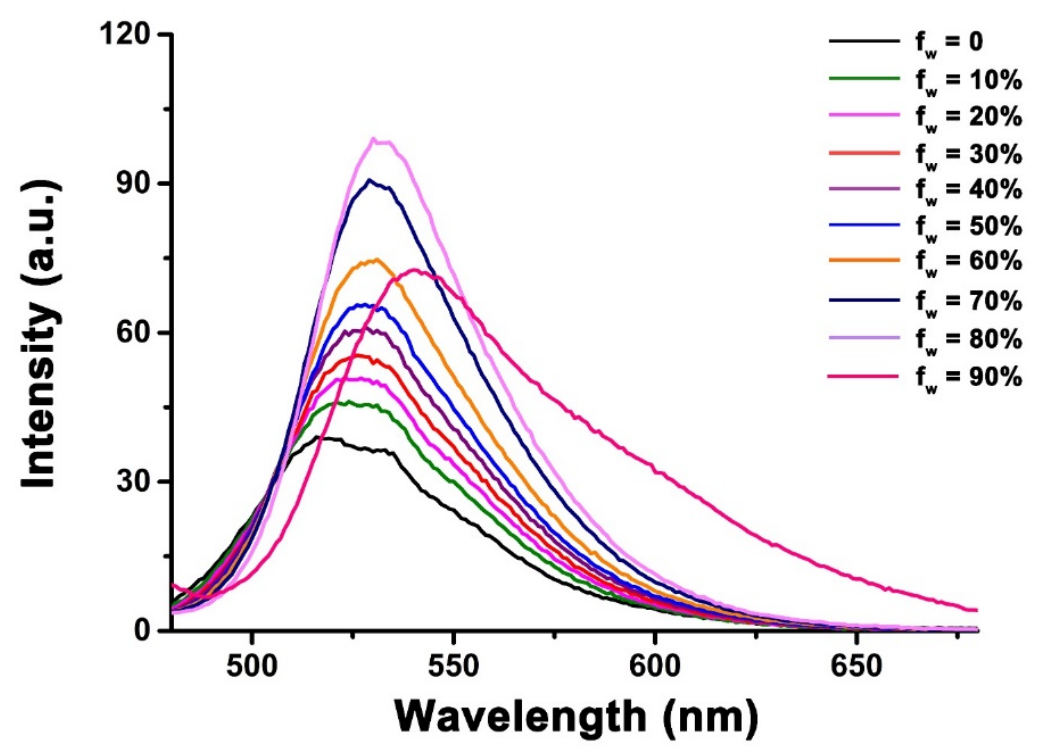

Figure S46. Fluorescence emission spectra of CV-1-TA-CN in THF upon addition of water of different $f_{\mathrm{w}}$. Experimental condition: $\lambda_{\mathrm{ex}}=460 \mathrm{~nm}$; slit widths: ex $5 \mathrm{~nm}$, em $5 \mathrm{~nm}$; [CV-1-TA-CN] $=4 \mu \mathrm{M} ; 25^{\circ} \mathrm{C}$. 


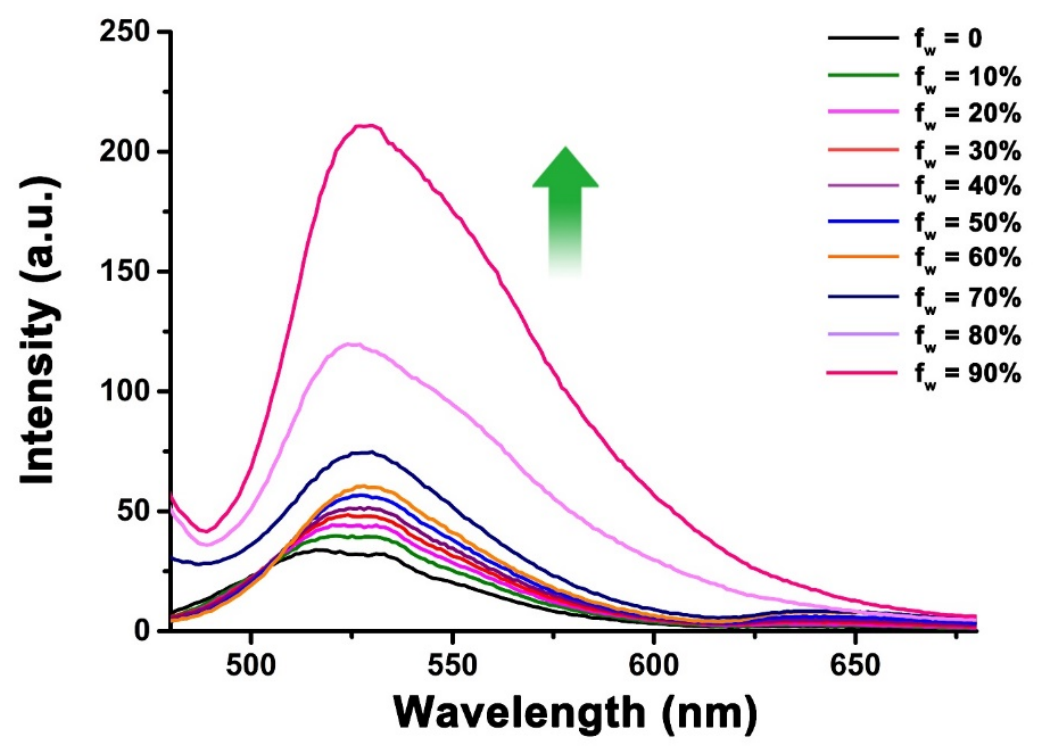

Figure S47. Fluorescence emission spectra of CV-1-TA-CNCDMP[5]A in THF upon addition of water of different $f_{w}$. Experimental condition: $\lambda_{\mathrm{ex}}=460 \mathrm{~nm}$; slit widths: ex $5 \mathrm{~nm}$, em $5 \mathrm{~nm}$; [DMP[5]A] $=36$ $\mu \mathrm{M} ;[\mathrm{CV}-1-\mathrm{TA}-\mathrm{CN}]=4 \mu \mathrm{M} ; 25^{\circ} \mathrm{C}$.

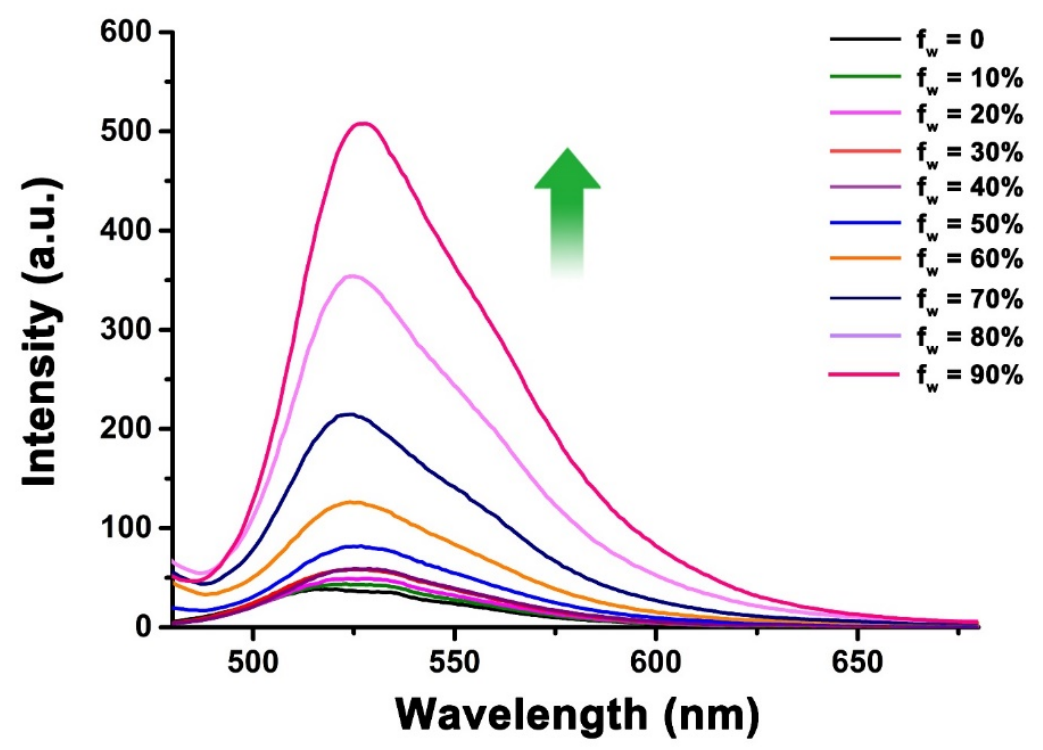

Figure S48. Fluorescence emission spectra of CV-1-TA-CNCPH-1 in THF upon addition of water of different $\mathrm{f}_{\mathrm{w}}$. Experimental condition: $\lambda_{\mathrm{ex}}=460 \mathrm{~nm}$; slit widths: ex $5 \mathrm{~nm}$, em $5 \mathrm{~nm}$; [pillar[5]arene unit] $=$ $36 \mu \mathrm{M} ;[\mathrm{CV}-1-\mathrm{TA}-\mathrm{CN}]=4 \mu \mathrm{M} ; 25^{\circ} \mathrm{C}$. 


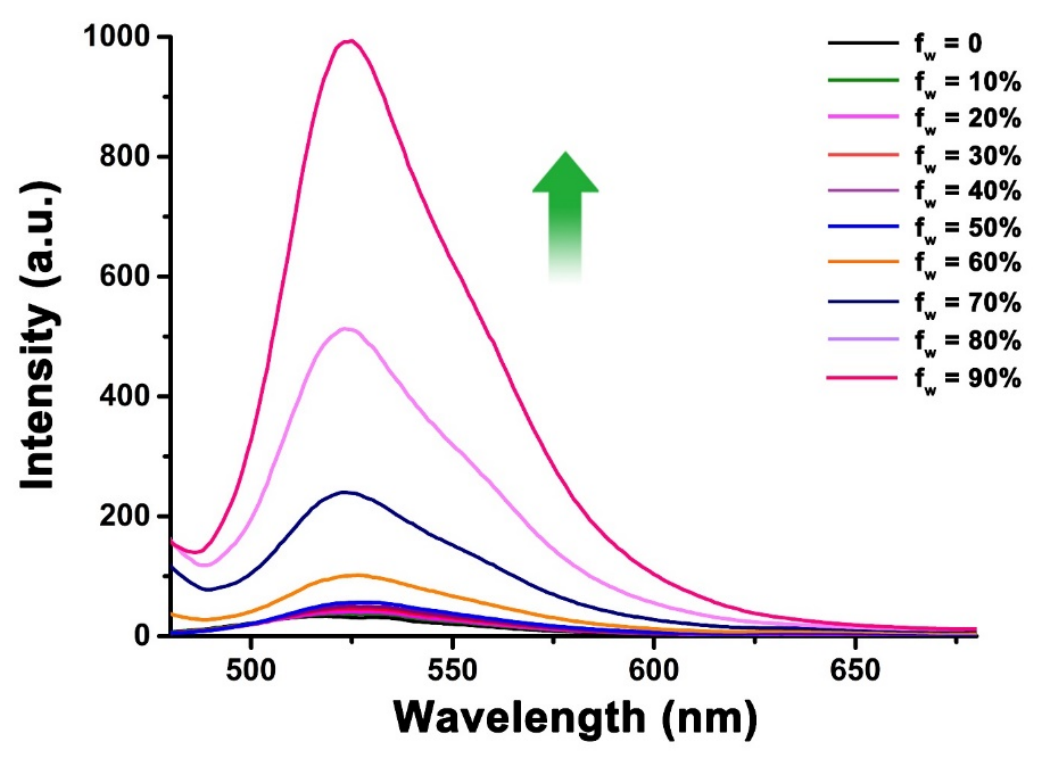

Figure S49. Fluorescence emission spectra of CV-1-TA-CNCPH-2 in THF upon addition of water of different $\mathrm{f}_{\mathrm{w}}$. Experimental condition: $\lambda_{\mathrm{ex}}=460 \mathrm{~nm}$; slit widths: ex $5 \mathrm{~nm}$, em $5 \mathrm{~nm}$; [pillar[5]arene unit] $=$ $36 \mu \mathrm{M} ;[\mathrm{CV}-1-\mathrm{TA}-\mathrm{CN}]=4 \mu \mathrm{M} ; 25^{\circ} \mathrm{C}$.
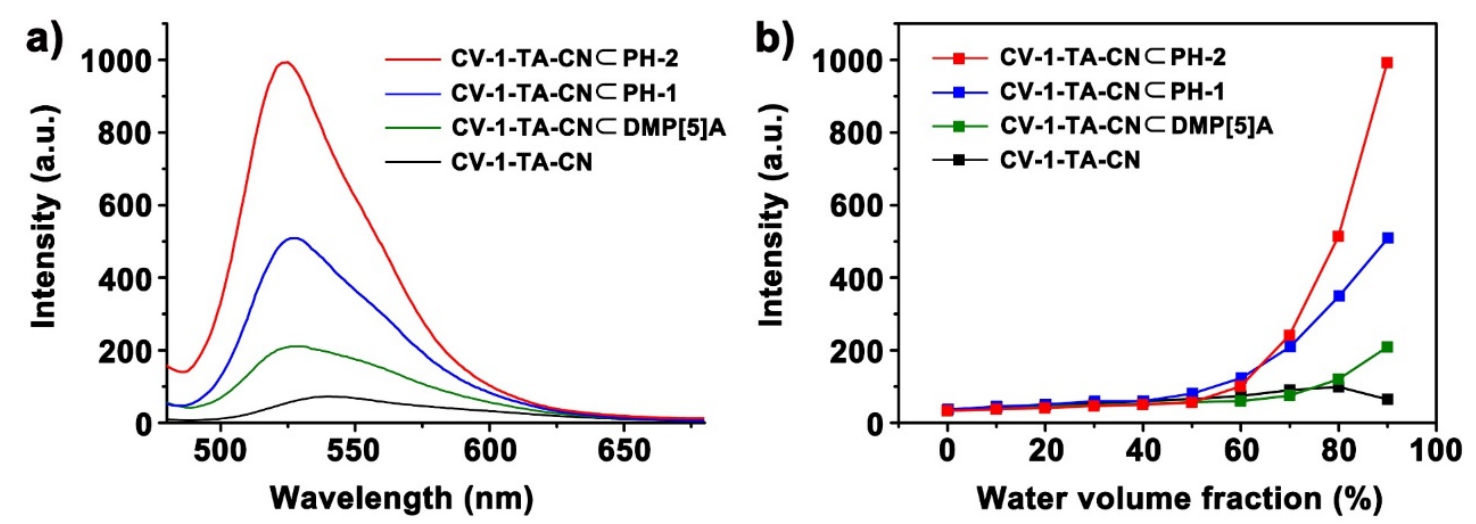

Figure S50. (a) Comparison of fluorescence emission spectra of CV-1-TA-CN, CV-1-TA-CNCDMP[5]A, CV-1-TA-CNCPH-1 SPNs and CV-1-TA-CNCPH-2 SPNs in THF/ $\mathrm{H}_{2} \mathrm{O}$ mixture solution with $\mathrm{f}_{\mathrm{w}}=90 \%$.

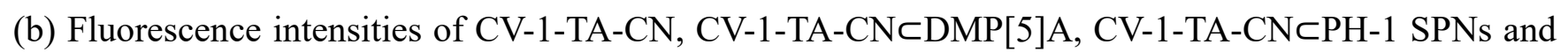
CV-1-TA-CNCPH-2 SPNs at emission maxima. 

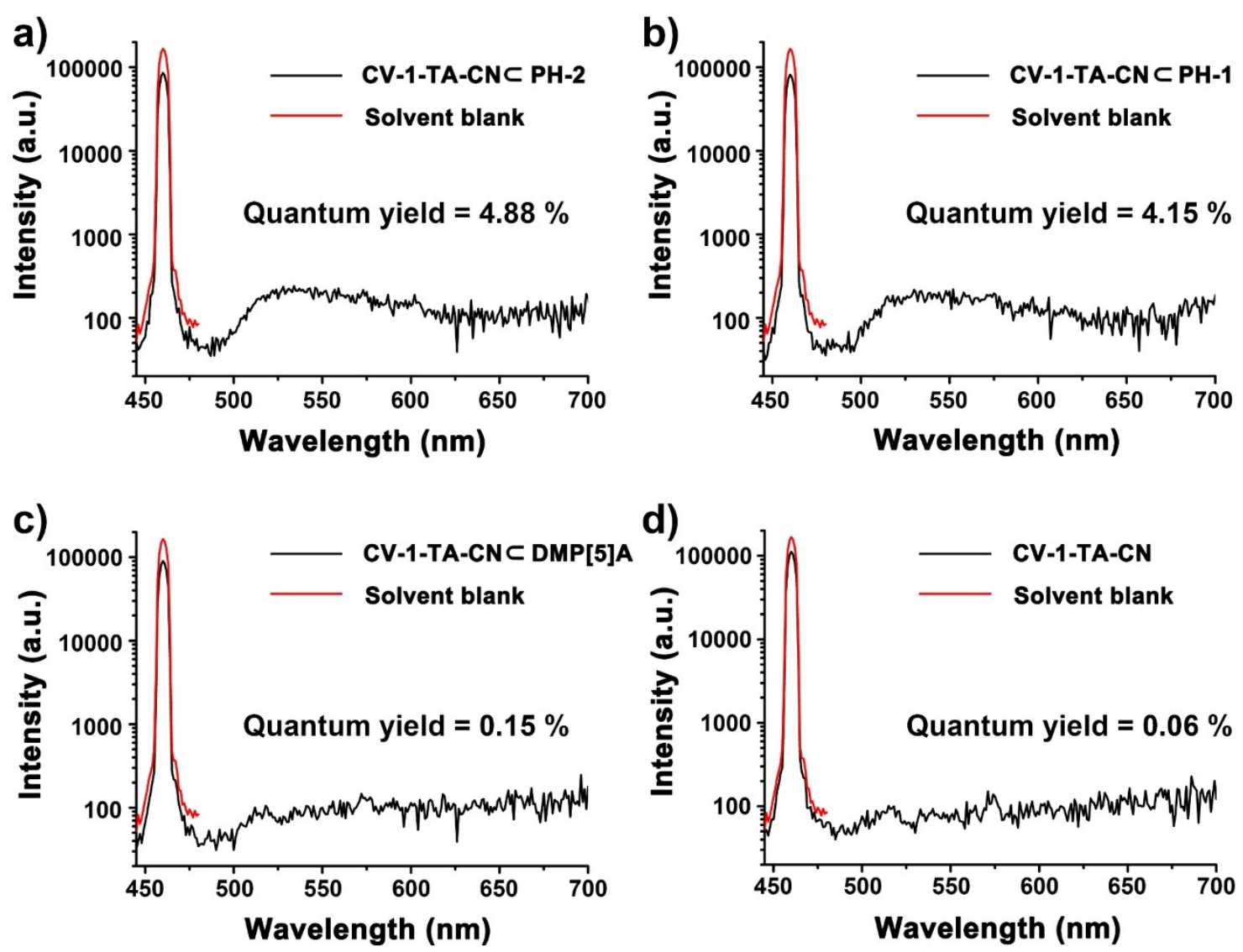

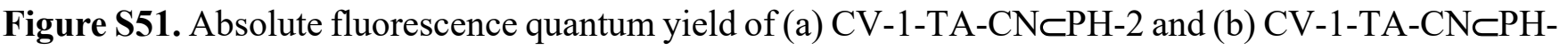
$1 \mathrm{SPNs}$ in $\mathrm{THF} / \mathrm{H}_{2} \mathrm{O}$ mixed solvent, $\mathrm{f}_{\mathrm{w}}=90 \%$. Experiment condition: $\lambda_{\mathrm{ex}}=460 \mathrm{~nm}$, [pillar[5]arene unit]

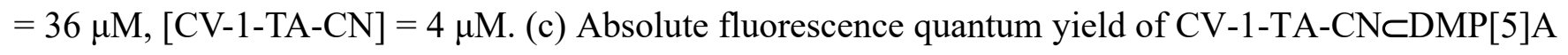
in $\mathrm{THF} / \mathrm{H}_{2} \mathrm{O}$ mixed solvent, $\mathrm{f}_{\mathrm{w}}=90 \%$. Experiment condition: $\lambda_{\mathrm{ex}}=460 \mathrm{~nm},[\mathrm{DMP}[5] \mathrm{A}]=36 \mu \mathrm{M},[\mathrm{CV}-$ 1-TA-CN] $=4 \mu \mathrm{M}$. (d) Absolute fluorescence quantum yield of CV-1-TA-CN in $\mathrm{THF} / \mathrm{H}_{2} \mathrm{O}$ mixed solvent, $\mathrm{f}_{\mathrm{w}}=90 \%$. Experiment condition: $\lambda_{\mathrm{ex}}=460 \mathrm{~nm},[\mathrm{CV}-1-\mathrm{TA}-\mathrm{CN}]=4 \mu \mathrm{M}$. 


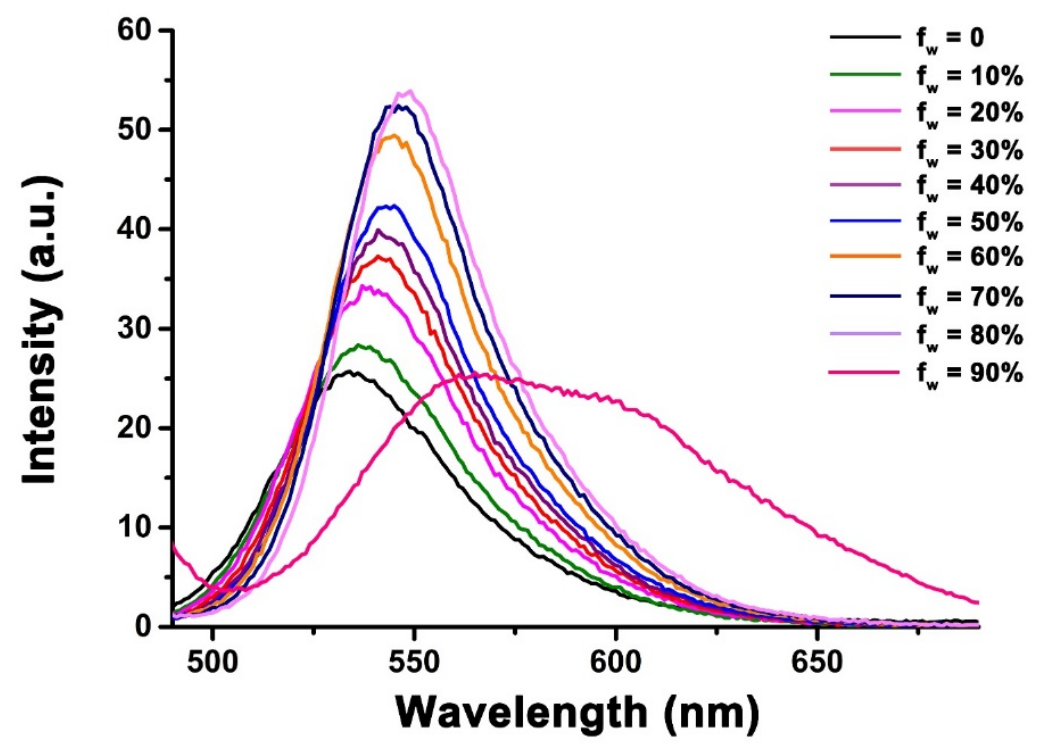

Figure S52. Fluorescence emission spectra of CV-2-CN in THF upon addition of water of different $f_{w}$.

Experimental condition: $\lambda_{\mathrm{ex}}=474 \mathrm{~nm}$; slit widths: ex $5 \mathrm{~nm}$, em $3 \mathrm{~nm} ;[\mathrm{CV}-2-\mathrm{CN}]=4 \mu \mathrm{M} ; 25{ }^{\circ} \mathrm{C}$.

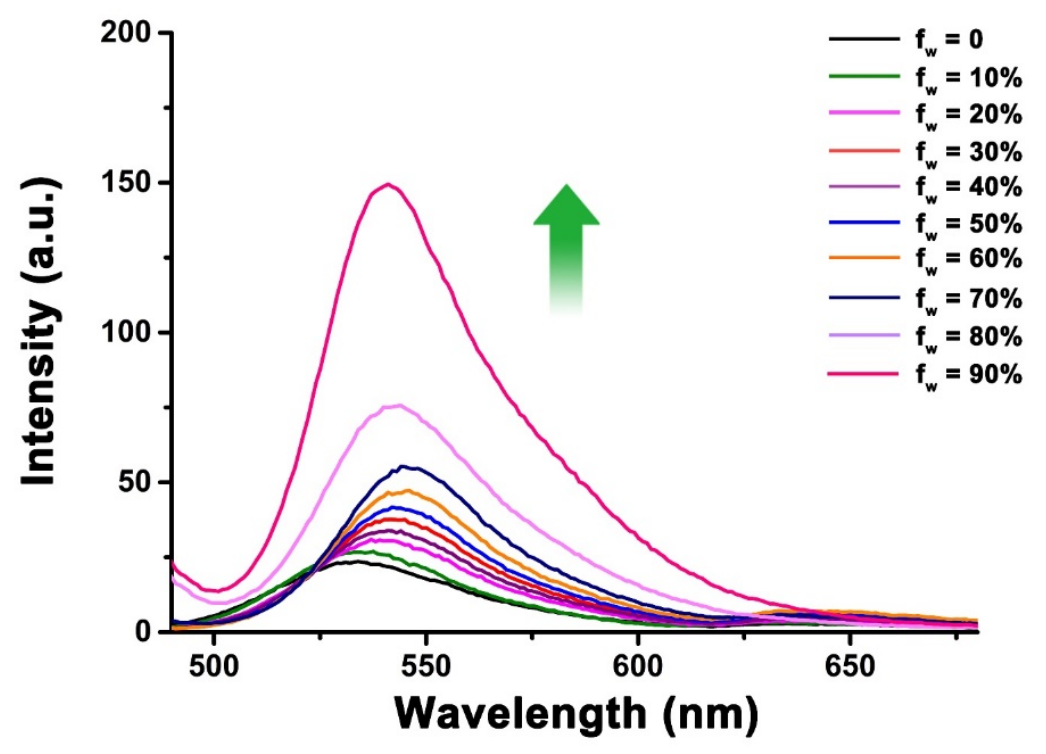

Figure S53. Fluorescence emission spectra of CV-2-CNCDMP[5]A in THF upon addition of water of different $\mathrm{f}_{\mathrm{w}}$. Experimental condition: $\lambda_{\mathrm{ex}}=474 \mathrm{~nm}$; slit widths: ex $5 \mathrm{~nm}$, em $3 \mathrm{~nm}$; [DMP[5]A] $=36 \mu \mathrm{M}$; $[\mathrm{CV}-2-\mathrm{CN}]=4 \mu \mathrm{M} ; 25^{\circ} \mathrm{C}$. 


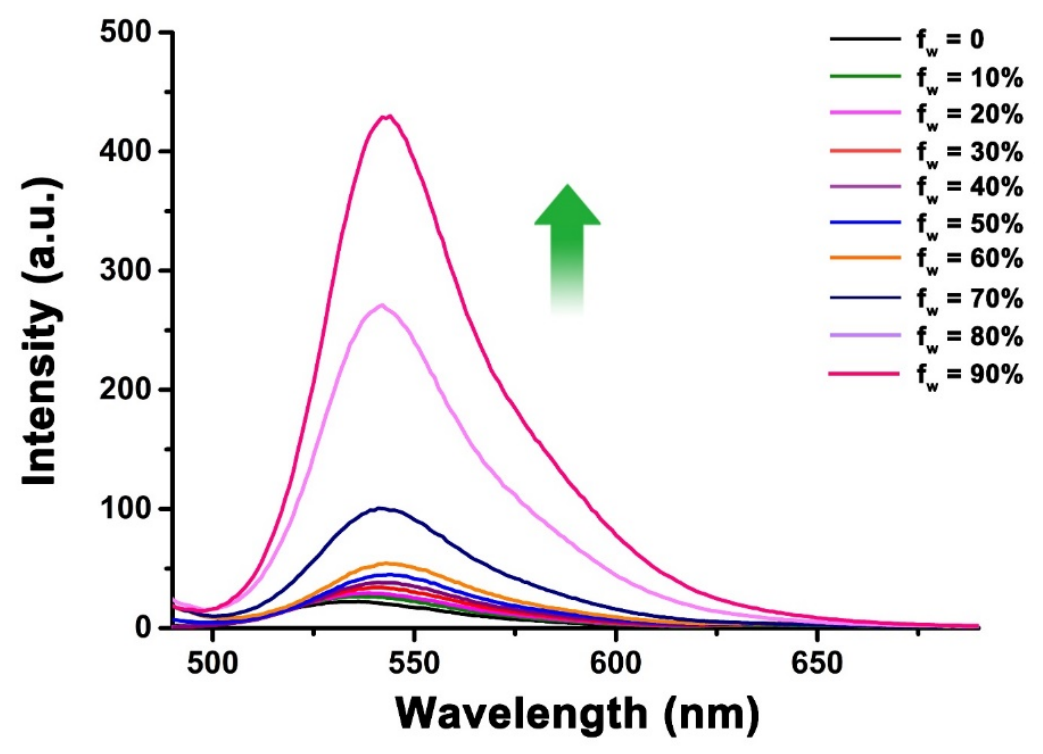

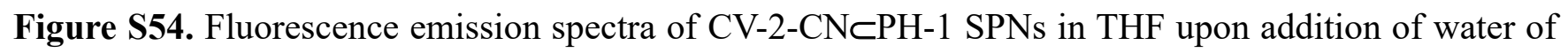
different $\mathrm{f}_{\mathrm{w}}$. Experimental condition: $\lambda_{\mathrm{ex}}=474 \mathrm{~nm}$; slit widths: ex $5 \mathrm{~nm}$, em $3 \mathrm{~nm}$; [pillar[5]arene unit] $=$ $36 \mu \mathrm{M} ;[\mathrm{CV}-2-\mathrm{CN}]=4 \mu \mathrm{M} ; 25^{\circ} \mathrm{C}$.

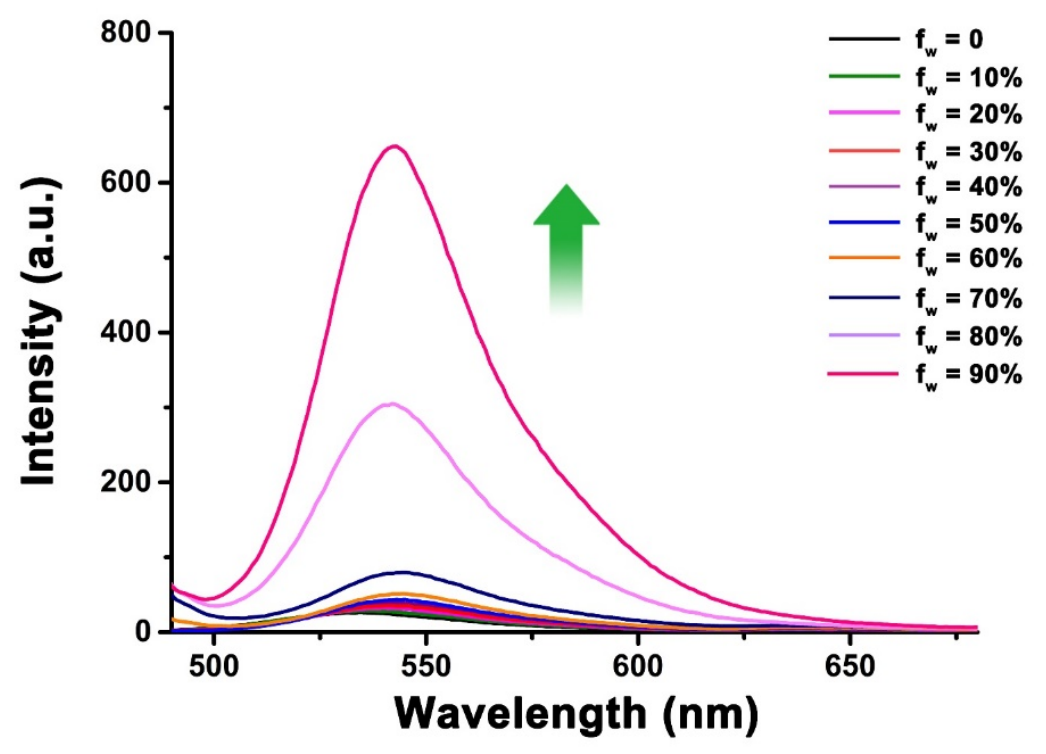

Figure S55. Fluorescence emission spectra of CV-2-CNСPH-2 SPNs in THF upon addition of water of different $f_{w}$. Experimental condition: $\lambda_{\mathrm{ex}}=474 \mathrm{~nm}$; slit widths: ex $5 \mathrm{~nm}$, em $3 \mathrm{~nm}$; [pillar[5]arene unit] $=$ $36 \mu \mathrm{M} ;[\mathrm{CV}-2-\mathrm{CN}]=4 \mu \mathrm{M} ; 25^{\circ} \mathrm{C}$. 

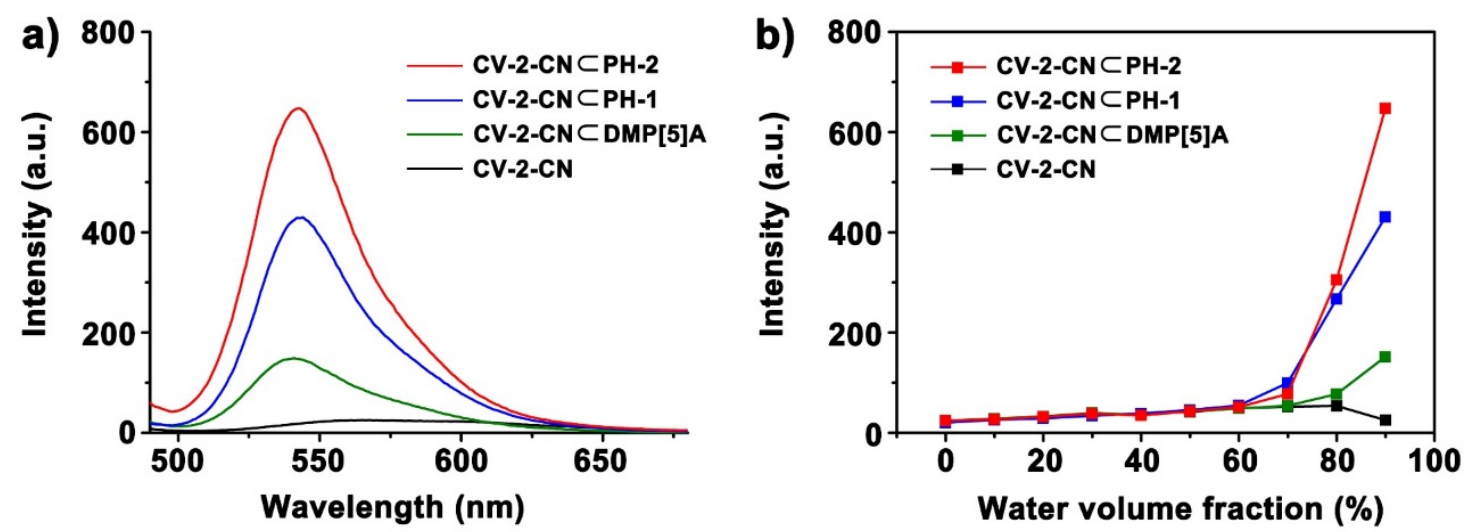

Figure S56. (a) Comparison of fluorescence emission spectra of CV-2-CN, CV-2-CNCDMP[5]A, CV-2-

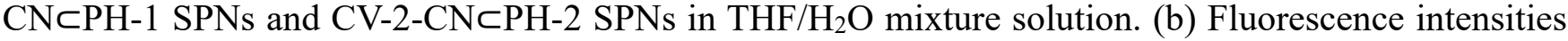
of $\mathrm{CV}-2-\mathrm{CN}, \mathrm{CV}-2-\mathrm{CN} \subset \mathrm{DMP}[5] \mathrm{A}, \mathrm{CV}-2-\mathrm{CN} \subset \mathrm{PH}-1$ supramolecular polymer nanoparticles and $\mathrm{CV}-2-$ $\mathrm{CN} \subset \mathrm{PH}-2$ supramolecular polymer nanoparticles at emission maxima.

a)
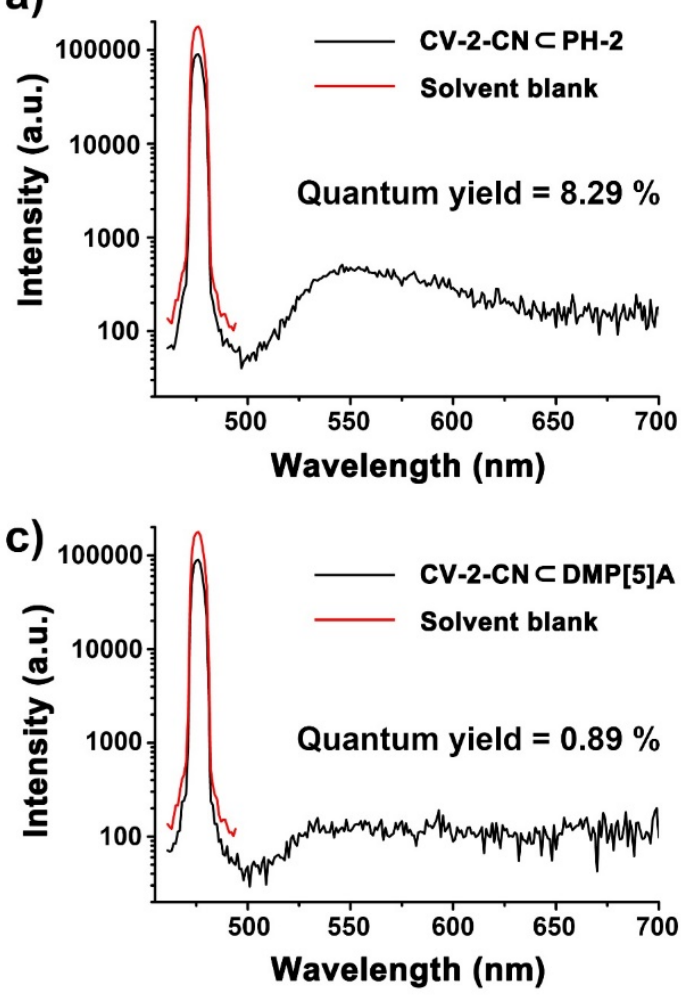

b)
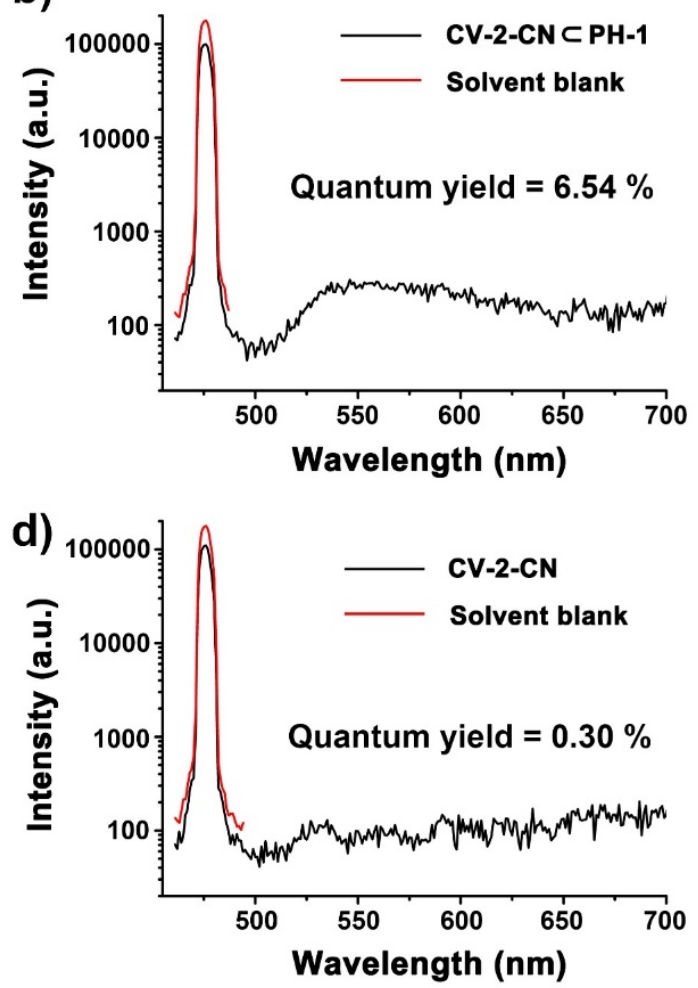

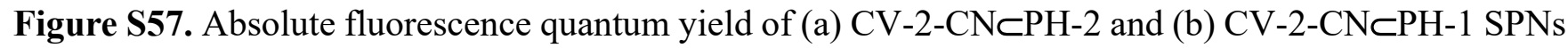
in $\mathrm{THF} / \mathrm{H}_{2} \mathrm{O}$ mixed solvent, $\mathrm{f}_{\mathrm{w}}=90 \%$. Experiment condition: $\lambda_{\mathrm{ex}}=460 \mathrm{~nm}$, [pillar[5]arene unit $]=36 \mu \mathrm{M}$,

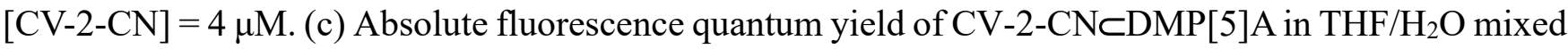


solvent, $\mathrm{f}_{\mathrm{w}}=90 \%$. Experiment condition: $\lambda_{\mathrm{ex}}=460 \mathrm{~nm},[\mathrm{DMP}[5] \mathrm{A}]=36 \mu \mathrm{M},[\mathrm{CV}-2-\mathrm{CN}]=4 \mu \mathrm{M}$. (d) Absolute fluorescence quantum yield of $\mathrm{CV}-2-\mathrm{CN}$ in $\mathrm{THF} / \mathrm{H}_{2} \mathrm{O}$ mixed solvent, $\mathrm{f}_{\mathrm{w}}=90 \%$. Experiment condition: $\lambda_{\mathrm{ex}}=460 \mathrm{~nm},[\mathrm{CV}-2-\mathrm{CN}]=4 \mu \mathrm{M}$.

\section{Thermoresponsive Behavior}

As shown in Figure S58a,b, the fluorescence intensity of CV-1-CNсPH-2 SPNs decreased with continually elevated temperature from $30^{\circ} \mathrm{C}$ to $80^{\circ} \mathrm{C}$ due to the debilitated host-guest interactions between pillar[5]arene units and chromophores. These results indicated that the SPNs underwent the dissociation process, accounting for the fluorescence quenching. In addition, the emission spectra of CV-1-CNCPH-2 SPNs were monitored for 5 cycles with the variation of temperature from $30^{\circ} \mathrm{C}$ to $80^{\circ} \mathrm{C}$, and the emission intensity could recover to the initial value after 5 thermal cycles, indicating that the desirable tolerance to temperature variation (Figure S58c,d). Similarly, the reversible thermoresponsiveness of SPNs fabricated by $\mathrm{CV}-2-\mathrm{CN}$ and $\mathrm{CV}-1-\mathrm{TA}-\mathrm{CN}$ with the assistance of $\mathrm{PH}-2$ were verified by fluorescence experiments under different temperature (Figures S59 and S60). It was clear that the SPNs exhibited reversible assembly and disassembly process in response to temperature consisted with the tunable fluorescence intensities, suggesting the responsiveness of SPNs. 

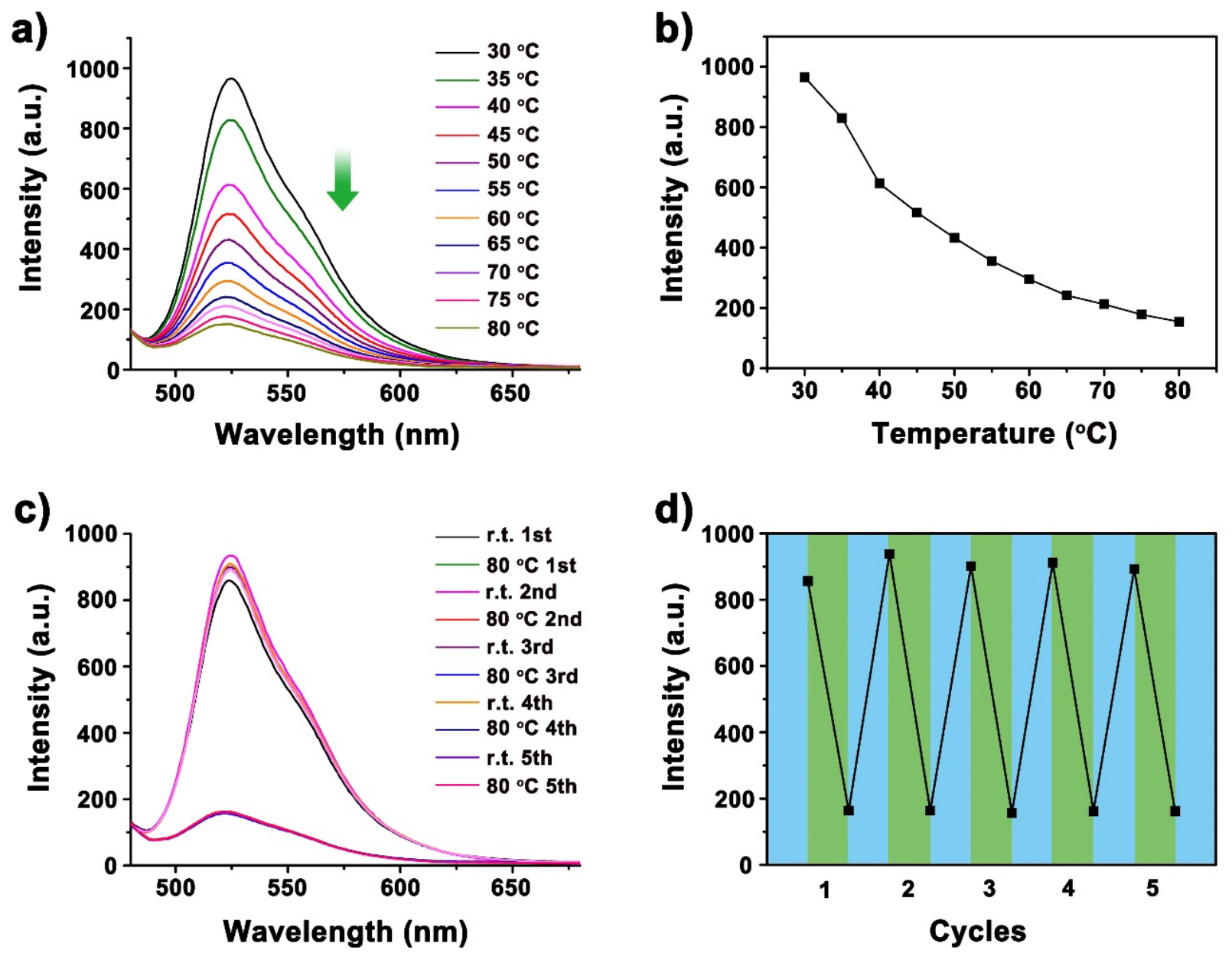

Figure S58. (a) Fluorescence emission spectra of CV-1-CNсPH-2 SPNs with incresaing temperature from $30^{\circ} \mathrm{C}$ to $80^{\circ} \mathrm{C}\left(\lambda_{\mathrm{ex}}=460 \mathrm{~nm} ; \lambda_{\mathrm{em}}=525 \mathrm{~nm}\right.$; slit widths: ex $5 \mathrm{~nm}$, em $5 \mathrm{~nm}$; [pillar[5]arene unit] $=36$ $\mu \mathrm{M} ;[\mathrm{CV}-1-\mathrm{CN}]=4 \mu \mathrm{M})$. (b) Line chart of fluorescence intensities with different temperature of CV-1-

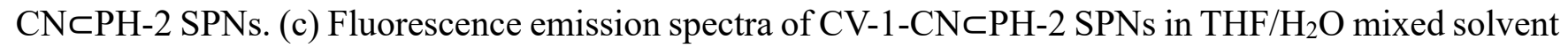
during 5 thermal cycles $\left(\lambda_{\mathrm{ex}}=460 \mathrm{~nm} ; \lambda_{\mathrm{em}}=525 \mathrm{~nm}\right.$; slit widths: ex $5 \mathrm{~nm}$, em $5 \mathrm{~nm}$; [pillar[5]arene unit] $=36 \mu \mathrm{M} ;[\mathrm{CV}-1-\mathrm{CN}]=4 \mu \mathrm{M})$. (d) Line chart of fluorescence intensities of CV-1-CNCPH-1 SPNs in $\mathrm{THF} / \mathrm{H}_{2} \mathrm{O}$ mixed solvent during 5 thermal cycles. 

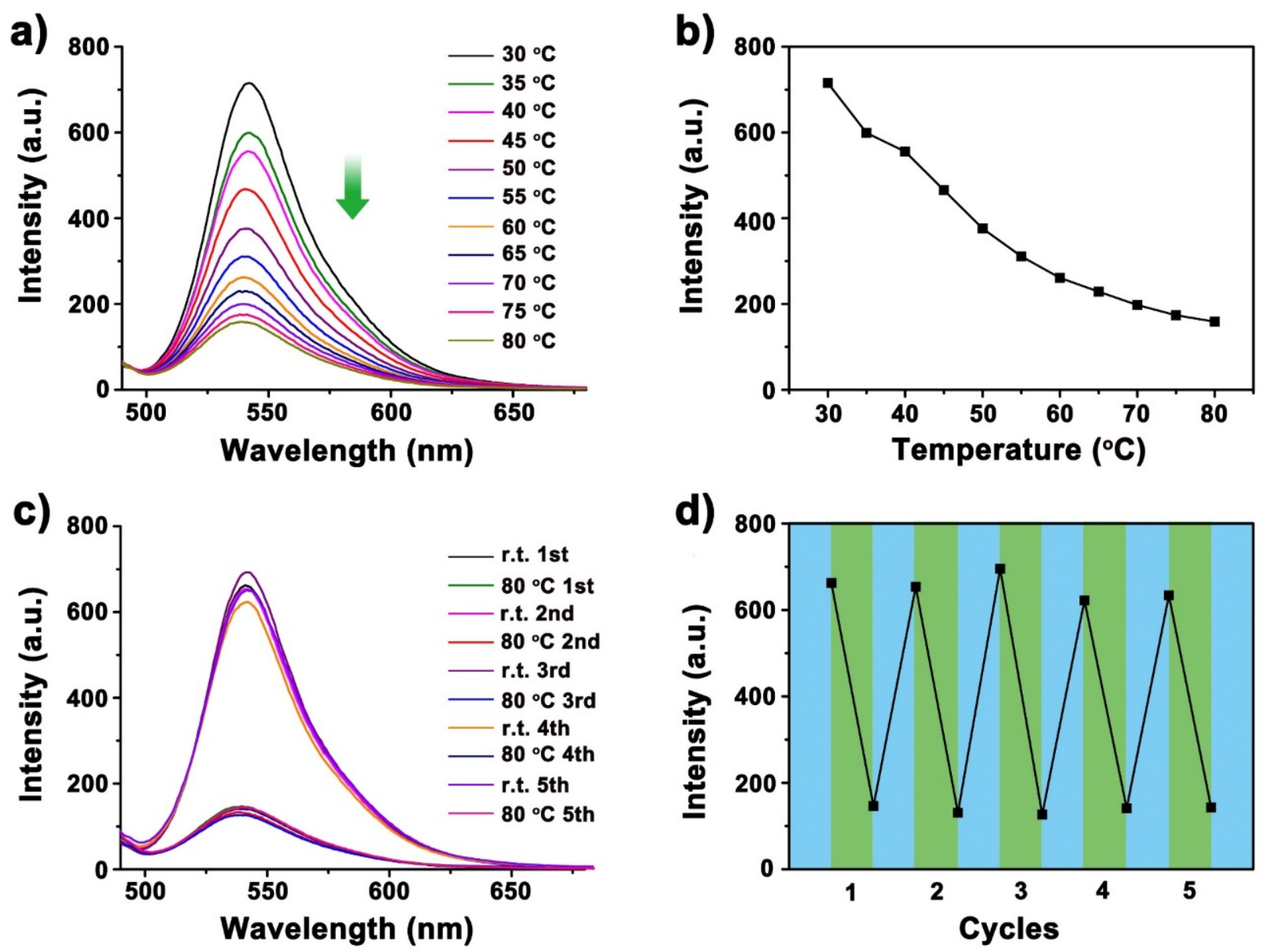

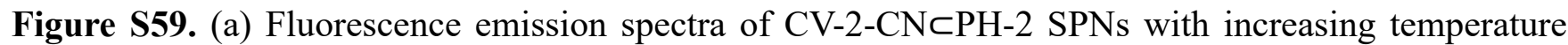
from $30^{\circ} \mathrm{C}$ to $80^{\circ} \mathrm{C}\left(\lambda_{\mathrm{ex}}=460 \mathrm{~nm} ; \lambda_{\mathrm{em}}=540 \mathrm{~nm}\right.$; slit widths: ex $5 \mathrm{~nm}$, em $3 \mathrm{~nm}$; [pillar[5] $\operatorname{corene}$ unit] $=36$ $\mu \mathrm{M} ;[\mathrm{CV}-2-\mathrm{CN}]=4 \mu \mathrm{M})$. (b) Line chart of fluorescence intensities with different temperature of CV-2$\mathrm{CN} \subset \mathrm{PH}-2$ SPNs. (c) Fluorescence emission spectra of CV-2-CNсPH-2 SPNs in THF/ $\mathrm{H}_{2} \mathrm{O}$ mixed solvent during 5 thermal cycles $\left(\lambda_{\mathrm{ex}}=460 \mathrm{~nm} ; \lambda_{\mathrm{em}}=540 \mathrm{~nm}\right.$; slit widths: ex $5 \mathrm{~nm}$, em $3 \mathrm{~nm}$; [pillar[5]arene unit] $=36 \mu \mathrm{M} ;[\mathrm{CV}-1-\mathrm{CN}]=4 \mu \mathrm{M})$. (d) Line chart of fluorescence intensities of CV-2-CNсPH-2 SPNs in $\mathrm{THF} / \mathrm{H}_{2} \mathrm{O}$ mixed solvent during 5 thermal cycles. 
a)
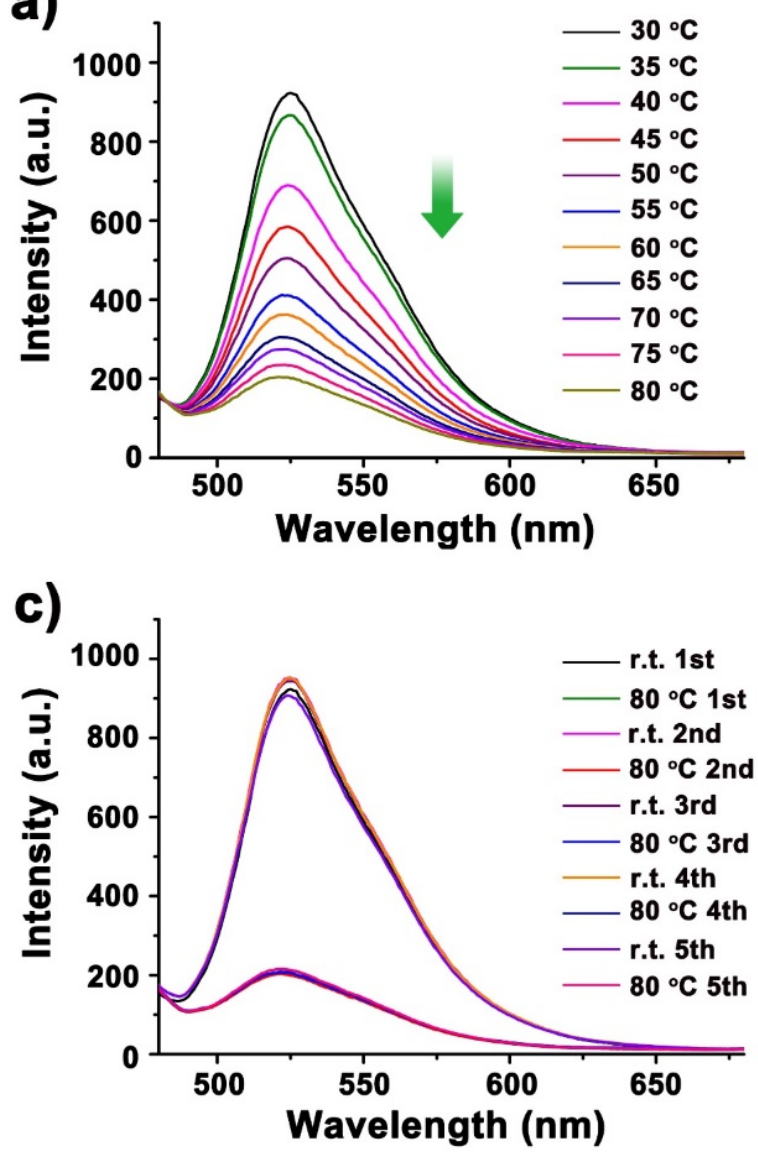

b)

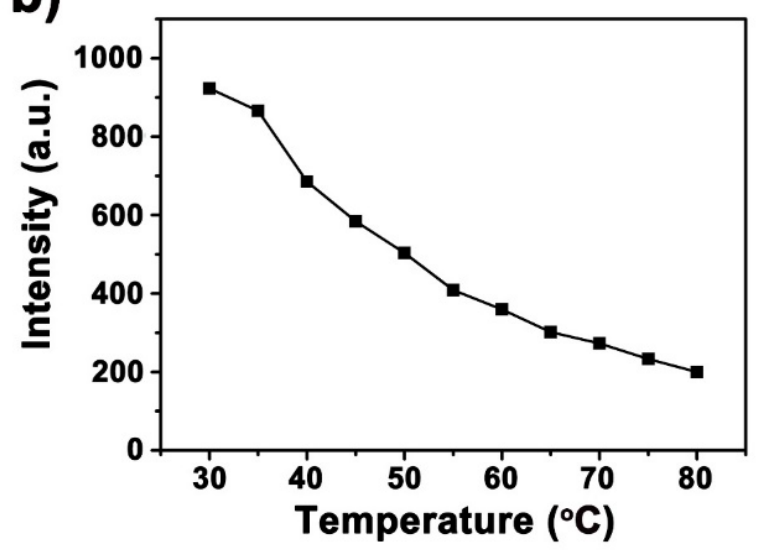

d)

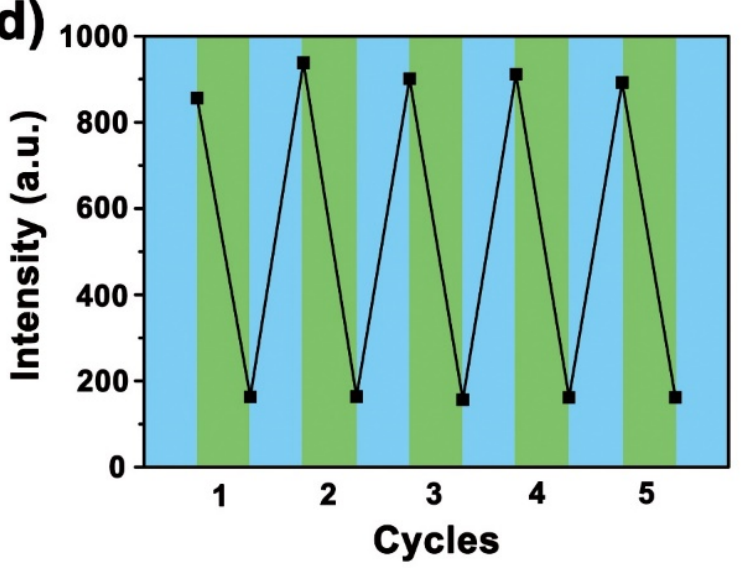

Figure S60. (a) Fluorescence emission spectra of CV-1-TA-CNCPH-2 SPNs with increasing temperature from $30^{\circ} \mathrm{C}$ to $80^{\circ} \mathrm{C}\left(\lambda_{\mathrm{ex}}=460 \mathrm{~nm} ; \lambda_{\mathrm{em}}=525 \mathrm{~nm}\right.$; slit widths: ex $5 \mathrm{~nm}$, em $5 \mathrm{~nm}$; [pillar[5]arene unit] $=36$ $\mu \mathrm{M} ;[\mathrm{CV}-1-\mathrm{TA}-\mathrm{CN}]=4 \mu \mathrm{M}$ ). (b) Line chart of fluorescence intensities with different temperature of CV-

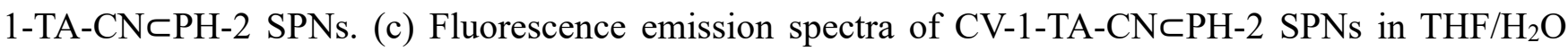
mixed solvent during 5 thermal cycles $\left(\lambda_{\mathrm{ex}}=460 \mathrm{~nm} ; \lambda_{\mathrm{em}}=525 \mathrm{~nm}\right.$; slit widths: ex $5 \mathrm{~nm}$, em $5 \mathrm{~nm}$; [pillar[5]arene unit $]=36 \mu \mathrm{M} ;[\mathrm{CV}-1-\mathrm{TA}-\mathrm{CN}]=4 \mu \mathrm{M})$. (d) Line chart of fluorescence intensities of CV1-TA-CNCPH-2 SPNs in THF/ $\mathrm{H}_{2} \mathrm{O}$ mixed solvent during 5 thermal cycles. 
a)

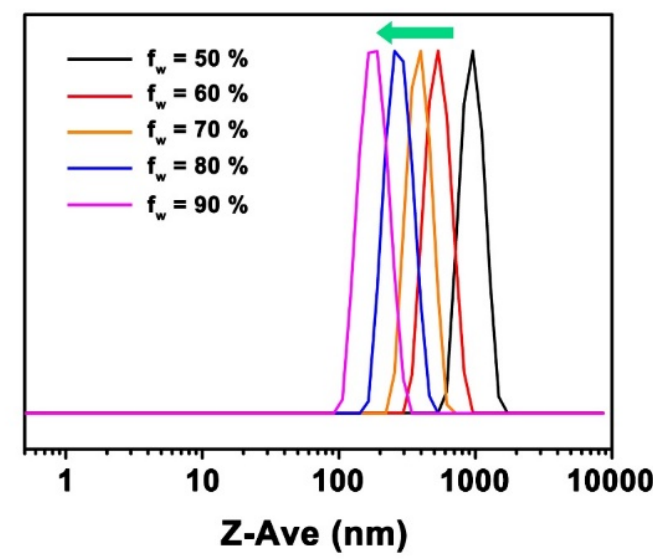

c)

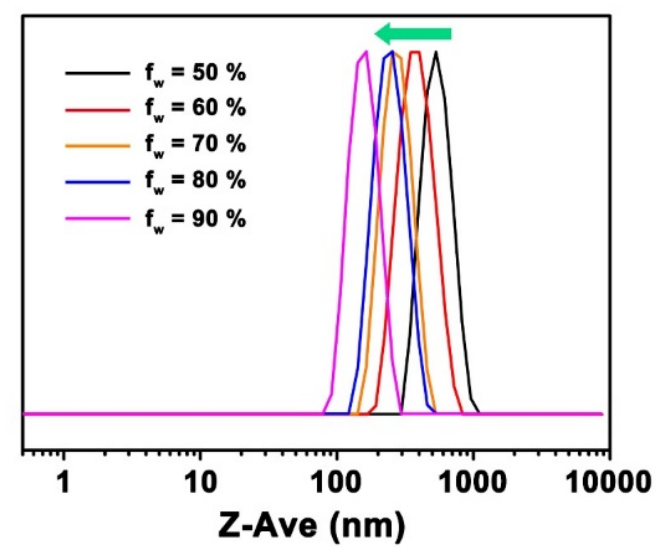

b)

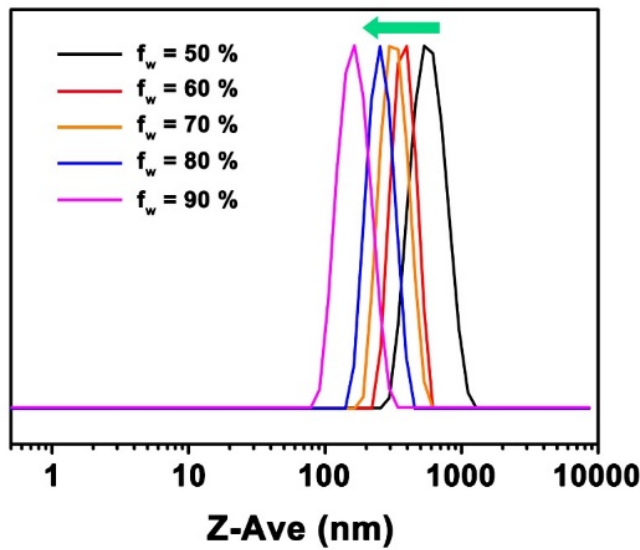

d)

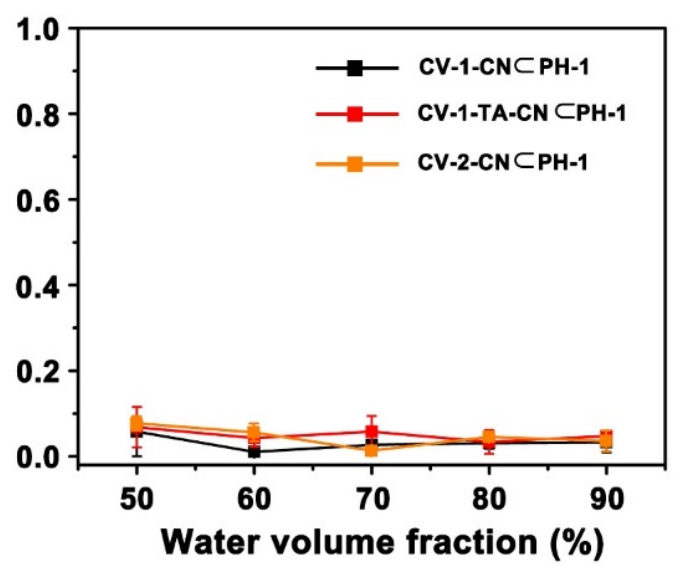

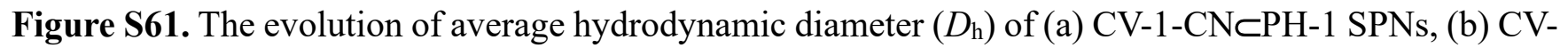

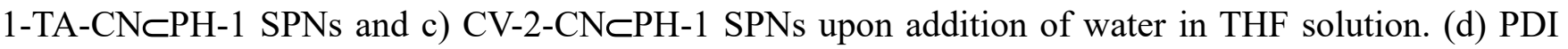

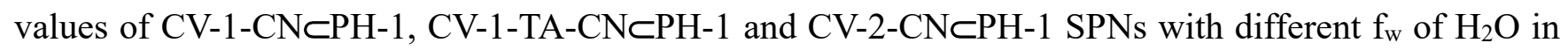
mixture solution. Experimental condition: $[$ pillar[5]arene unit $]=36 \mu \mathrm{M} ;[\mathrm{CV}-1-\mathrm{CN}]=4 \mu \mathrm{M} ;[\mathrm{CV}-1-\mathrm{TA}-$ $\mathrm{CN}]=4 \mu \mathrm{M} ;[\mathrm{CV}-2-\mathrm{CN}]=4 \mu \mathrm{M} ; 25^{\circ} \mathrm{C}$. 
a)

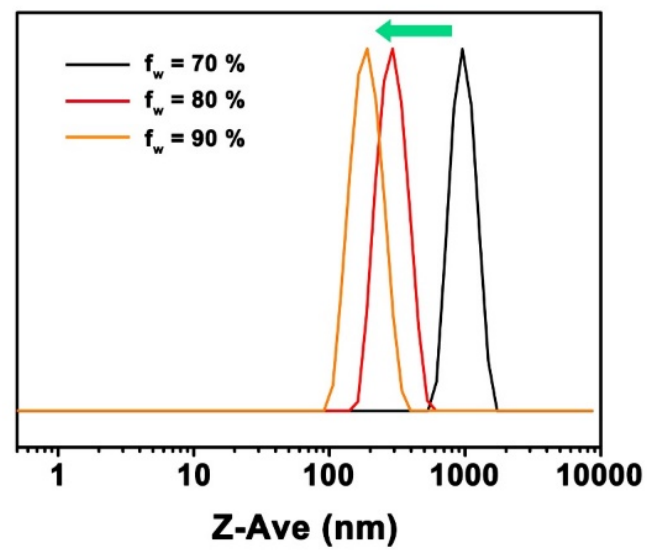

c)

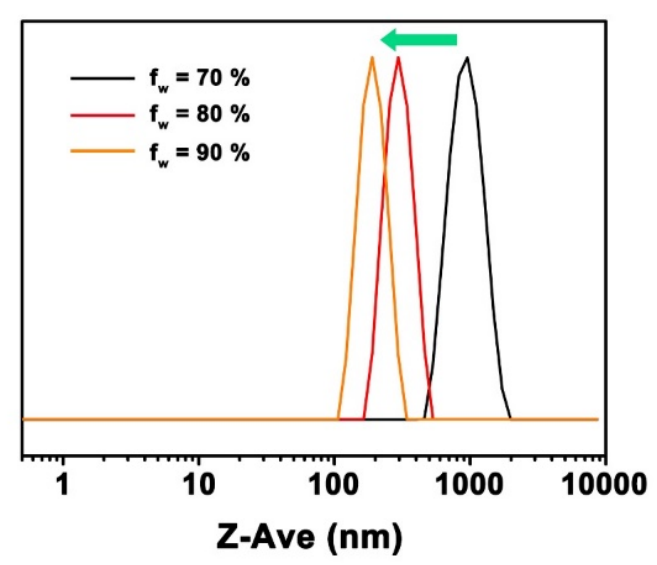

b)
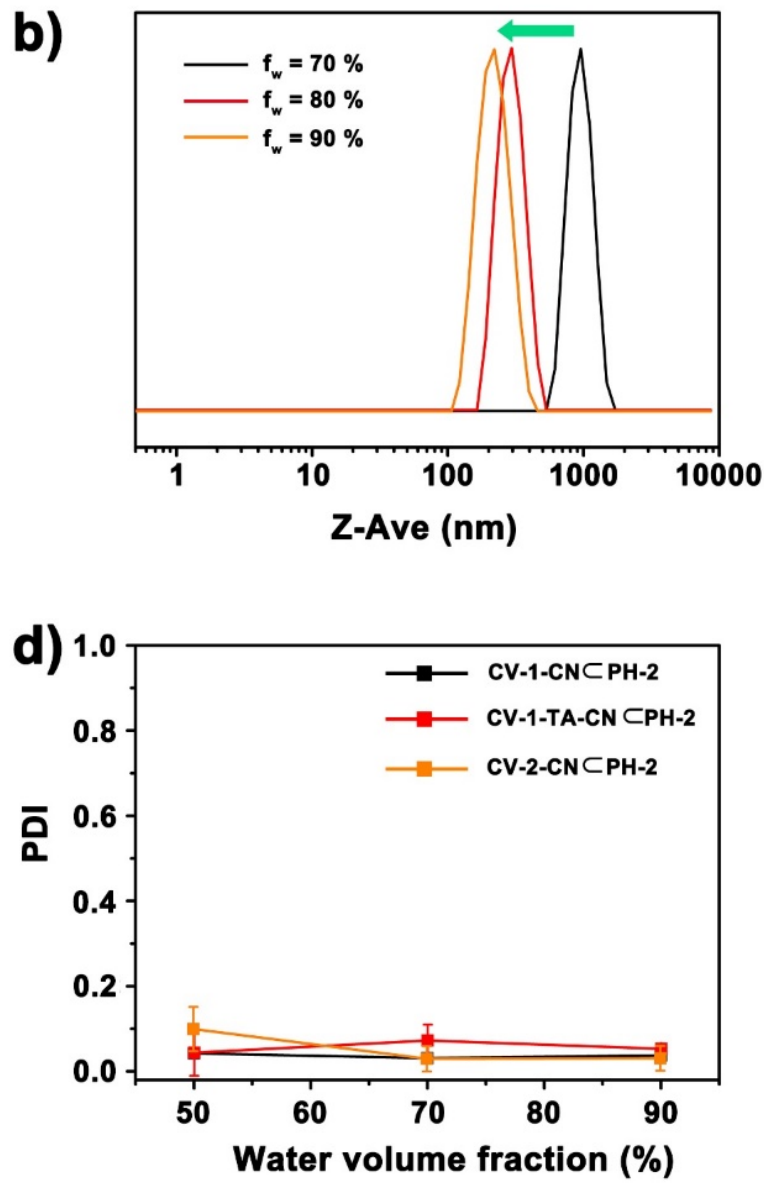

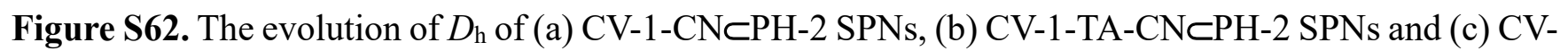

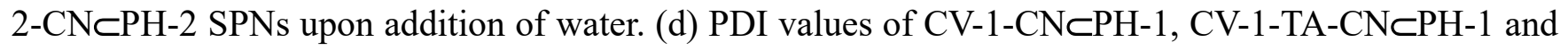
CV-2-CNсPH-1 SPNs with different $\mathrm{f}_{\mathrm{w}}$ of $\mathrm{H}_{2} \mathrm{O}$ in the mixed solvent. Experimental condition: $[$ pillar$[5]$ arene unit $]=36 \mu \mathrm{M} ;[\mathrm{CV}-1-\mathrm{CN}]=4 \mu \mathrm{M} ;[\mathrm{CV}-1-\mathrm{TA}-\mathrm{CN}]=4 \mu \mathrm{M} ;[\mathrm{CV}-2-\mathrm{CN}]=4 \mu \mathrm{M} ; 25^{\circ} \mathrm{C}$. 
8. Tunable emission wavelength regulated by polymer hosts

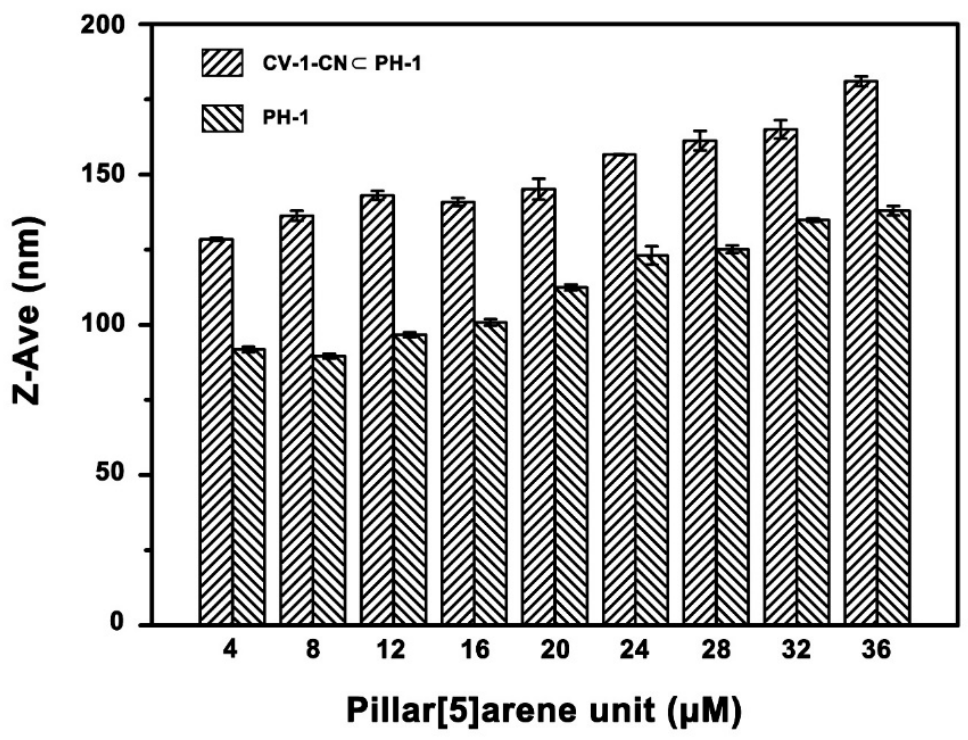

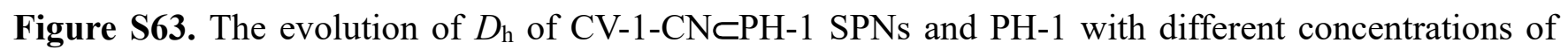
pillar[5]arene unit in $\mathrm{THF} / \mathrm{H}_{2} \mathrm{O}$ mixed solution $(1 / 9 \mathrm{v} / \mathrm{v})$.

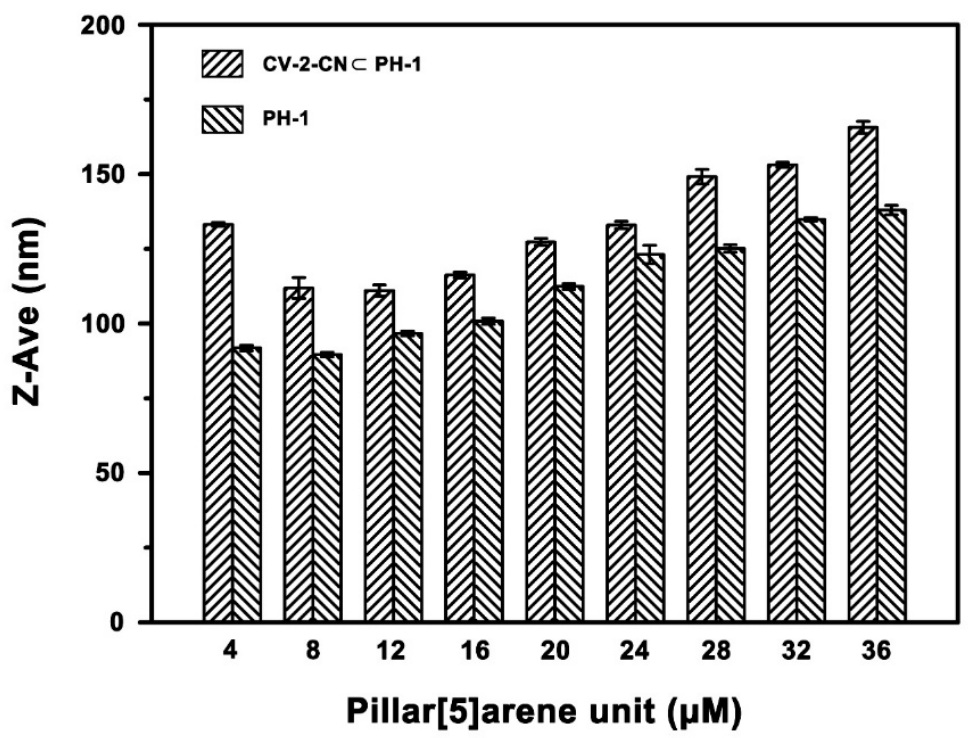

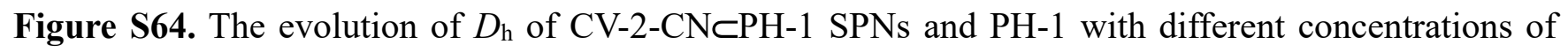
pillar[5] arene unit in $\mathrm{THF} / \mathrm{H}_{2} \mathrm{O}$ mixed solution $(1 / 9 \mathrm{v} / \mathrm{v})$. 


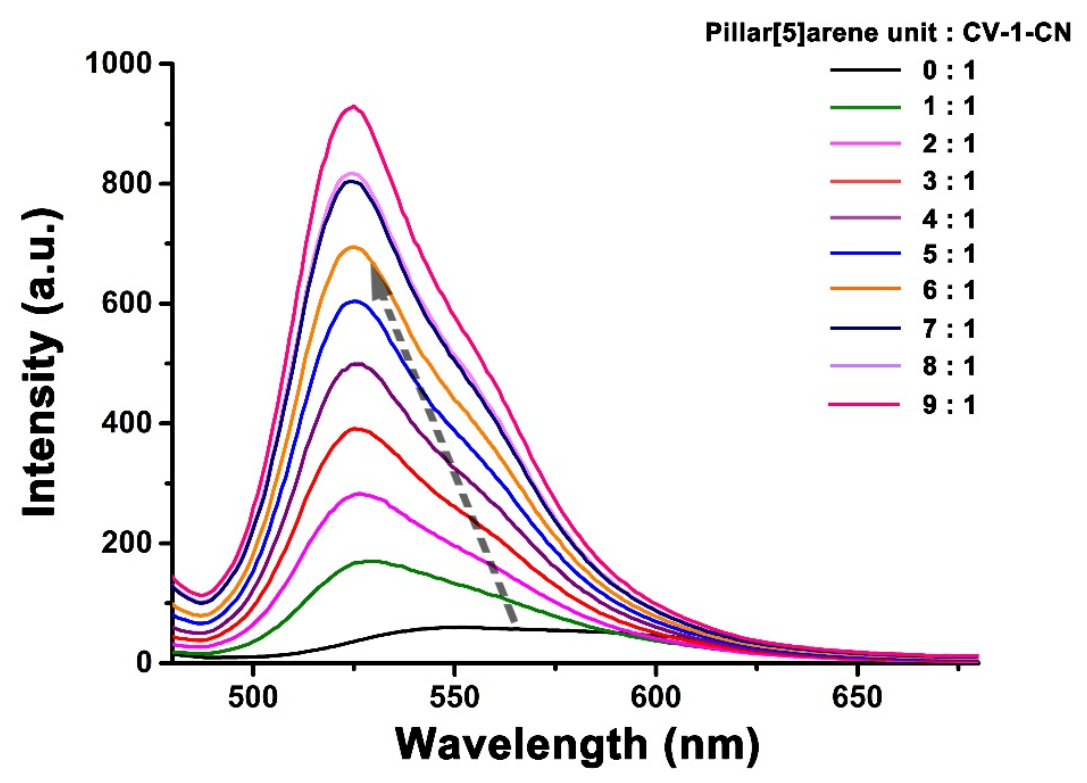

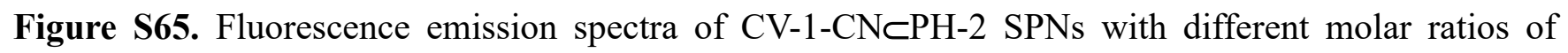
[pillar[5]arene unit] and [CV-1-CN]. Experimental condition: $\lambda_{\mathrm{ex}}=460 \mathrm{~nm}$; slit widths: ex $5 \mathrm{~nm}$, em 5 $\mathrm{nm}$; [pillar[5]arene unit] $=0,4,8,12,16,20,24,28,32,36 \mu \mathrm{M} ;[\mathrm{CV}-1-\mathrm{CN}]=4 \mu \mathrm{M} ; \mathrm{THF} / \mathrm{H}_{2} \mathrm{O}=1 / 9$ $(\mathrm{v} / \mathrm{v}) ; 25^{\circ} \mathrm{C}$.

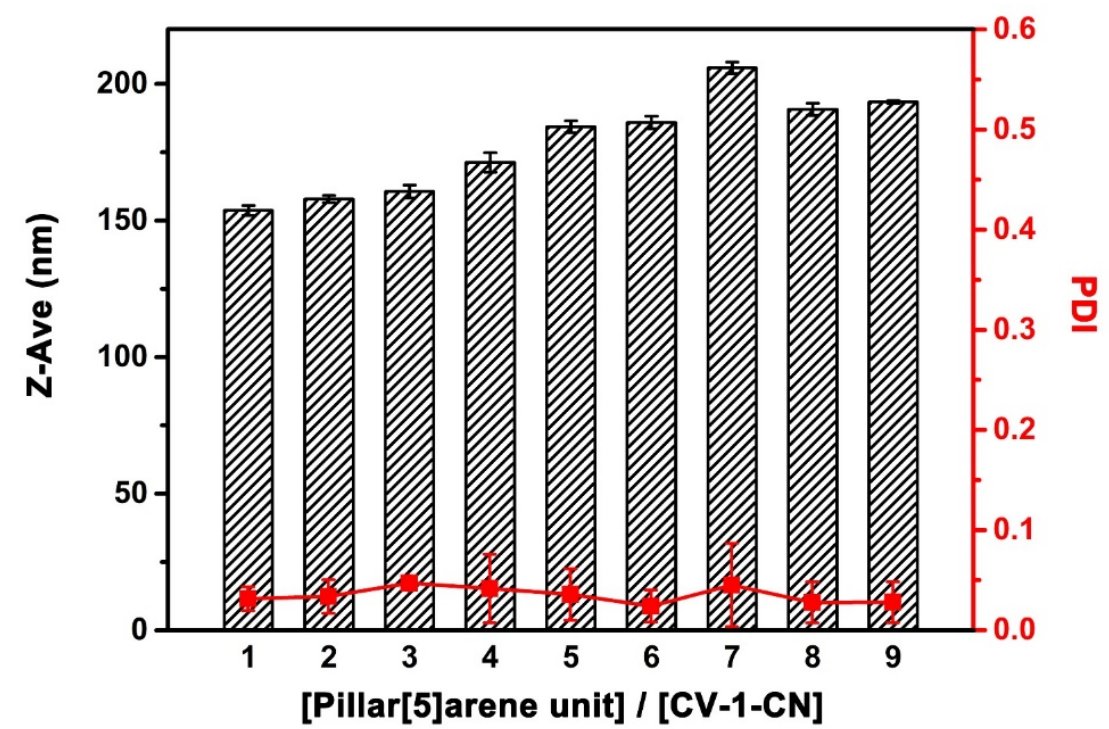

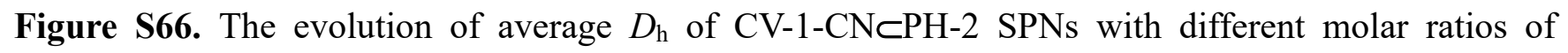
[pillar[5]arene unit] and [CV-1-CN] and PH-1 with different concentration of pillar[5]arene unit in $\mathrm{THF} / \mathrm{H}_{2} \mathrm{O}$ mixture solution $(1 / 9 \mathrm{v} / \mathrm{v}) ; 25^{\circ} \mathrm{C}$. 


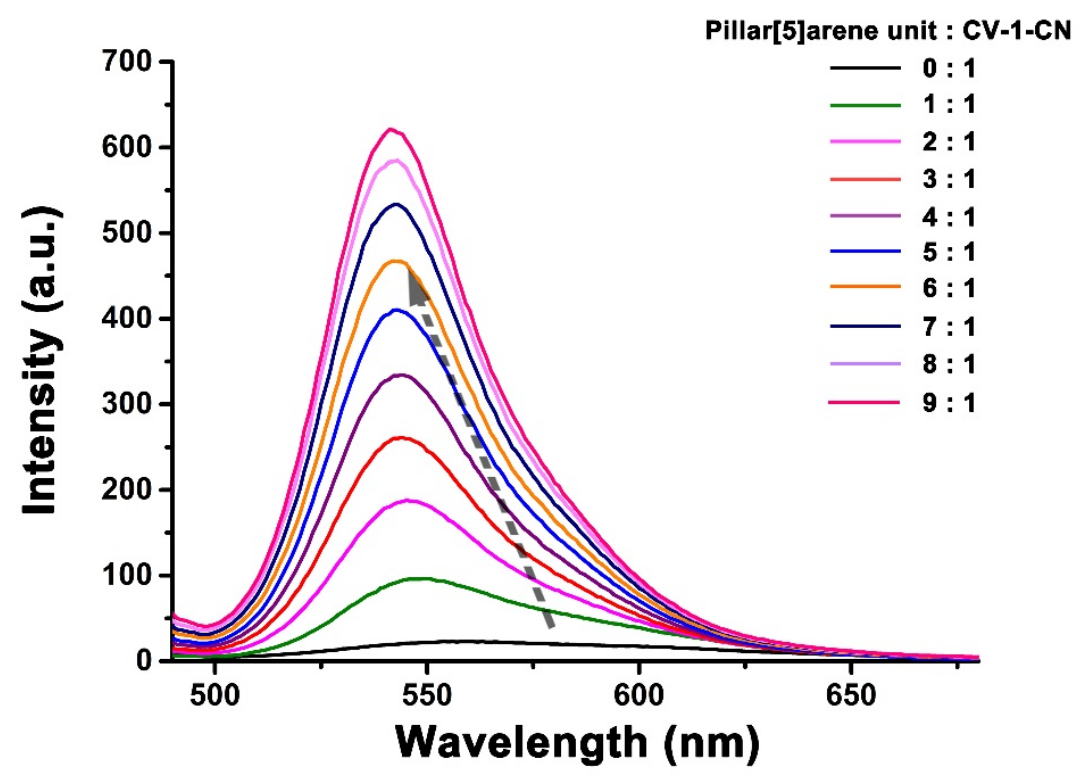

Figure S67. Fluorescence emission spectra of CV-2-CNсPH-2 SPNs with different molar ratios of [pillar[5]arene unit] and [CV-2-CN]. Experimental condition: $\lambda_{\mathrm{ex}}=476 \mathrm{~nm}$; slit widths: ex $5 \mathrm{~nm}$, em 3 $\mathrm{nm}$; [pillar[5]arene unit] $=0,4,8,12,16,20,24,28,32,36 \mu \mathrm{M} ;[\mathrm{CV}-2-\mathrm{CN}]=4 \mu \mathrm{M} ; \mathrm{THF} / \mathrm{H}_{2} \mathrm{O}=1 / 9 \mathrm{v} / \mathrm{v}$; $25^{\circ} \mathrm{C}$.

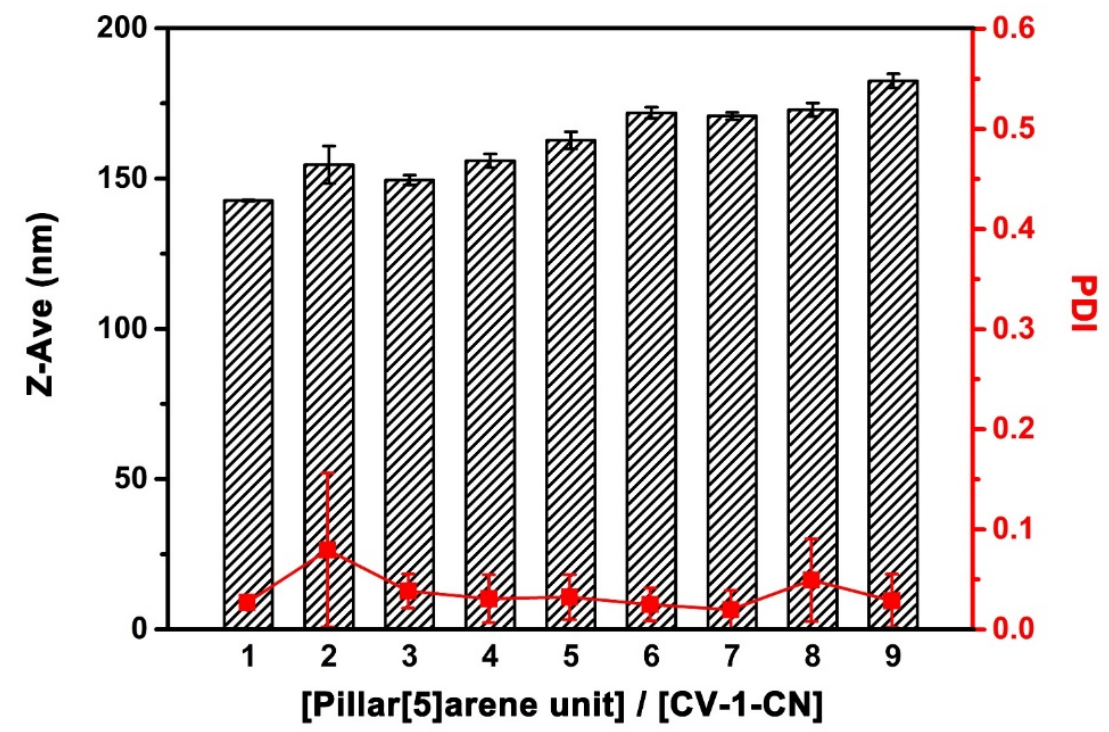

Figure S68. The evolution of average $D_{\mathrm{h}}$ of $\mathrm{CV}-2-\mathrm{CN} \subset \mathrm{PH}-2$ SPNs with different concentration of pillar[5]arene unit in $\mathrm{THF} / \mathrm{H}_{2} \mathrm{O}$ mixture solution $(1 / 9 \mathrm{v} / \mathrm{v}) ; 25^{\circ} \mathrm{C}$. 
The fluorescence intensities of CV-1-TA-CN regulated by random copolymers containing pillar[5]arene units were also investigated as shown in Figure S69, which displayed a blue-shifted sharp and intense emission with the rising concentration of pillar[5]arene units in $\mathrm{THF} / \mathrm{H}_{2} \mathrm{O}$ mixture solution.

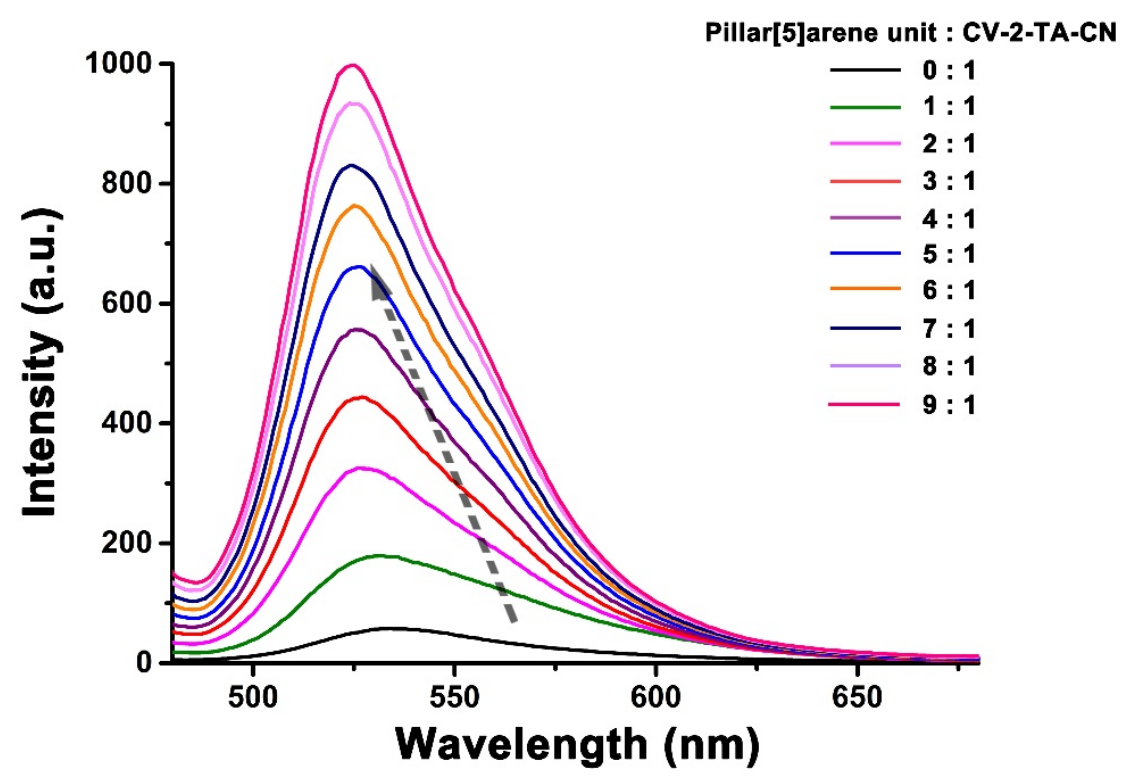

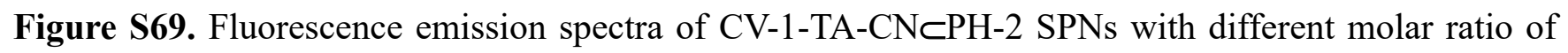
[pillar[5]arene unit] and [CV-1-TA-CN]. Experimental condition: $\lambda_{\mathrm{ex}}=460 \mathrm{~nm}$; slit widths: ex $5 \mathrm{~nm}$, em $5 \mathrm{~nm}$; [pillar[5]arene unit] $=0,4,8,12,16,20,24,28,32,36 \mu \mathrm{M} ;[\mathrm{CV}-2-\mathrm{CN}]=4 \mu \mathrm{M} ; \mathrm{THF} / \mathrm{H}_{2} \mathrm{O}=1 / 9$ $\mathrm{v} / \mathrm{v} ; 25^{\circ} \mathrm{C}$.

\section{Fluorescence decay experiments}

Fluorescence decay experiments of SPNs for all three types of CV derivatives (CV-1-CN, CV-1-TA-CN and $\mathrm{CV}-2-\mathrm{CN}$ ) were carried out to further illustrate the working mechanism. For instance, fluorescence lifetimes of three types of nano-aggregates containing CV-1-CN were depicted in Figure S70, and nanoaggregates formed by CV-1-CN alone exhibited longer fluorescence lifetime than SPNs formed by CV1-CN and PH-1. As we have certified that the excimer-like fluorophore, CV derivative, exhibited long fluorescence lifetime ( $\tau=7.001 \mathrm{~ns})$ in solid state because of the formation of aggregates. As consequence, 
the short fluorescence lifetime of $\mathrm{CV}-1-\mathrm{CN} \subset \mathrm{PH}-1$ stemed from the discrete nature of chromophores in SPNs which was different from the aggerated states of CV-1-CN in the mixed solvent. The fluorescence decay for all supramolecular nanoassemblies were summarized in Table S1. By virtue of polymer host materials to compress and separate $\mathrm{CV}$ derivatives upon formation of SPNs, the monomeric emission was remarkably enhanced, while the fluorescence lifetimes became short. Moreover, the fluorescence decay of CV-2-CN and CV-1-TA-CN as fluorophores revealed the same trends as that of CV-1-CN (Figures S71 and S72 and Tables S2 and S3).

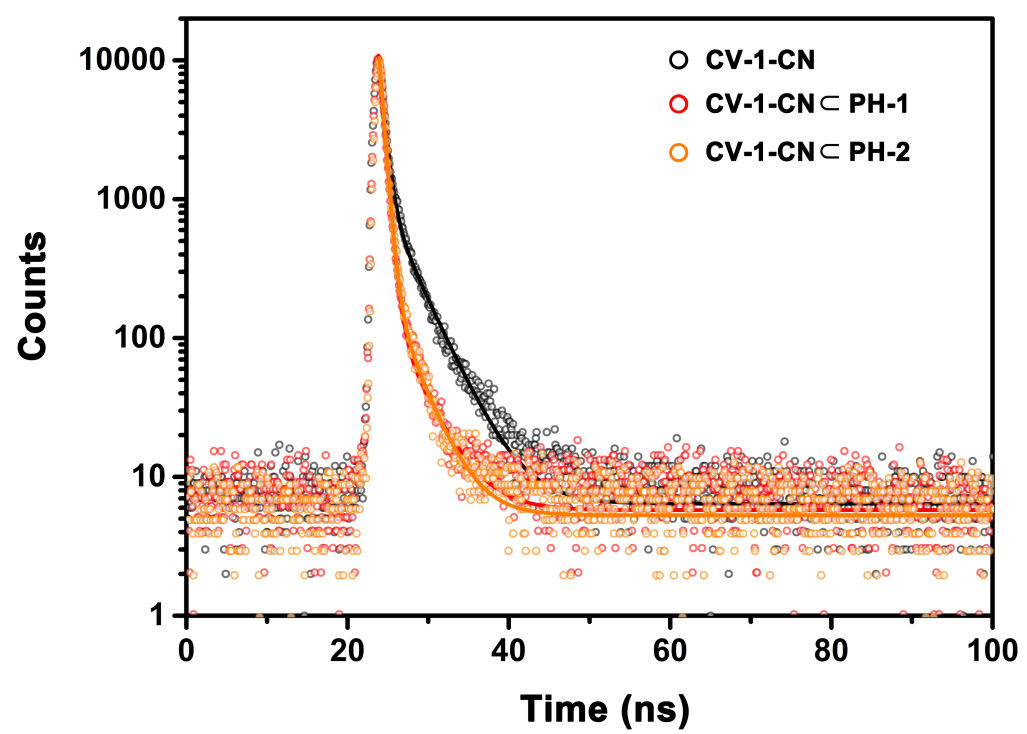

Figure S70. Fluorescence decay of CV-1-CN (black line), CV-1-CNсPH-1 SPNs (red line) and CV-1$\mathrm{CN} \subset \mathrm{PH}-2 \mathrm{SPNs}$ (orange line) in $\mathrm{THF} / \mathrm{H}_{2} \mathrm{O}(1 / 9 \mathrm{v} / \mathrm{v})$ mixed solvent. 


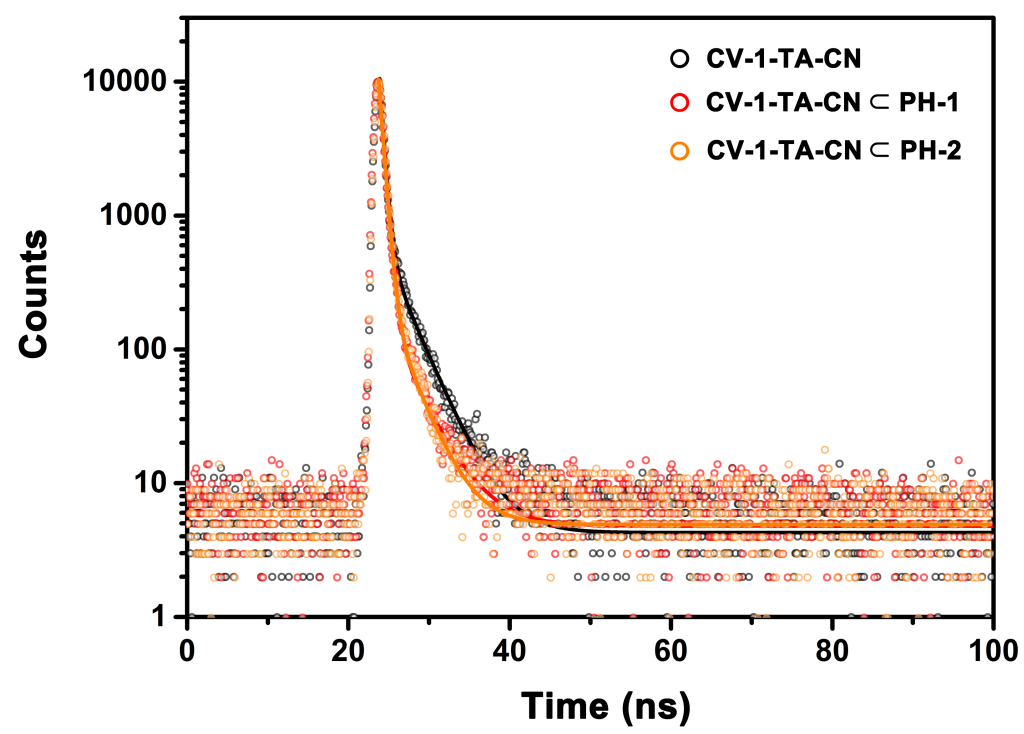

Figure S71. Fluorescence decay of CV-1-TA-CN (black line), CV-1-TA-CNCPH-1 SPNs (red line) and CV-1-TA-CNCPH-2 SPNs (orange line) in THF/ $\mathrm{H}_{2} \mathrm{O}(1 / 9 \mathrm{v} / \mathrm{v})$ mixed solvent.

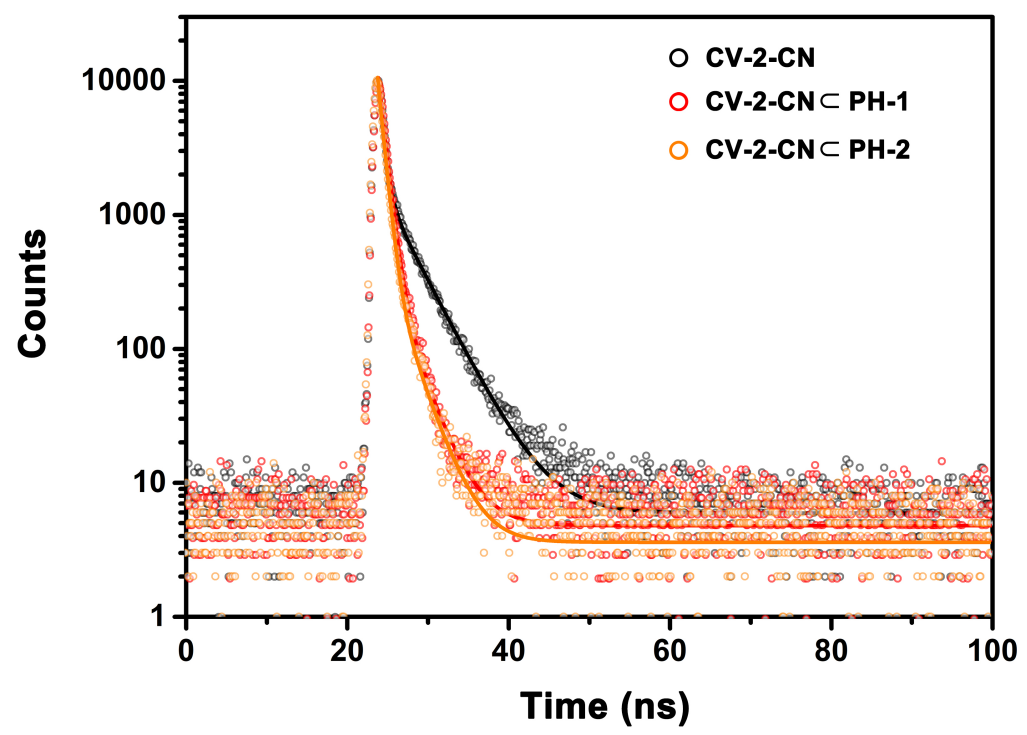

Figure S72. Fluorescence decay of CV-2-CN (black line), CV-2-CNсPH-1 SPNs (red line) and CV-2$\mathrm{CN} \subset \mathrm{PH}-2 \mathrm{SPNs}$ (orange line) in $\mathrm{THF} / \mathrm{H}_{2} \mathrm{O}(1 / 9 \mathrm{v} / \mathrm{v})$ mixed solvent. 
Table S1. Fluorescence decay of CV-1-CN in mixed solution ${ }^{a}$

\begin{tabular}{cccccccc}
\hline & $\tau_{1}(\mathrm{~ns})$ & $\tau_{2}(\mathrm{~ns})$ & $\tau(\mathrm{ns})$ & $\mathrm{B}_{1}$ & $\mathrm{~B}_{2}$ & $\mathrm{~A}$ & $\chi^{2 c}$ \\
\hline $\mathrm{CV}-1-\mathrm{CN}$ & 0.6251 & 3.358 & 1.6406 & 10543.926 & 1160.717 & 6.346 & 1.536 \\
$\mathrm{CV}-1-\mathrm{CN} \subset \mathrm{PH}-1^{b}$ & 0.5832 & 3.346 & 0.8295 & 13545.656 & 220.679 & 6.201 & 1.632 \\
$\mathrm{CV}-1-\mathrm{CN} \subset \mathrm{PH}-2^{b}$ & 0.5512 & 2.839 & 0.8152 & 12191.549 & 308.594 & 5.338 & 1.390 \\
$\begin{array}{l}\text { a) } \mathrm{THF} / \mathrm{H}_{2} \mathrm{O} \text { mixture solution with } \mathrm{f}_{\mathrm{w}}=90 \%{ }^{\text {b) }} \text { the molar ratio of pillar[5]arene unit and } \mathrm{CV}-1-\mathrm{CN} \text { is } 9: 1 ; \\
\text { c) the fitting equation: A+B } \mathrm{B}_{1} \exp \left(-\mathrm{t} / \tau_{1}\right)+\mathrm{B}_{2} \mathrm{exp}\left(-\mathrm{t} / \tau_{2}\right) .\end{array}$
\end{tabular}

Table S2. Fluorescence decay of CV-1-TA-CN in mixed solution ${ }^{a}$

\begin{tabular}{cccccccc}
\hline & $\tau_{1}(\mathrm{~ns})$ & $\tau_{2}(\mathrm{~ns})$ & $\tau(\mathrm{ns})$ & $\mathrm{B}_{1}$ & $\mathrm{~B}_{2}$ & $\mathrm{~A}$ & $\chi^{2 c}$ \\
\hline CV-1-TA-CN & 0.4674 & 3.020 & 1.1418 & 12315.302 & 684.219 & 4.321 & 1.678 \\
CV-1-TA-CNсPH-1 & 0.5460 & 3.415 & 0.8085 & 13762.044 & 221.711 & 5.384 & 1.698 \\
CV-1-TA-CNCPH-2 $^{b}$ & 0.5232 & 2.794 & 0.7728 & 12391.294 & 286.588 & 4.976 & 1.475 \\
\hline
\end{tabular}

a) $\mathrm{THF} / \mathrm{H}_{2} \mathrm{O}$ mixture solution with $\mathrm{f}_{\mathrm{w}}=90 \%$; b) the molar ratio of pillar[5]arene unit and CV-1-TA-CN is $9: 1 ;{ }^{c)}$ the fitting equation: $\mathrm{A}+\mathrm{B}_{1} \exp \left(-\mathrm{t} / \tau_{1}\right)+\mathrm{B}_{2} \exp \left(-\mathrm{t} / \tau_{2}\right)$.

Table S3. Fluorescence decay of CV-2-CN in mixed solution ${ }^{a}$

\begin{tabular}{cccccccc}
\hline & $\tau_{1}(\mathrm{~ns})$ & $\tau_{2}(\mathrm{~ns})$ & $\tau(\mathrm{ns})$ & $\mathrm{B}_{1}$ & $\mathrm{~B}_{2}$ & $\mathrm{~A}$ & $\chi^{2 c}$ \\
\hline $\mathrm{CV}-2-\mathrm{CN}$ & 0.5454 & 3.683 & 2.223 & 10050.531 & 1709.241 & 5.812 & 1.356 \\
$\mathrm{CV}-2-\mathrm{CN} \subset \mathrm{PH}-1^{b}$ & 0.7586 & 2.619 & 1.008 & 11987.360 & 538.113 & 5.026 & 1.565 \\
$\mathrm{CV}-2-\mathrm{CN} \subset \mathrm{PH}-2^{b}$ & 0.6714 & 2.485 & 0.936 & 12006.399 & 554.641 & 3.716 & 1.460 \\
\hline $\begin{array}{l}\text { a) } \mathrm{THF} / \mathrm{H}_{2} \mathrm{O} \text { mixture solution with } \mathrm{f}_{\mathrm{w}}=90 \%{ }^{\text {b) }} \text { the molar ratio of pillar[5]arene unit and } \mathrm{CV}-2-\mathrm{CN} \text { is } 9: 1 ; \\
\text { c) the fitting equation: A+B }{ }_{1} \exp \left(-\mathrm{t} / \tau_{1}\right)+\mathrm{B}_{2} \exp \left(-\mathrm{t} / \tau_{2}\right) .\end{array}$
\end{tabular}




\section{Construction of artificial light-harvesting systems}

In order to construct artificial light-harvesting systems, two prerequisites should be mentioned. Firstly, the absorption band of Nile red (NR) should be well overlapped with the emission spectrum of CV-2$\mathrm{CN} \subset \mathrm{PH}-2$ SPNs in mixed solvent to provide a solid foundation for the energy transfer from donor to

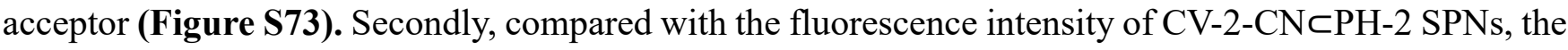
fluorescence intensity of NR should be negligible under the same concentration, ruling out possibility of the acceptor being directly excited by $474 \mathrm{~nm}$ (Figure S74).

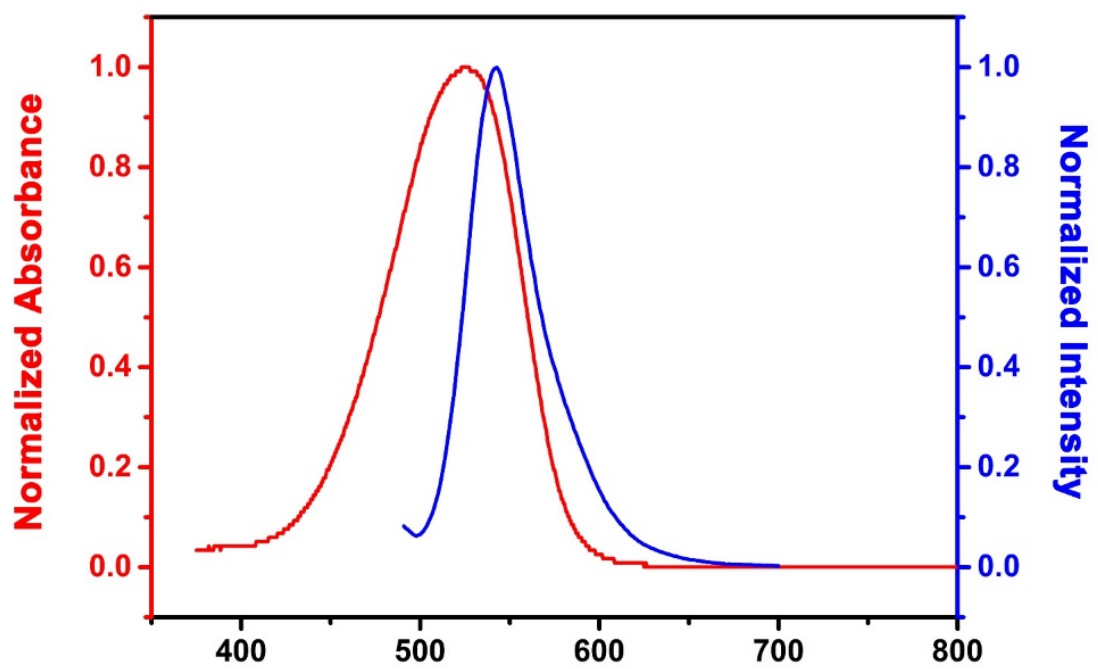

Figure S73. Normalized absorbance of NR and normalized fluorescence intensity of CV-2-CNCPH-2 SPNs (blue line). 


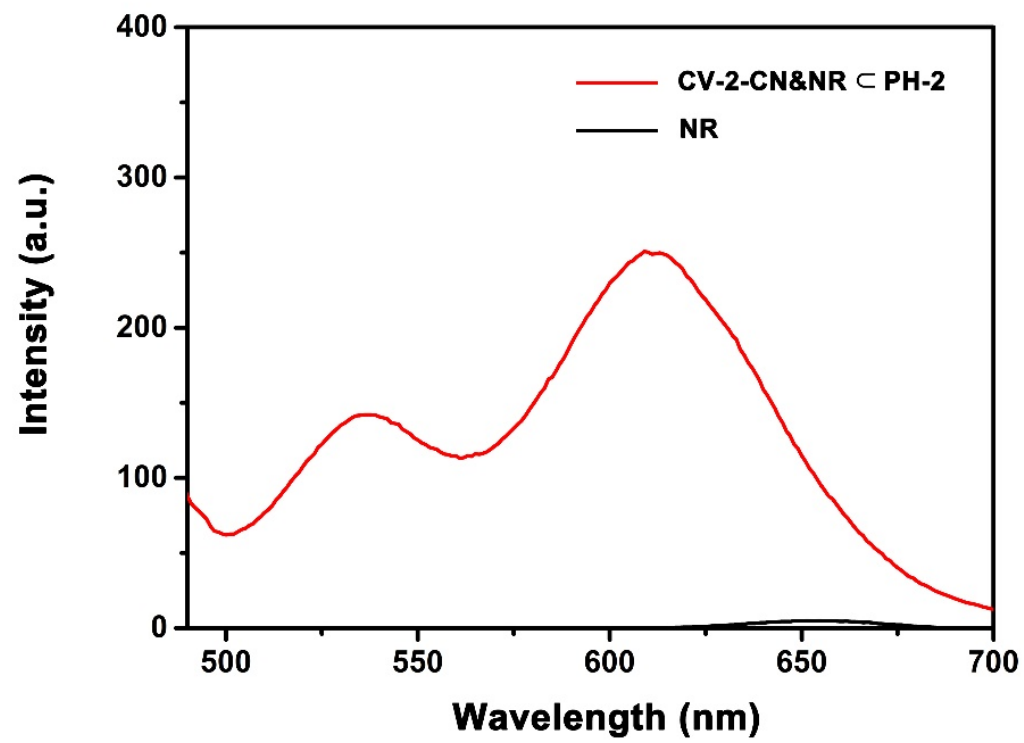

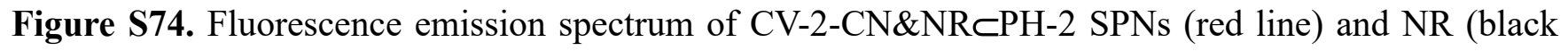
line). (Experimental condition: $\lambda_{\mathrm{ex}}=474 \mathrm{~nm}$; slit widths: ex $5 \mathrm{~nm}$, em $3 \mathrm{~nm}$; [pillar[5]arene unit] $=36$ $\left.\mu \mathrm{M} ;[\mathrm{CV}-2-\mathrm{CN}]=4 \mu \mathrm{M},[\mathrm{NR}]=4 \mu \mathrm{M}, \mathrm{THF} / \mathrm{H}_{2} \mathrm{O}=1 / 9 ; 25^{\circ} \mathrm{C}\right)$.

Table S4. Fluorescence decay of artificial light-harvesting systems ${ }^{a}$

\begin{tabular}{cccccccc}
\hline & $\tau_{1}(\mathrm{~ns})$ & $\tau_{2}(\mathrm{~ns})$ & $\tau(\mathrm{ns})$ & $\mathrm{B}_{1}$ & $\mathrm{~B}_{2}$ & $\mathrm{~A}$ & $\chi^{2 c}$ \\
\hline $\mathrm{CV}-2-\mathrm{CN} \subset \mathrm{PH}-2$ & 0.5499 & 1.963 & 0.9319 & 12244.751 & 1270.953 & 4.025 & 1.181 \\
$\mathrm{CV}-2-\mathrm{CN} \& \mathrm{NR} \subset \mathrm{PH}-2^{b}$ & 0.4536 & 2.344 & 0.7279 & 13562.735 & 445.541 & 3.289 & 1.265 \\
\hline
\end{tabular}

a) $\mathrm{THF} / \mathrm{H}_{2} \mathrm{O}$ mixture solution with $\mathrm{f}_{\mathrm{w}}=90 \%$; ) the molar ratio of $\mathrm{CV}-2-\mathrm{CN}$ and $\mathrm{NR}$ is $8: 1$; ${ }^{\mathrm{c})}$ the fitting equation: $\mathrm{A}+\mathrm{B}_{1} \exp \left(-\mathrm{t} / \tau_{1}\right)+\mathrm{B}_{2} \exp \left(-\mathrm{t} / \tau_{2}\right)$. 


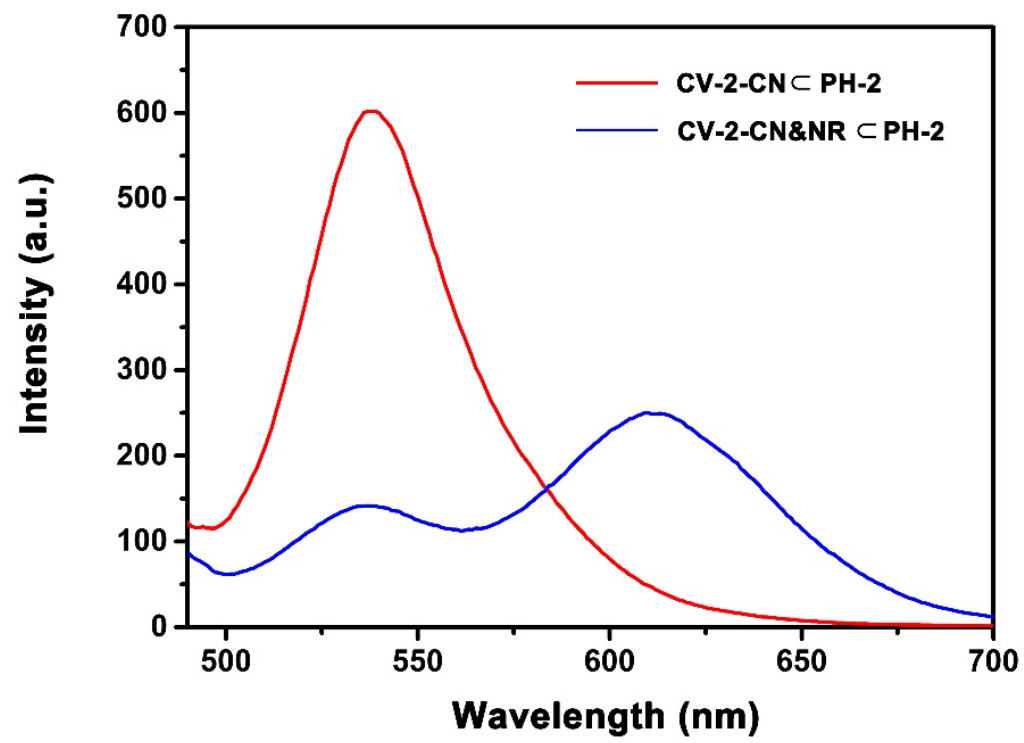

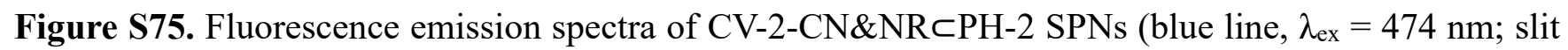
widths: ex $5 \mathrm{~nm}$, em $3 \mathrm{~nm}$; [pillar[5]arene unit] $=36 \mu \mathrm{M}$; [CV-2-CN] $=4 \mu \mathrm{M},[\mathrm{NR}]=4 \mu \mathrm{M}, \mathrm{THF} / \mathrm{H}_{2} \mathrm{O}=$ $1 / 9 ; 25^{\circ} \mathrm{C}$ ) and fluorescence emission spectra of CV-2-CNсPH-2 SPNs (red line, $\lambda_{\mathrm{ex}}=474 \mathrm{~nm}$; slit widths: ex $5 \mathrm{~nm}$, em $3 \mathrm{~nm}$; [pillar[5]arene unit] = $36 \mu \mathrm{M} ;[\mathrm{CV}-2-\mathrm{CN}]=4 \mu \mathrm{M}, \mathrm{THF} / \mathrm{H}_{2} \mathrm{O}=1 / 9 ; 25^{\circ} \mathrm{C}$ ).

Energy transfer efficiency $\left(\Phi_{\mathrm{ET}}\right)$ was calculated according to the following equation.

$$
\Phi_{\mathrm{ET}}=1-\mathrm{I}_{\mathrm{DA}} / \mathrm{I}_{\mathrm{D}}
$$

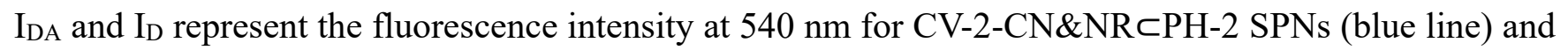
CV-2-CNсPH-2 SPNs (red line), respectively, under excitation at $474 \mathrm{~nm}$. $\Phi_{\mathrm{ET}}$ was calculated to be $76.41 \%$ under experiment condition of $[\operatorname{pillar}[5]$ arene unit $]=36 \mu \mathrm{M},[\mathrm{CV}-2-\mathrm{CN}]=4 \mu \mathrm{M},[\mathrm{NR}]=4 \mu \mathrm{M}$. 


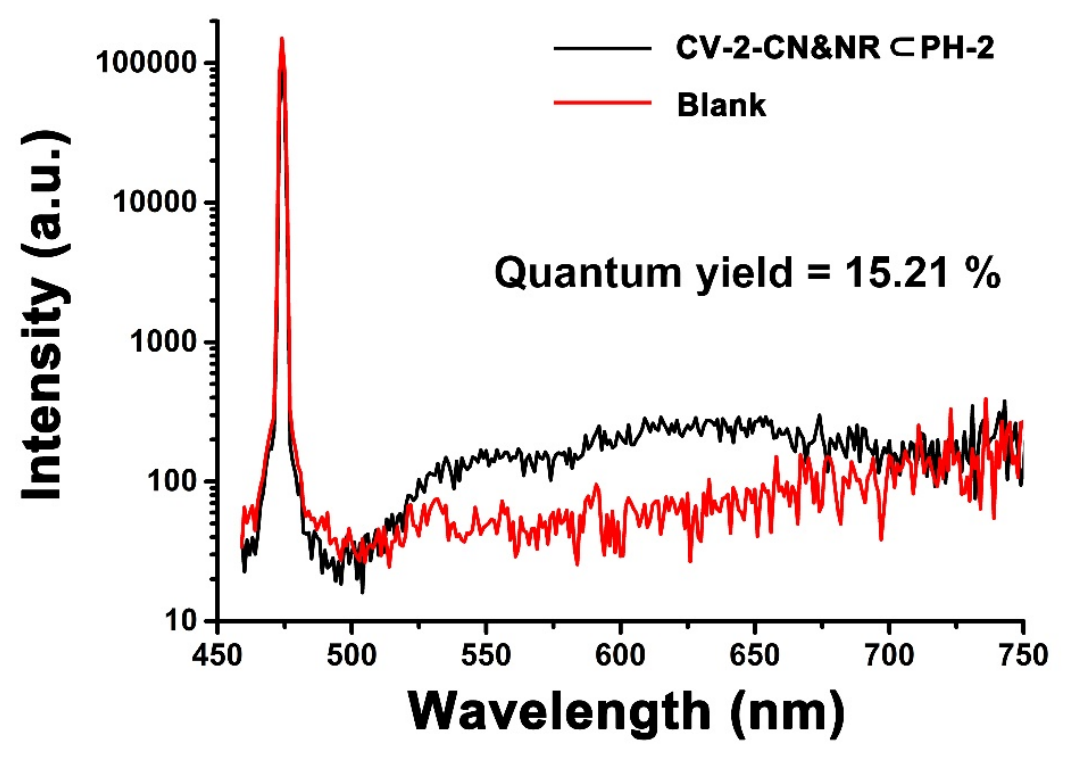

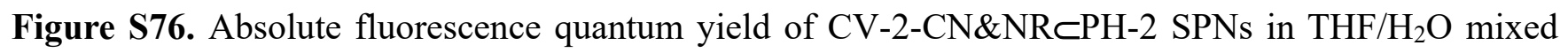
solvent, $\mathrm{f}_{\mathrm{w}}=90 \%$. Experiment condition: $\lambda_{\mathrm{ex}}=460 \mathrm{~nm}$, [pillar[5]arene unit $]=36 \mu \mathrm{M},[\mathrm{CV}-2-\mathrm{CN}]=4$ $\mu \mathrm{M},[\mathrm{NR}]=1 \mu \mathrm{M}$.

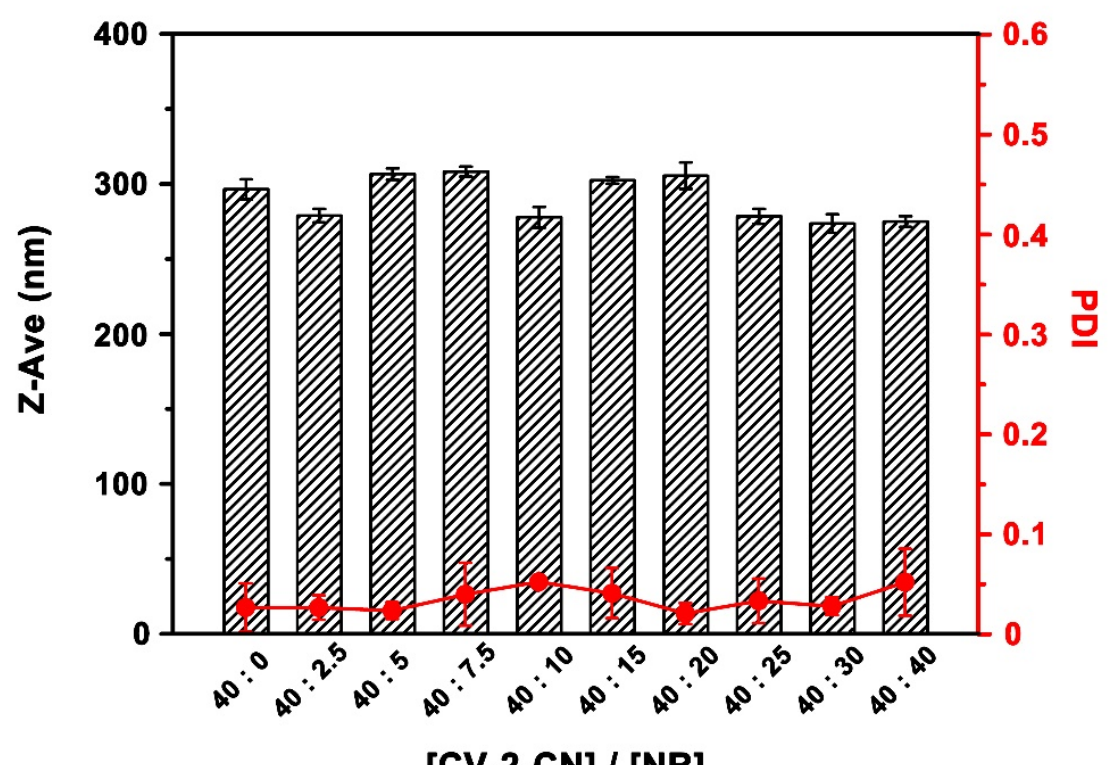

\section{[CV-2-CN] / [NR]}

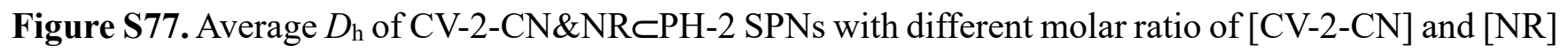
and PH-1 with different concentrations of pillar[5]arene unit. (Experimental condition: [pillar[5]arene unit $]=36 \mu \mathrm{M},[\mathrm{CV}-2-\mathrm{CN}]=0,0.25 \mu \mathrm{M}, 0.5 \mu \mathrm{M}, 0.75 \mu \mathrm{M}, 1 \mu \mathrm{M}, 1.5 \mu \mathrm{M}, 2 \mu \mathrm{M}, 2.5 \mu \mathrm{M}, 3 \mu \mathrm{M}$ and 4 $\left.\mu \mathrm{M}, \mathrm{THF} / \mathrm{H}_{2} \mathrm{O}=1: 9 \mathrm{v} / \mathrm{v} ; 25^{\circ} \mathrm{C}\right)$ 
Table S5. Single Crystal Data of CV-1-CN

\begin{tabular}{ll}
\hline Empirical formula & $\mathrm{C}_{25} \mathrm{H}_{26} \mathrm{~N}_{4} \mathrm{OS}$ \\
\hline Formula weight & 430.56 \\
Temperature & $295 \mathrm{~K}$ \\
Wavelength & $0.71073 \AA$ \\
Crystal system & triclinic \\
Space group & $\mathrm{P}-1$ \\
$\mathrm{a} / \AA$ & $10.2816(4)$ \\
$\mathrm{b} / \AA$ & $10.7860(3)$ \\
$\mathrm{c} / \AA$ & $11.5784(4)$ \\
$\mathrm{a} /$ deg. & $99.889(1)$ \\
$\mathrm{b} /$ deg. & $98.500(1)$ \\
$\mathrm{g} /$ deg. & $111.270(1)$ \\
$\mathrm{V} / \AA^{3}$ & $1147.48(7)$ \\
$\mathrm{Z}$ & 2 \\
$\mathrm{D}$ calcd $/ \mathrm{g} \cdot \mathrm{cm}{ }^{-3}$ & 1.246 \\
$\mathrm{~m} / \mathrm{mm}{ }^{-1}$ & 0.165 \\
$\mathrm{~F}(000)$ & 456.0 \\
Theta range/deg. & 2.98 to 29.61 \\
Reflections collected & 6424 \\
$\mathrm{R}($ int $)$ & 0.0268 \\
$\mathrm{R} 1$, wR2 (all data) & $0.0611,0.1790$ \\
$\mathrm{GOOF}$ & 1.036 \\
$\mathrm{CCDC}$ number & 2022734 \\
\hline & \\
\hline & \\
\hline
\end{tabular}


Table S6. Single Crystal Data of CV-2-CN

\begin{tabular}{|c|c|}
\hline Empirical formula & $\mathrm{C}_{27} \mathrm{H}_{26} \mathrm{~N}_{4} \mathrm{OS} \bullet 0.45 \mathrm{O}$ \\
\hline Formula weight & 461.78 \\
\hline Temperature & $100 \mathrm{~K}$ \\
\hline Wavelength & 0.71073 \\
\hline Crystal system & monoclinic \\
\hline Space group & $\mathrm{P} 2{ }_{1} / \mathrm{c}$ \\
\hline $\mathrm{a} / \AA$ & $14.1525(17)$ \\
\hline $\mathrm{b} / \AA$ & $22.975(3)$ \\
\hline $\mathrm{c} / \AA$ & $15.2020(17)$ \\
\hline a/deg. & 90 \\
\hline b/deg. & $107.265(4)$ \\
\hline g/deg. & 90 \\
\hline $\mathrm{V} / \AA^{3}$ & $4720.3(10)$ \\
\hline Z & 8 \\
\hline $\mathrm{D}_{\text {calcd }} / \mathrm{g} \cdot \mathrm{cm}^{-3}$ & 1.300 \\
\hline $\mathrm{m} / \mathrm{mm}^{-1}$ & 0.167 \\
\hline $\mathrm{F}(000)$ & 1949.0 \\
\hline Theta range/deg. & 2.90 to 26.85 \\
\hline Reflections collected & 10086 \\
\hline $\mathrm{R}$ (int) & 0.1087 \\
\hline R1, wR2 (all data) & $0.1035,0.3350$ \\
\hline GOOF & 1.105 \\
\hline CCDC number & 2033130 \\
\hline
\end{tabular}




\section{References}

S1. Wang, X.-H.; Song, N.; Hou, W.; Wang, C.-Y.; Wang, Y.; Tang, J.; Yang, Y.-W. Efficient AggregationInduced Emission Manipulated by Polymer Host Materials. Adv. Mater. 2019, 31, 1903962.

S2. Sheldrick, G. M. Experimental Phasing with SHELXC/D/E: Combining Chain Tracing with Density Modification. Acta Cryst. Sect. D 2010, 66, 479-485.

S3. Sheldrick, G. M. SHELXT - Integrated space-group and crystalstructure determination. Acta Cryst. Sect. $A$ 2015, 71, 3-8.

S4. Sheldrick, G. M. A Short History of SHELX. Acta Cryst. Sect. A 2008, 64, 112-122.

S5. Sheldrick, G. M. Crystal Structure Refinement with SHELXL. Acta Cryst. Sect. C 2015, 71, 3-8.

S6. Dolomanov, O. V.; Bourhis, L. J.; Gildea, R. J.; Howard, J. A. K.; Puschmann, H. OLEX2: A Complete Structure Solution, Refinement and Analysis Program. J. Appl. Cryst. 2009, 42, 339-341. 